Bernardo Pinheiro de Senna Nogueira Batista

\title{
Estudo de acurácia diagnóstica da glicemia capilar da borda da ferida operatória para a predição de necrose cutânea de espessura total do retalho pós-mastectomia
}
Tese apresentada à Faculdade de Medicina da Universidade de São Paulo para obtenção do título de Doutor em Ciências

Programa de Clínica Cirúrgica

Orientador: Prof. Dr. José Carlos Marques de Faria

São Paulo 


\section{Dados Internacionais de Catalogaçăo na Publicaçāo (CIP)}

Preparada pela Biblioteca da

Faculdade de Medicina da Universidade de Săo Paulo

Creproduçalo autorizada pelo autor

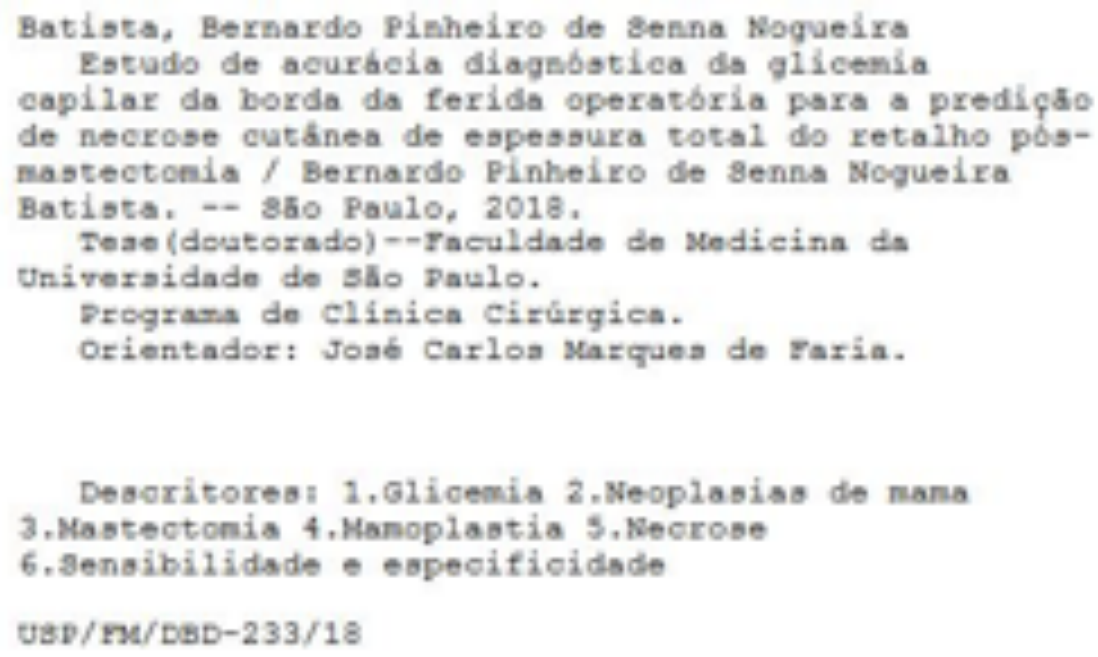

Responsável: Katia Maria Bruno Ferreira = CRB-8/6008 


\section{Dedicatória}

Dedico esta tese e o título de Doutor em Ciências a minha esposa e parceira de vida, Maria Augusta, e às minhas filhas, Julia e Olivia. Em vocês encontro a motivação para buscar respostas para as perguntas que me desafiam na minha prática médica diária, assim como a serenidade para aceitar aquelas que nunca poderei responder. 


\section{Agradecimentos}

Agradeço aos meus pais João Pinheiro Nogueira Batista e Adrienne Senna Jobim pelo amor incondicional e pelo apoio ao longo dos anos. Esta conquista é tão sua quanto minha.

Agradeço a todos os professores e mestres da Casa de Arnaldo que me ensinaram os ofícios de Médico e de Cirurgião Plástico. Em nome de todos, reverencio o Prof. Marcus Castro Ferreira que me transmitiu a paixão pela cirurgia plástica reconstrutiva e pela microcirurgia.

Aos profs. Rolf Gemperli e José Carlos Marques de Faria agradeço a oportunidade de realizar esta Pós-Graduação na minha escola e segunda casa. Os valores de excelência em assistência, ensino e pesquisa que aprendi aqui serão os alicerces de uma carreira dedicada ao paciente, à Academia e à construção de um sistema de saúde mais justo e inclusivo.

À Dra. Stephanie Kasabkojian, na época aluna de graduação e bolsista de iniciação científica pela FAPESP, agradeço a ajuda na coleta e organização dos dados deste estudo. Aos Drs. Luis Fernando Reis e Vivian Avelino, agradeço o incentivo e suporte nos estudos de Epidemiologia e Bioestatística que me instrumentalizaram para fazer a análise que deu fruto a esta tese.

Agradeço ao Dr. Marcelo Sampaio e ao Prof. Alfredo Barros pelas oportunidades e pela confiança ao longo dos anos. Conviver e trabalhar com pessoas como vocês é um privilégio que poucos médicos terão ao longo de suas vidas profissionais.

Por fim, reverencio as pacientes e os funcionários do Projeto Mama da Filantropia do Hospital Sírio Libanês, guerreiros anônimos na batalha contra o câncer de mama. Sem vocês, nada disto seria possível. 


\section{Normatização}

Esta tese está de acordo com as seguintes normas, em vigor no momento desta publicação:

Referências: adaptado de International Committee of Medical Journals Editors (Vancouver).

Universidade de São Paulo. Faculdade de Medicina. Divisão de Biblioteca e Documentação. Guia de apresentação de dissertações, teses e monografias. Elaborado por Anneliese Carneiro da Cunha, Maria Julia de A. L. Freddi, Maria F. Crestana, Marinalva de Souza Aragão, Suely Campos Cardoso, Valéria Vilhena. 3a ed. São Paulo: Divisão de Biblioteca e Documentação; 2011.

Abreviaturas dos títulos dos periódicos de acordo com List of Journals Indexed in Index Medicus. 


\section{Sumário}

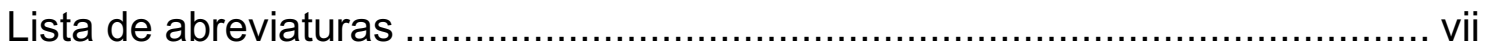

Lista de unidades e símbolos ............................................................... viii

Lista de quadros e tabelas............................................................ ix

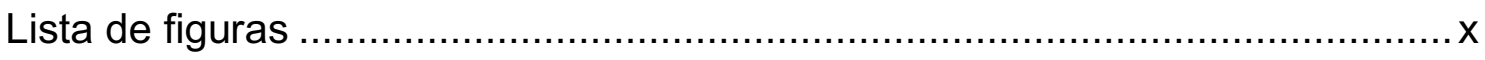

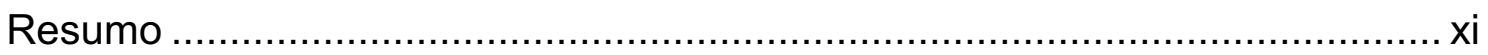

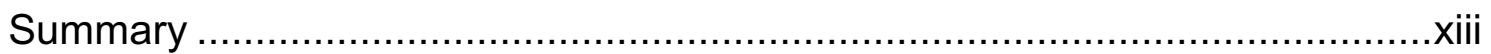

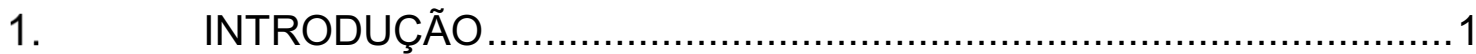

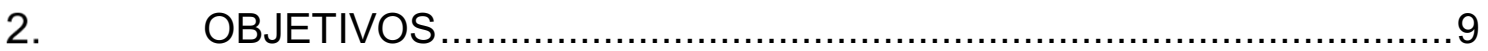

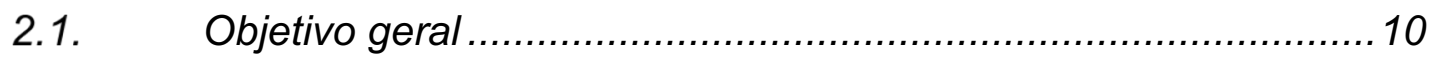

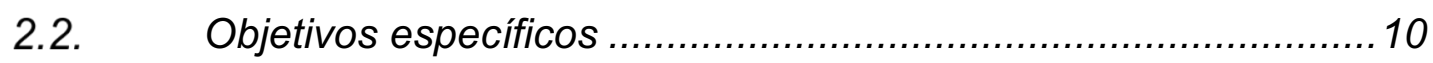

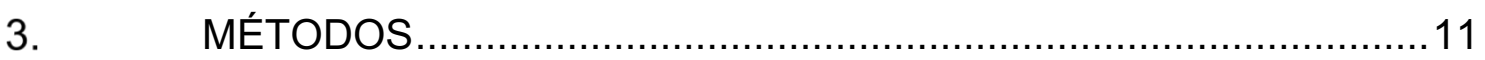

3.1. Desenho e população do estudo......................................... 12

3.2. Teste índice - Glicemia capilar (GC) ................................. 13

3.3. Teste referência - diagnóstico clínico de necrose.....................16

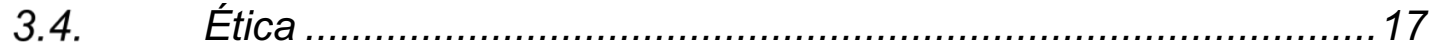

3.5. Tamanho da amostra e análise estatística ...............................17

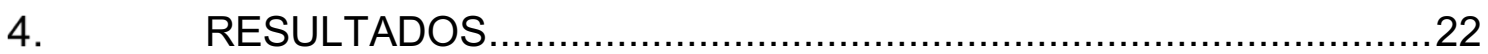

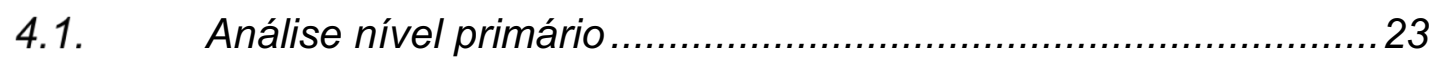

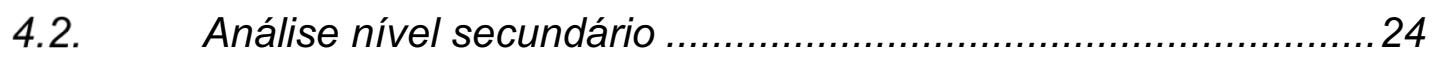

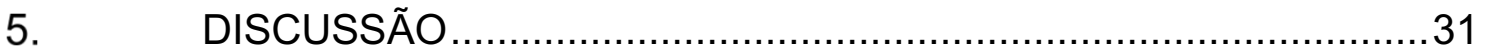

5.1. Caracterização da casuística utilizada ................................... 32

5.2. Mensuração das variáveis............................................... 33

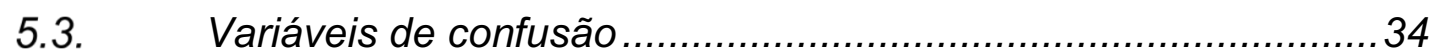

5.4. Acurácia para a predição de NCET ...................................... 36

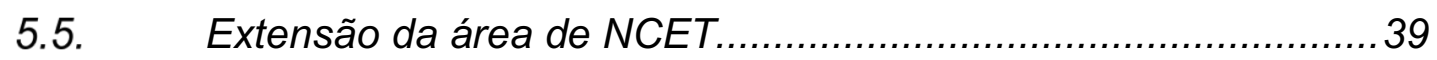

5.6. Perspectivas futuras................................................... 40

5.7. Considerações finais ......................................................... 41

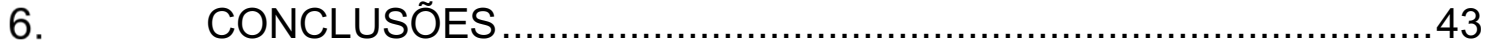

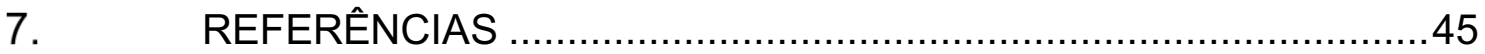

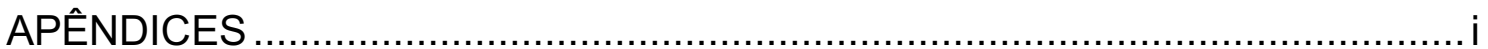




\section{LISTA DE ABREVIATURAS}

\begin{tabular}{|c|c|}
\hline EUA & Estados Unidos da América \\
\hline IMC & Índice de massa corpórea \\
\hline ALA-VI & $\begin{array}{l}\text { Angiografia laser assistida com injeção intravenosa de verde } \\
\text { de indocianina }\end{array}$ \\
\hline DM & Diabetes melitus \\
\hline HSL & Hospital Sírio Libanês \\
\hline FMUSP & Faculdade de Medicina da Universidade de São Paulo \\
\hline CEP & Comitê de Ética em Pesquisa \\
\hline TCLE & Termo de Consentimento Livre Esclarecido \\
\hline GC & Glicemia capilar \\
\hline GCA & Valor absoluto de GC \\
\hline GCP & Valor absoluto de GC periférica \\
\hline GCR & Valor relativo da GCA pela GCP \\
\hline NCET & Necrose cutânea de espessura total \\
\hline$\| \mathrm{Q}$ & Intervalo interquartil \\
\hline EEG & equações de estimação generalizada \\
\hline OR & Razão de chance \\
\hline \multirow[t]{2}{*}{ ROC } & Curva de Características Operacionais (Receiver Operating \\
\hline & Curve) \\
\hline AUC (ou $C)$ & Área sob a curva ROC \\
\hline Sn & Sensilidade \\
\hline b & Especificidade \\
\hline VPP & Valor preditivo positivo \\
\hline VPN & Valor preditivo negativo \\
\hline LR+ & Razão de verossimilhança positivo \\
\hline LR- & Razão de verossimilhança negativo \\
\hline $95 \%$ & Intervalo de confiança para 95\% \\
\hline
\end{tabular}




\section{LISTA DE UNIDADES E SÍMBOLOS}

$\begin{array}{ll}\mathrm{h} & \text { Hora (posição do ponteiro do relógio) } \\ \mathrm{cm} & \text { Centímetros } \\ \mathrm{mg} / \mathrm{dL} & \text { Miligramas por decilitro } \\ \leq & \text { Menor ou igual a } \\ > & \text { Maior que } \\ < & \text { Menor que } \\ = & \text { Igual }\end{array}$




\section{LISTA DE QUADROS E TABELAS}

\section{Quadros}

Quadro 1 - Estruturação dos dados e análise de desfecho.

Quadro 2 - Critérios de inclusão e exclusão.

Quadro 3 - Variáveis de confusão observadas.

\section{Tabelas}

Tabela 1 - Características demográficas e análise exploratória das variáveis observadas

Tabela 2 - Razão de chance (OR) entre as potenciais variáveis de confusão para NCET ajustadas para GCA ou GCR 27

Tabela 3 - Acurácia diagnóstica da GC para predição de NCET 30 


\section{LISTA DE FIGURAS}

Figura 1 - Foto A (exemplo). Registro fotográfico ao final da cirurgia. Em azul, a demarcação dos pontos de coleta de amostras para determinação da glicemia capilar 15

Figura 2 - Foto B (exemplo). Registro fotográfico da mama no $9^{\circ}$ dia de pós-operatório. Necrose de espessura total envolvendo 3 pontos de coleta demarcados na foto 1 podem ser observados, as $11 \mathrm{~h}, 12 \mathrm{~h}$ e $1 \mathrm{~h}) \ldots \ldots \ldots \ldots \ldots \ldots . . . .15$

Figura 3 - Distribuição das GCAs medidas (histograma) ……...............25

Figura 4 - Gráfico de caixas demonstrando a distribuição das GCA entre os pontos de observação que não apresentaram NCET (0) e os que

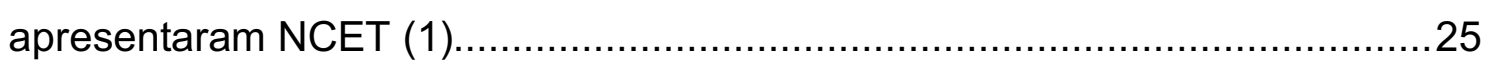

Figura 5 - Distribuição das GCAs medidas (histograma) …..................26

Figura 6 - Gráfico de caixas demonstrando a distribuição das GCR entre os pontos de observação que não apresentaram NCET (0) e os que

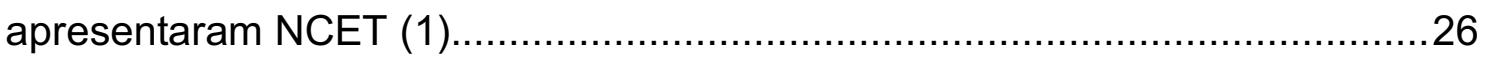

Figura 7 - Curva ROC. Poder discriminatório da GCA para NCET do retalho da mastectomia 28

Figura 8 - Curva ROC. Poder discriminatório da GCR para NCET do retalho da mastectomia .28

Figura 9 - DAG. Relação de influência entre variáveis observadas ......35

Figura 10 - Valores preditivos negativos (NPV) e positivos (PPV) dos critérios combinados ( $<90 \mathrm{mg} / \mathrm{DL}$ ou $<80 \%$ ), de acordo com o risco pré-teste de NCET 38 


\section{Resumo}

Batista BPSN. Estudo de acurácia diagnóstica da glicemia capilar da borda da ferida operatória para a predição de necrose cutânea de espessura total do retalho pós-mastectomia [tese]. São Paulo: Faculdade de Medicina, Universidade de São Paulo; 2018.

INTRODUÇÃO: As necroses de retalhos da mastectomia (RM) afetam até um terço das mulheres submetidas à reconstrução imediata de suas mamas e aumentam o risco de outras complicações e, por fim, de falha da reconstrução. A glicemia capilar (GC) tem sido usada para monitorização clínica de mudanças agudas na perfusão tecidual de retalhos livres. Nós avaliamos a acurácia diagnóstica da GC para predição de necrose de espessura total (NET) em RM após mastectomia com reconstrução imediata. MÉTODOS: Duzentos e trinta amostras de sangue para mensuração de GC foram coletadas ao longo da ferida operatória de 30 mulheres submetidas à ressecção total de suas mamas. Uma amostra de sangue periférico para mensuração da GC periférica foi colhida em cada paciente. Fotografias da mama foram capturadas no final da cirurgia e no pós-operatório (entre 7 e 14 dias). Estas fotos foram comparadas por um investigador cego aos valores das GCs para determinar a ocorrência de necrose e em que pontos de coleta ela ocorreu. A associação entre GC e a ocorrência de NET foi testada usando modelos de equações de estimação generalizadas. Nós analisamos a acurácia diagnóstica da GC como um teste intraoperatório de predição de NET usando curvas de Característica de Operação do Receptor e a estatística C (ou área sob a Curva). RESULTADOS: NET ocorreu em 21/230 (9.1\%) pontos de coleta aleatória de $9 / 30$ pacientes $(30 \%)$. Cada decréscimo de $10 \mathrm{mg} / \mathrm{dL}$ no valor absoluto da $\mathrm{GC}\left(\mathrm{GC}_{\mathrm{A}}\right)$ foi associada a uma razão de chance (RC) de 1.71 (1.21-2.41; $p=.002$ ) para NET e $C=.78$ (.65-.92). Cada queda em $10 \%$ da razão entre a $\mathrm{GC}$ e a $\mathrm{GC}$ periférica $\left(\mathrm{GC}_{\mathrm{r}}\right)$ foi associada com uma $\mathrm{RC}=1.77$ (1.23-2.55; $\mathrm{p}=.002)$ para NET e $C=.75$ (.47-.89). Para pontos de corte de $\mathrm{GC}_{\mathrm{A}}<90 \mathrm{mg} / \mathrm{dL}$ ou $\mathrm{GC}_{\mathrm{R}}<80 \%$, a especificidade e sensibilidade para o teste como uma ferramenta de rastreamento para NET foi de $67 \%(14 / 21)$ e $86 \%$ (179/209), respectivamente. CONCLUSÕES: A performance da GC como uma 
ferramenta de rastreamento para NET foi sub ótima, com um poder discriminatório moderado. No entanto, sua mensuração pode ser informativa como uma ferramenta adicional para esta avaliação ainda altamente subjetiva. As associações observadas entre a GC e a ocorrência de NET pós-operatória suportam nossa hipótese de que os tecidos dos RM sob stress perfusional demonstram alterações metabólicas precoces.

Descritores: glicemia; neoplasias de mama; mastectomia; mamoplastia; necrose; sensibilidade e especificidade. 


\section{Summary}

Batista BPSN. Diagnostic accuracy of interstitial glucose levels at the surgical wound edges to predict full thickness necrosis in mastectomy flaps [thesis]. São Paulo: "Faculdade de Medicina, Universidade de São Paulo"; 2018.

INTRODUCTION: Mastectomy skin flap (MSF) necrosis affects up to one-third of patients undergoing immediate breast reconstruction and increases the risk other complications rand, ultimately, reconstruction failure. Interstitial glucose level (IGL) has been used clinically to monitor acute changes in local tissue perfusion in free flaps. We evaluated the accuracy of IGL for prediction of full thickness necrosis (FTN) in MSF after mastectomy with immediate breast reconstruction. METHODS: Two hundred and thirty random blood samples for IGL measurement along the surgical wound edges of 30 women undergoing unilateral total breast resection with immediate reconstruction were collected. At the same time, a peripheral blood sample was also tested. Pictures of the breast were taken after skin closure with markings identifying the position where the samples were taken and 7 to 14 days post-operatively. These pictures were compared by an investigator blinded to IGL values to determine the occurrence of FTN and at which IGL sampling sites it occurred. The association between IGL and the occurrence of FTN was tested using generalized estimating equation models. We analyzed the diagnostic accuracy of IGL as an intraoperative test for FTN with the use of Receiver Operating Curves and their C-statistics (or Area Under the Curve). RESULTS: FTN occurred in 21/230 (9.1\%) random sampling points from 9/30 patients (30\%). Each $10 \mathrm{mg} / \mathrm{dL}$ decrease in absolute IGL (IGL $\mathrm{A}_{\mathrm{A}}$ ) was associated with an $\mathrm{OR}=1.71$ (1.21-2.41; $\mathrm{p}=.002)$ for FTN and $C=.78$ (.65-.92). Each $10 \%$ decrease in the ratio of IGL to peripheral glucose level (IGLR) was associated with an $\mathrm{OR}=1.77(1.23-2.55 ; \mathrm{p}=.002)$ for FTN, with $C=.75$ (.47-.89). For cut-offs of $I G L_{A}<90 \mathrm{mg} / \mathrm{dL}$ or $I G L_{R}<80 \%$, the specificity and sensitivity of the test as a screening tool for FTN were 67\% (14/21) and 86\% (179/209), respectively. CONCLUSIONS: The performance of IGL as a screening tool for FTN was suboptimal, with a moderate discriminative power for FTN. However, it can be informative as an additional tool to the still highly subjective intraoperative 
evaluation of MSFs. The observed association between IGL measurements and post-operative FTN supports our hypothesis that tissues of the MSF under perfusion stress will show early metabolic alterations.

Descriptors: blood glucose; breast neoplasm; mastectomy; mammoplasty; necrosis; sensitivity and specificity. 


\section{INTRODUÇÃO}


A mama feminina sempre assumiu um papel fundamental em todas as culturas humanas. Cultuada como símbolo de fertilidade, representa a feminilidade e tem uma função central no desenvolvimento da espécie e na autoestima da mulher. Nos tempos modernos, um número considerável de mulheres hígidas se submete a cirurgias de mama com objetivo exclusivamente estético. Dados de um censo anual realizado pela International Society of Aesthetic Plastic Surgery (ISAPS) revelam que as cirurgias de mama são as cirurgias plásticas estéticas mais realizadas no Brasil e no Mundo. No ano de 2016, 400 mil mulheres no Brasil e 2.8 milhões no mundo se submeteram a uma cirurgia nas suas mamas com finalidade exclusivamente estética (1).

Assim como as mamas, as patologias mamárias também têm um papel importante na vida da mulher. O câncer de mama é o segundo tipo de câncer mais comum entre elas, atrás apenas das neoplasias cutâneas não melanoma. Em termos de mortalidade, é também o segundo câncer mais relevante, ultrapassado apenas pelo câncer de pulmão (2). No Brasil, o Instituto Nacional do Câncer estima 57.960 novos casos de câncer de mama em 2016 com 14.206 mortes registadas entre mulheres no ano de 2013 (3). Com o avanço do diagnóstico precoce, o maior acesso ao tratamento adequado e o desenvolvimento de terapias mais eficazes, estas pacientes cada vez mais podem esperar altas taxas de cura e boa sobrevida. Nos Estados Unidos (EUA), onde 1 em cada 8 mulheres terá um diagnóstico de câncer de mama durante a vida (4), as taxas de sobrevida são de $89 \%$ aos 5 anos, $83 \%$ aos 10 anos e $78 \%$ aos 15 anos após o diagnóstico. Estima-se que em $1^{\circ}$ de janeiro de 2016, 3.5 milhões de mulheres americanas com um antecedente de câncer de mama estavam vivas (5).

Para estas mulheres, o tratamento cirúrgico ainda é o padrão-ouro (6). Embora alternativas cirúrgicas conservadoras possam ser oferecidas a pacientes com doença menos avançada mantendo boa segurança oncológica (7-9), a ressecção de toda a mama acometida ainda é indicada em boa parte das mulheres vítimas do câncer de mama. Nos EUA, cerca de $36 \%$ das mulheres com câncer de mama estadio I ou II e $72 \%$ das com doença em estádio III são ainda submetidas a mastectomias (5). Considerando que no mundo desenvolvido as mastectomias correspondam a cerca de um terço das 
indicações de tratamento cirúrgico destas pacientes e dado o acesso ainda limitado ao diagnóstico precoce e ao tratamento em tempo hábil em nosso meio, podemos estimar que no Brasil estas taxas devem ser bem maiores.

O impacto psicológico da amputação de uma mama pode ser devastador, principalmente se considerarmos as altas taxas de cura possíveis e o longo tempo de sobrevida esperado. O direito à reconstrução é uma luta antiga dos movimentos de vítimas do câncer de mama e o acesso à reconstrução imediata ainda é um desafio no tratamento integral destas mulheres. Nos EUA, em 1998, o Women's Health and Cancer Rights Act (10) tornou obrigatória a cobertura da reconstrução mamária. No Brasil, em 2013, nossos legisladores aprovaram uma lei que diz que o Sistema Único de Saúde deve garantir a reconstrução mamária às pacientes em tratamento para câncer de mama.

A reconstrução mamária utiliza conhecimentos de cirurgia plástica para devolver uma mama social para as pacientes mutiladas pelo tratamento cirúrgico do câncer de mama (11). Diferentes técnicas e materiais podem ser empregados e a melhor abordagem para cada reconstrução deverá ser definida com a paciente e o time multidisciplinar envolvido no seu cuidado, levando-se em consideração as comorbidades da paciente, a eventual necessidade de tratamento adjuvante, a disponibilidade de recursos e os aspectos culturais envolvidos.

Tradicionalmente, a reconstrução mamária se faz em três etapas. $\mathrm{Na}$ primeira, se busca reconstruir no tórax da paciente um cone mamário recoberto por pele, mimetizando uma mama. Para tal, podem ser utilizados retalhos autólogos, dispositivos implantáveis (expansores, implante-expansores e próteses) ou combinações dos dois. Em uma segunda etapa, são feitos ajustes à neo-mama e a mama contralateral é operada, buscando simetria com a mama reconstruída. O complexo aréolo-papilar é reconstruído em um último estágio. Essas etapas podem ser combinadas em um mesmo procedimento ou ainda, mais de um procedimento cirúrgico pode ser necessário para cada uma delas. $A$ reconstrução mamária é, portanto, um tratamento longo e deve ser entendida como um tratamento paralelo e integrado ao tratamento global e multiespecialidade da paciente com câncer de mama. 
Independente da estratégia e da técnica escolhida, a primeira decisão que deve ser tomada frente a uma paciente que será submetida a extirpação de sua mama e deseja uma reconstrução mamária é o momento de se iniciar o processo da reconstrução. A reconstrução imediata, na qual a primeira cirurgia do processo reconstrutivo acontece no mesmo momento da cirurgia oncológica, apresenta sobre a reconstrução tardia algumas vantagens. A primeira, e mais óbvia, é a redução do tempo total até que se alcance uma reconstrução satisfatória, reduzindo o stress da amastia durante o tratamento oncológico adjuvante. Além disso, a reconstrução imediata normalmente permite uma melhor preservação do envelope cutâneo do tórax mesmo em pacientes que serão submetidos a radioterapia pós-mastectomia (12).

Por outro lado, pacientes submetidas à reconstrução mamária imediata estão sujeitas a um perfil de morbidade maior. Analisando dados de 47.443 pacientes submetidas mastectomias, sendo 30.468 sem reconstrução e 16.975 com reconstrução imediata, operadas entre 2005 e 2011 e registradas em uma base de dados multicêntrica para avaliação de qualidade em cirurgia mantida pelo Colégio Americano de Cirurgiões (ACS NSQIP - American College of Surgeons National Surgical Quality Improvement Program), Fisher et al observaram que as pacientes submetidas à reconstrução mamária imediata apresentavam taxas não ajustadas de complicações gerais e cirúrgicas maiores, apesar de um perfil demográfico mais favorável. Nesta coorte, as taxas de complicação gerais foram de $11.2 \%$ no grupo submetido a reconstrução imediata contra $9.2 \%$ no grupo submetido apenas a mastectomia $(p<.001)$. Além disso, o primeiro grupo também apresentou um risco maior de necessidade de nova intervenção cirúrgica não planejada nos primeiros 30 dias $(7.8 \%$ vs $4.7 \%$; p<.001) (13). Essas complicações podem retardar o início do tratamento adjuvante, colocando em risco a segurança do tratamento oncológico (14). No entanto, não existe comprovação de que este atraso tenha um impacto clínico relevante em termos de recidiva ou sobrevida. Pacientes submetidas a reconstrução imediata apresentam sobrevidas global e livre de doença semelhantes às pacientes submetidas a mastectomia sem reconstrução $(15,16)$.

Necroses do retalho da mastectomia são uma complicação desafiadora nas reconstruções imediatas (17). A prevalência relatada na literatura varia de 
$5 \%$ a $30 \%$ (18). Essa grande variabilidade se deve, provavelmente, a diferenças nos desenhos dos estudos, dos protocolos de avaliação e nas características demográficas e cirúrgicas de suas casuísticas, além do caráter retrospectivo da maioria das séries $(19,20)$. Em um estudo de coorte prospectivo incluindo 606 mastectomias realizadas em 376 pacientes, Matsen et al identificaram 14\% de necroses de qualquer extensão (20). O manejo da complicação é complexo e depende da extensão e profundidade dos tecidos acometidos (21). Enquanto necroses superficiais e limitadas podem ser tratadas conservadoramente, frequentemente estas complicações requerem novos procedimentos para o debridamento de tecidos desvitalizados e ressutura e aumentam os riscos de infecção do sítio cirúrgico e/ou do implante. Se muito extensas, podem comprometer o resultado estético da reconstrução e, em última instância, levar à sua perda.

A preservação do plexo vascular subcutâneo da pele anterior do tórax durante a cirurgia oncológica é vital para a sobrevivência deste retalho. Uma camada de tecido subcutâneo que contêm quantidade mínima de epitélio mamário existe entre a pele e glândula mamária. Sua espessura é variável dentro da mesma mama e entre mamas diferentes (22). Não existe uma correlação definida entre idade, índice de massa corpórea (IMC) ou peso da mama e a espessura dessa camada e uma fáscia mamária superficial separando esses planos pode ser identificada macroscopicamente em apenas $56 \%$ dos casos (23), dificultando a sua dissecção durante a cirurgia oncológica da mama. A ressecção da glândula deve idealmente proteger essa camada, buscando um equilíbrio entre a segurança vascular deste retalho e a efetividade da ressecção oncológica. Uma maior agressividade cirúrgica pode explicar a diferença observada nas taxas de necrose observadas entre cirurgiões. Em uma coorte de 3142 mastectomias consecutivas com reconstrução com implantes realizadas por quatro cirurgiões oncológicos diferentes, Gfrerer et al identicaram uma diferença significativa entre as taxas de necrose observadas entre os cirurgiões oncológicos $(1,69 \%$ a 5,95\%; $p<.001)$. Essa diferença se manteve mesmo após ajuste para potenciais fatores de confusão relacionados aos pacientes (24).

Diversos fatores de riscos para necroses do retalho da mastectomia foram identificados e descritos na literatura. Idade, tabagismo, obesidade, diabetes, 
tamanho das mamas, cirurgia mamária e radioterapia prévias são fatores de risco bem estabelecidos (18). Além destes, um tempo cirúrgico prolongado, o uso de soluções tumescentes e o tipo de reconstrução realizada (25) também parecem estar associadas a um maior risco de complicação. Cirurgias preservadoras de pele e do complexo aréolo-papilar também apresentam maior risco, uma vez que os retalhos cutâneos resultantes são mais extensos (26-28).

Como em qualquer retalho cutâneo, segmentos mal perfundidos do retalho da mastectomia evoluirão com sofrimento e necrose. A detecção precoce destes segmentos, preferencialmente no intraoperatório, é de fundamental importância para prevenir tal complicação, evitando seus efeitos adversos na sequencia do tratamento, na segurança e na qualidade de vida das pacientes. Para a maioria dos cirurgiões plásticos envolvidos na reconstrução mamária, a avaliação clínica da perfusão dos retalhos remanescentes após a cirurgia oncológica continua sendo a principal ferramenta disponível. Classicamente, essa avaliação se faz pela avaliação da coloração dos retalhos, da sua espessura, do tempo de enchimento capilar e do padrão de sangramento das bordas da ferida operatória (18). Essa avaliação, de caráter subjetivo, é naturalmente imprecisa e depende, entre outros, da experiência do avaliador. Assim, diversos métodos objetivos de avaliação destes retalhos foram desenvolvidos e testados na prática clínica. Entre eles, se destacam a angiografia pela injeção intravascular de corantes que podem ser visualizados através da pele com o auxílio de equipamentos específicos.

Losken et al avaliaram o uso intravenoso da tintura de fluoresceína na avaliação intra-operatória da viabilidade do retalho da mastectomia preservadora de pele. Em um grupo de 50 mamas submetidas a reconstrução imediata com retalhos autólogos (31 TRAMs e 19 GD com expansor), os pesquisadores compararam as áreas não fluorescentes após o término da reconstrução com eventuais áreas de necrose cutânea. O teste demonstrou um valor preditivo positivo (VPP) de 96\%. Das 21 áreas com falhas de fluorescência, 5 apresentaram necrose, resultando em um valor preditivo negativo (VPN) de $24 \%$ (29).

A angiografia laser assistida com injeção intravenosa de verde de indocianina $(A L A-V I)$ tem encontrado espaço crescente na cirurgia plástica 
reconstrutiva $(30,31)$. Sua utilidade na avaliação da viabilidade do retalho da mastectomia tem sido demonstrada pela redução das taxas de complicações (32-40). Em uma análise retrospectiva comparando uma coorte com 184 pacientes submetidas a reconstrução mamária com o uso de ALA-VI com uma coorte histórica similar de mesmo tamanho anterior a aquisição do equipamento, Duggal et al demonstraram uma redução nas taxas de necrose de retalho da mastectomia de 23,4\% para 13\% ( $p=.01)(41)$. Um estudo semelhante com 467 reconstruções em 269 mulheres demonstrou uma redução de 86\% nas taxas da complicação (6,7\% (pré ALA-VI) vs 0,9\% (com ALA-VI); p=.02) (42). Infelizmente, a aquisição do equipamento para a realização da ALA-VI é extremamente cara e impeditiva para a maioria dos serviços envolvidos no tratamento do câncer de mama. Assim, testes diagnósticos alternativos que permitam uma avaliação mais objetiva destes retalhos são necessários.

Tecidos mal vascularizados apresentam aporte reduzido de oxigênio. Em um estudo piloto com 10 pacientes em que se mediu a saturação de oxigênio do retalho da mastectomia, Rao et al observaram que a única paciente que evoluiu com necrose apresentava uma redução na saturação de oxigênio nas áreas acometidas enquanto as pacientes que evoluíram de maneira satisfatória apresentaram um aumento da mesma (43). A baixa oferta de oxigênio nos tecidos induz um stress metabólico anaeróbio nas células. A glicose é a principal fonte de energia para o metabolismo celular. No citoplasma, ela é convertida em 2 moléculas de piruvato pelo mecanismo de glicolisação, com a produção de duas moléculas de adenosina trifosfato (ATP), principal fonte de energia para as reações químicas intracelulares. Em condições normais de oferta de oxigênio, o piruvato é convertida em acetilcoenzima A (Acetil-CoA) que será então oxidada na matriz mitocondrial por reações químicas sucessivas. Essa cadeia de reações é conhecida como ciclo do acido cítrico (ou ciclo de Krebs) e produz 36 moléculas adicionais de ATP, tendo como subprodutos dióxido de carbono e água. O saldo energético da respiração celular é, portanto, de 38 moléculas de ATP para cada molécula de glicose. Em condição anaeróbica, o piruvato é convertido em lactato sem produção adicional de energia levando a um consumo aumentado de glicose para manutenção do metabolismo celular (44-46). 
A mensuração destes metabolitos pode ser usada clinicamente para a monitorização da perfusão de diferentes tecidos $(47,48)$. Cateteres de microdiálise capazes de medir na beira do leito a concentração intersticial de glicose, glicerol, lactato e piruvato são usados experimentalmente e na prática clínica de diversas especialidades (49).

A avaliação da viabilidade do tecido e a identificação precoce de problemas de perfusão é uma ferramenta essencial nas transferências microcirúrgicas de retalhos. Em um modelo animal de trombose vascular venoso ou arterial de 18 retalhos abdominais em ratos, Sietzman et al observaram queda significativa na concentração intersticial de glicose 15 minutos após a oclusão arterial ou venosa dos retalhos. Concentração capilar abaixo dos limites euglicêmicos do animal e queda igual ou superior de $7 \mathrm{mg} / \mathrm{dl}$ em um minuto mostraram especificidade e sensibilidade entre 95,2 e 100\% (50). Clinicamente, o primeiro relato de uma reexploração bem sucedida em uma transferência livre de tecido diagnosticada pela mensuração da glicemia no retalho foi descrita em 2011 (51). Hara et al relataram que uma relação entre as glicemias do retalho e periférica do paciente inferior a 0,38 foi $87 \%$ sensível e $93 \%$ específica para sofrimento em segmentos de retalhos livres (52). Recentemente, Bashir et al avaliaram a acurácia diagnóstica da glicemia para detectar trombose venosa em 127 retalhos. Com um valor de referência de $62 \mathrm{mg} / \mathrm{dL}$, a sensibilidade e o valor preditivo positivo do teste foram de $90 \%$ e $91 \%$ respectivamente, enquanto a especificidade e o valor preditivo foram de $78 \%$ e $76 \%$ (53). Em um modelo experimental de retalhos pediculados, Cohen et al realizaram biopsias seriadas em retalhos abdominais de ratos e demonstraram um aumento acentuado no consumo de glicose e produção de lactato em comparação com a pele normal. A magnitude das alterações no metabolismo da glicose foi proporcional ao grau de isquemia no tecido do retalho in vivo (54).

No entanto, nenhum estudo prévio avaliou a acurácia diagnóstica da glicemia intersticial para a predição de necrose nos retalhos das mastectomias. Nós desenhamos um estudo para testar a hipótese de que alterações metabólicas precoces podem ser medidas em tecidos destes retalhos que posteriormente evoluirão com necrose. 
2. OBJETIVOS 


\subsection{Objetivo geral}

O objetivo deste trabalho foi avaliar a acurácia diagnóstica da glicemia capilar realizada nas bordas da ferida operatória do retalho cutâneo da mastectomia para a predição de necrose de espessura total.

\subsection{Objetivos especificos}

1. Testar a associação entre alteração na glicemia capilar na borda da ferida operatória no transoperatório e posterior necrose do retalho da mastectomia;

2. Determinar a capacidade de predição de necrose pela glicemia capilar;

3. Determinar valores de corte que apresentem o melhor perfil de acurácia para uso na prática clínica. 
3. MÉTODOS 


\subsection{Desenho e população do estudo}

Trata-se de um estudo de acurácia de teste diagnóstico. O estudo seguiu um desenho prospectivo, em uma comparação cega com o padrão ouro (desfecho clínico).

Para otimização dos recursos, foi utilizada uma estrutura de dados hierarquizada (55). Em cada paciente incluída no estudo, múltiplas amostras foram coletadas em localizações diferentes ao longo da borda da ferida operatória. O desfecho foi observado separadamente para cada ponto de coleta. Desse modo, a estrutura de dados tem as pacientes com unidades primárias de amostragem, ou clusters, e as múltiplas observações em cada paciente como as unidades secundárias de observação (quadro 1).

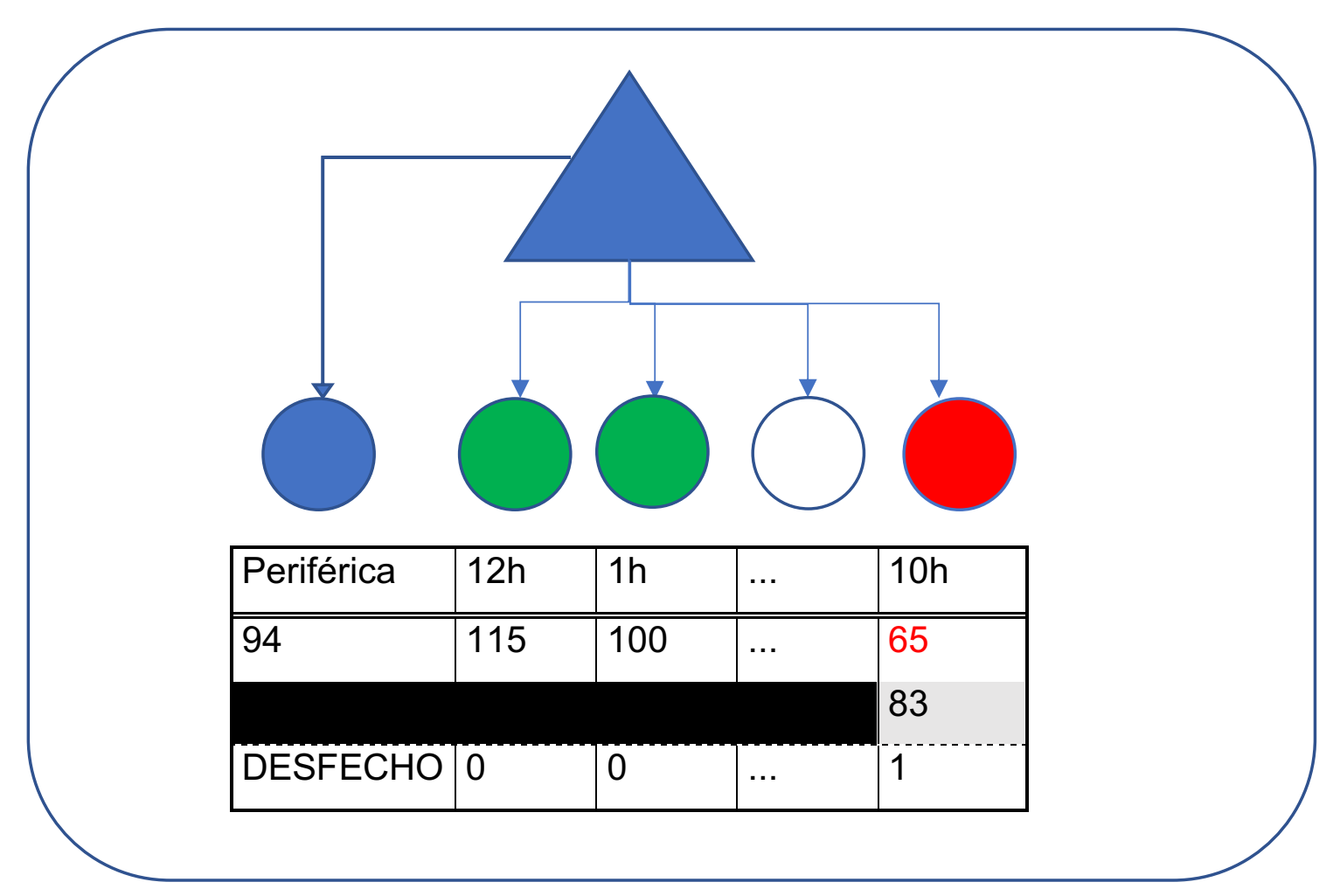

Quadro 1 - Estruturação dos dados e análise de desfecho

NOTA:

Triangulo - Unidade primária de observação (paciente)

Círculo - Unidade secundária de amostragem (GC) verde - sem sofrimento / vermelho - NCET

Valores de GCs e GCP em mg/dL 
A população alvo do estudo foram as mulheres submetidas à mastectomia ou adenectomia unilateral por câncer de mama associada à reconstrução imediata. A população acessível foram as pacientes atendidas no Serviço de Filantropia do Hospital Sírio-Libanês (HSL), entre dezembro de 2012 e abril de 2015. Uma amostragem por conveniência, determinada pelo encaminhamento randômico de pacientes para reconstrução mamária imediata para o mesmo cirurgião plástico, foi realizada para recrutamento de indivíduos para o estudo.

Por se tratar de um potencial fator de confusão importante para a associação entre a glicemia capilar e complicações pós-operatórias, como necroses do retalho de mastectomia, restringimos a amostra a pacientes que não tinham diagnóstico pré-operatório de diabetes melitus (DM). Outro critério de exclusão pré-determinado no desenho do estudo foi instabilidade hemodinâmica no pós-operatório mas nenhum sujeito precisou ser excluído por esta razão (quadro 2).

\section{Critérios de inclusão}

1. Sexo feminino;

2. Mastectomia ou adenectomia unilateral;

3. Reconstrução mamária imediata pelo mesmo cirurgião plástico.

\section{$\underline{\text { Critérios de exclusão }}$}

1. Diagnóstico prévio relatado de DM;

2. Instabilidade hemodinâmica no pós-operatório.

Quadro 2 - Critérios de inclusão e exclusão

3.2. Teste índice - Glicemia capilar (GC)

Após o término da cirurgia oncológica, a reconstrução da mama seguiu o planejamento pré-operatório normal, sem sofrer nenhuma interferência em 
função da inclusão da paciente no estudo. A indicação da técnica de reconstrução foi definida conforme os protocolos assistenciais do Núcleo de Mastologia do HSL. A viabilidade do retalho cutâneo foi avaliada subjetivamente pelo cirurgião responsável e as ressecções de pele foram determinadas baseando-se na espessura e coloração do retalho além do posicionamento final da cicatriz, como se faz habitualmente.

Antes do fechamento final da ferida operatória, pontos aleatórios para mensuração da glicemia capilar foram demarcados no retalho da mastectomia. Inicialmente, 4 pontos nas extremidades mais cranial, caudal, medial e lateral foram selecionados. Se a distância entre 2 destes pontos fosse maior do que 5 $\mathrm{cm}$, um ponto adicional era demarcado entre eles. Os pontos de coleta foram identificados conforme a sua posição do ponteiro de um relógio, tendo o ponto mais cranial como referência (12 horas $(h)$ ). Com o auxílio de pequenas lâminas de plástico estéreis, confeccionadas a partir da régua que acompanha a caneta de marcação cirúrgica, uma pequena amostra de sangue foi coletada da derme da borda da ferida operatório de cada ponto demarcado. Assim que coletadas, as amostras foram entregues a um pesquisador fora do campo cirúrgico que procedeu a aferição da GC de cada amostra com auxílio do glicosímetro disponível no centro cirúrgico (FreeStyle Precision Pro, Abbott Diabetes Care Ltd, UK). Por segurança, toda vez que uma amostra apresentava uma GC inferior a $80 \mathrm{mg} / \mathrm{dL}$, uma amostra confirmatória era coletada no mesmo ponto de coleta. A medida de maior valor absoluto foi considerada para a análise, a menor foi descartada. Nenhuma ressecção adicional foi realizada após a coleta das amostras. Ao final do procedimento do estudo, uma glicemia capilar periférica (GCP) também foi realizada em amostra de sangue coletado fora do campo cirúrgico (dedo ou lóbulo da orelha). O fechamento da ferida operatória foi concluído e um registro fotográfico (foto $A$ - fechamento) da demarcação dos pontos de coleta foi realizado (figura 1). Os cuidados pós-operatórios das pacientes seguiram os protocolos institucionais. 


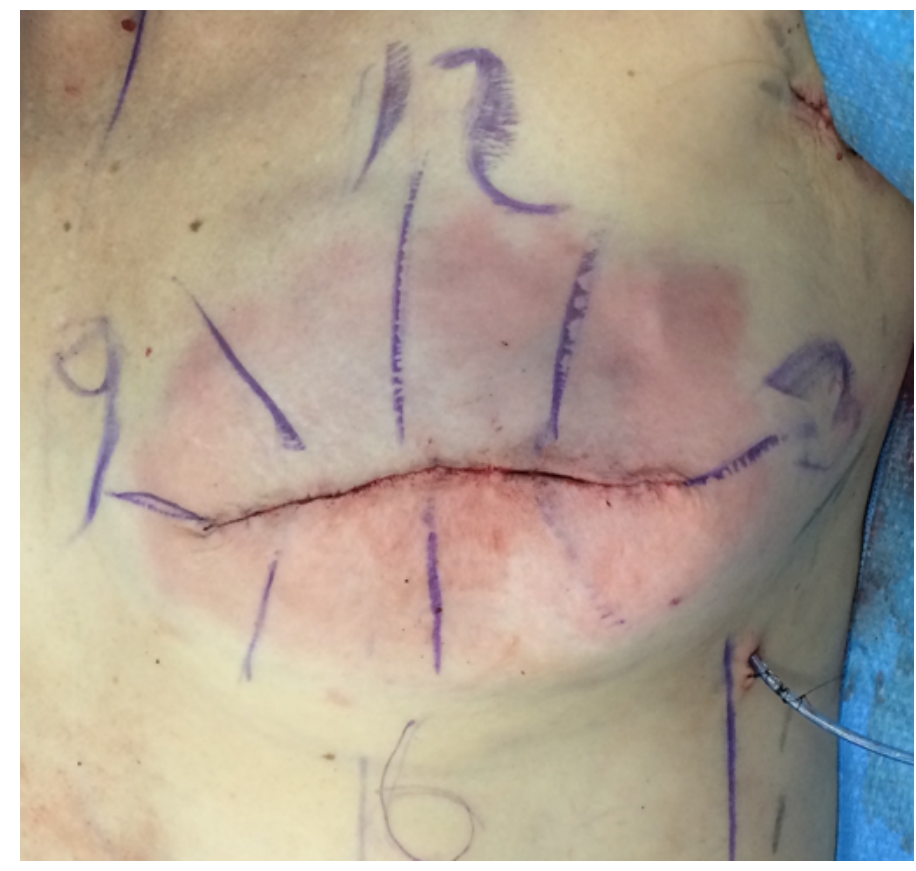

Figura 1 - Foto A (exemplo). Registro fotográfico ao final da cirurgia. Em azul, a demarcação dos pontos de coleta de amostras para determinação da glicemia capilar

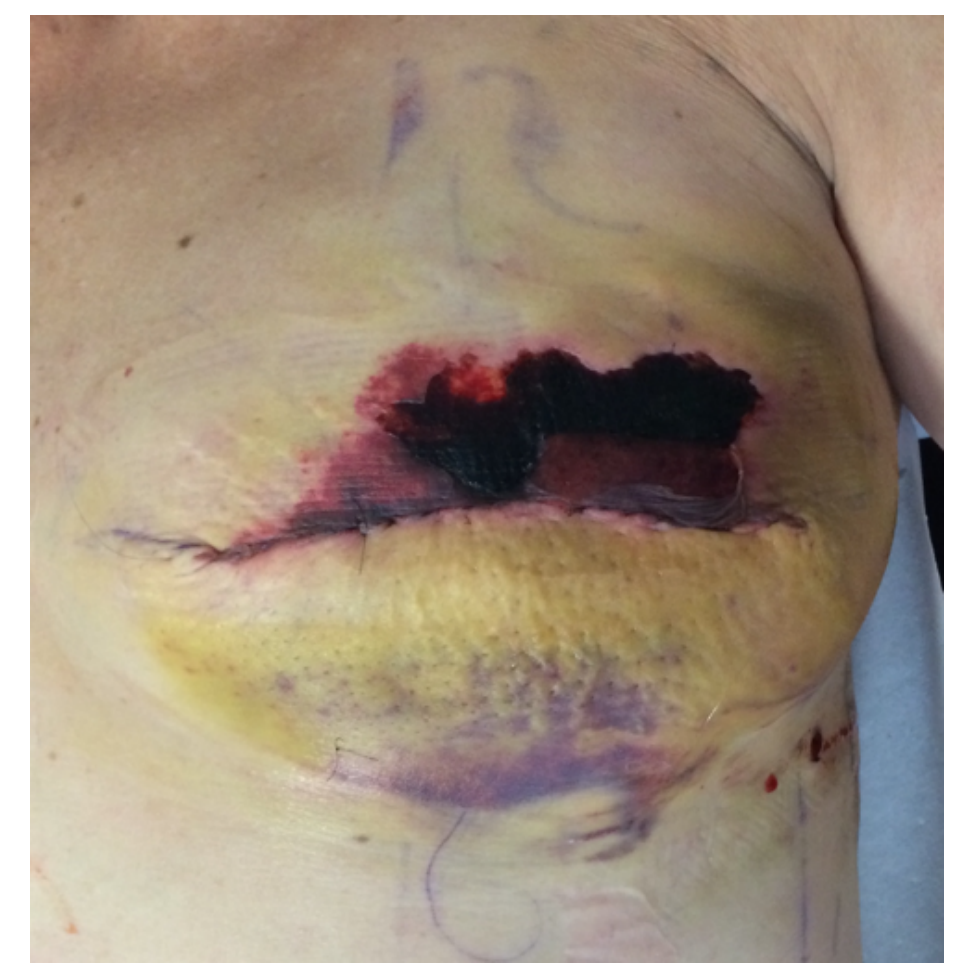

Figura 2 - Foto B (exemplo). Registro fotográfico da mama no $9^{\circ}$ dia de pós-operatório. Necrose de espessura total envolvendo 3 pontos de coleta demarcados na foto 1 podem ser observados, as $11 \mathrm{~h}, 12 \mathrm{~h} \mathrm{e} 1 \mathrm{~h}$ ) 
Os dados gerados foram anotados imediatamente em ficha de coleta préconcebida e aprovada pelo Comitê de Ética em Pesquisa (CEP) do HSL (apêndice A). Outras potenciais variáveis de confusão identificadas na revisão da literatura foram recuperadas dos prontuários das pacientes (quadro 3 ).

- Idade (contínua - anos);

- Índice de massa corpórea (contínua - IMC=peso/altura²);

- Tabagismo atual referido (binomial - sim ou não);

- Estadio clínico da doença, baseado no tamanho radiológico préoperatório da lesão (ordinal - in situ; $\leq 2 \mathrm{~cm}$; >2 cm) ${ }^{1}$;

- Conservação da papila (binomial - sim (adenectomia) ou não (mastectomia));

- Necessidade de retalho autólogo (binomial - sim ou não).

Quadro 3 - Variáveis de confusão observadas

\subsection{Teste referência - diagnóstico clínico de necrose}

Necroses por problemas de perfusão do retalho da mastectomia são complicações precoces e podem ser observadas nos primeiros dias após o procedimento. Um novo registro fotográfico (foto $B$ - seguimento) foi realizado entre o $7^{\circ}$ e $14^{\circ}$ dias de pós-operatório (figura 2). Uma vez concluídas as fases de recrutamento e de coleta de dados, as fotos do fechamento (A) e do seguimento (B) de cada paciente foram utilizadas para a classificação do desfecho em cada ponto de coleta. Um avaliador cego para os valores das GCs medidas comparou as fotos, observando a ocorrência de necrose total do retalho da mastectomia nos segmentos demarcados no intraoperatório. A variável foi categorizada em 2 níveis para cada ponto de coleta:

${ }^{1}$ No desenho original do estudo esta variável tinha os níveis determinados pela classificação da American Joint Committee on Cancer, mas a baixa frequência de tumores mais avançados na amostra nos obrigou a agrupar os tumores T2, T3 e T4 em um único nível $(>2 \mathrm{~cm})$. Fonte: 56. Hortobagyi GN, Connolly JL, D'Orsi CJ, Edge SB, Mittendorf EA, Rugo HS, et al. Breast. 2017:589-636. 
0. Desfecho negativo - ausência de necrose cutânea de espessura total nos segmentos correspondentes aos pontos de coleta nas bordas da ferida;

1. Desfecho positivo - necrose cutânea de espessura total (NCET) nos segmentos correspondentes aos pontos de coleta nas bordas da ferida operatória, independente da sua extensão.

Todas as fotos utilizadas para a análise dos desfechos, suas classificações e as medidas aferidas de GC para cada ponto estão disponibilizadas nos apêndices $\mathrm{B}$ e $\mathrm{C}$.

\section{4. Ética}

Este estudo foi submetido previamente a análise pelo Comitê de Ética em Pesquisa (CEP) do HSL. Todas as pacientes foram informadas sobre os procedimentos do estudo e assinaram um Termo de Consentimento Livre Esclarecido (TCLE) previamente aprovado pelo mesmo CEP. O CEP da Faculdade de Medicina da Universidade de São Paulo (FMUSP) avaliou o projeto e o TCLE e deu ciência para efeito de matrícula na Pós-Graduação.

\subsection{Tamanho da amostra e análise estatística}

O cálculo do tamanho da amostra foi baseado em dados epidemiológicos e de especificidade publicados na literatura $(40,57)$. Com um risco estimado de $20 \%$ de necrose entre as pacientes recrutadas e presumindo que, em média, cada uma destas pacientes desenvolverá o desfecho de interesse em duas de uma média de sete unidades secundárias de coleta, estimamos uma incidência acumulada de necrose de $5,7 \%$ entre os pontos de mensuração. Para a 
determinação do tamanho da amostra, utilizamos uma especificidade de $.85 \mathrm{e}$ uma precisão de .05 , usando a seguinte fórmula ${ }^{2}$ :

$$
n=\frac{Z^{2} * P(1-P)}{\Delta^{2}}
$$

Assim, definimos uma amostra de 208 pontos de coletas necessários. Considerando a média de 7 pontos de glicemia por paciente utilizada anteriormente, estimamos que seria necessária a inclusão de 30 pacientes no estudo para alcançar a precisão desejada.

Variáveis contínuas foram descritas por suas medianas e intervalos interquartis (IIQ) ou por suas médias e desvios padrões. Variáveis categóricas foram descritas por suas distribuições absoluta e relativa entre os diferentes níveis. No nível das unidades primárias de amostragem (pacientes), testes de Wilcoxon-Mann-Whitney, Chi-quadrado ou exato de Fisher foram utilizados para avaliar a associação das variáveis idade, IMC, tabagismo, estadio, e cirurgias realizadas com a ocorrência de NCET em qualquer segmento do retalho da mastectomia.

Em cada ponto de coleta, foram analisados como variáveis independentes (exposição) o valor absoluto de GC aferido (GCA) e o valor da GC relativo a GCP (GCR = GCA/GCP). Para a análise ao nível das unidades secundárias (pontos de amostragem), um teste $\mathrm{T}$ de Student foi utilizado para comparar as medidas de GCA e GCR entre os grupos de desfecho (análise reversa (55)). Modelos de equações de estimação generalizada (EEGs) foram utilizados para avaliar a associação entre os dois preditores - GCA e GCR - e a chance (odds) do desfecho de interesse nos pontos avaliados. EEGs multivariadas foram modeladas para ajustar a relação entre a redução da GCA ou da GCP e a chance de NCET pelas potenciais variáveis observadas no estudo.

A acurácia diagnóstica da GCA e da GCR na descriminação de áreas de NCET foi estudada através do uso de Curvas de Características Operacionais

${ }^{2} \mathrm{P}=$ Especificidade, $\mathrm{Z}=$ score da curva normal para o nível de confiança desejado e $\Delta=$ Precisão desejada 
(ROC - Receiver Operating Curve), com o cálculo da área sob a curva (AUC ou estatística $C$ ). Para diferentes valores de GCA e GCR, os índices de performance dos testes - sensilidade ( $\mathrm{Sn}$ ), especificidade $(\mathrm{Sp})$, valores preditivos positivo e negativo (VPP e VPN, respectivamente) e as razões de verossimilhança positivo e negativo ( $L R+$ e LR-, respectivamente) - foram calculados com seus intervalos de confiança para 95\% (IC95\%), determinados por amostragem em bootstrap.

Todas as análises foram realizadas com o auxílio do pacote estatístico Stata, versão 14.0 para MacOS (StataCorp, TX/EUA). Um nível de significância estatística bicaudal de .05 foi assumido. 
4. RESULTADOS 


\subsection{Análise nível primário}

Foram recrutadas 30 pacientes que preencheram os critérios de inclusão e exclusão pré-determinados para o estudo. Nestas pacientes, foram coletadas amostras de sangue em 230 pontos diferentes. A hierarquização dos dados se mostrou bem balanceada, sendo que 27 pacientes apresentaram 8 pontos de amostragem enquanto duas pacientes tiveram 4 amostras coletadas e 1 contribuiu com 6 amostras. A idade mediana foi de 48.5 anos (IIQ= 38 a 55 anos) e o IMC mediano foi de 26.6 (IIQ= 21.8 a 30.1). Quatro indivíduos (13.3\%) referiram tabagismo ativo; 14 (46.7\%) tinham tumores maiores do que $2 \mathrm{~cm}(11$ com estadio T2, 2 com T3 ou 1 com um tumor T4), 9 (30\%) apresentavam tumores invasivos menores do que $2 \mathrm{~cm}$ enquanto 7 pacientes (23.3\%) foram operadas por lesões pré-malignas (in situ).

A prevalência de necrose nas unidades primárias de observação foi de $30 \%$ durante o período do estudo, acometendo 9 das 30 pacientes. A tabela 1 mostra as distribuições das variáveis analisadas entre os pacientes que apresentaram NCET e os que tiveram uma cicatrização sem complicações locais de suas feridas operatórias. Para as variáveis descritas anteriormente, não houve diferença significativa entre os pacientes dos diferentes grupos $(p=.62$, $.72, .56$ e .13 respectivamente). Em análise univariada, houve uma associação estatisticamente significativa entre preservação da aréola e a ocorrência de NCET (Razão de chance (odds ratio) - OR= 14.9; IC95\%= $2.2-100.6 ; p=.002$ ).

Não houve associação significativa do ponto de vista estatístico entre a necessidade de um retalho autólogo e um desfecho favorável $(p=.14)$. 
Tabela 1 - Características demográficas e análise exploratória das variáveis observadas

\begin{tabular}{|c|c|c|c|c|c|}
\hline & \multirow{2}{*}{\multicolumn{2}{|c|}{$\begin{array}{l}\text { SEM NECROSE } \\
\qquad N=21(70 \%)\end{array}$}} & \multirow{2}{*}{\multicolumn{2}{|c|}{$\begin{array}{c}\text { NCET } \\
\mathrm{N}=9(30 \%)\end{array}$}} & \multirow{3}{*}{$p$} \\
\hline & & & & & \\
\hline & Mediana & IIQ & Mediana & IIQ & \\
\hline Idade & 52 & $38-58$ & 48 & $39-55$ & $.62 *$ \\
\hline \multirow[t]{2}{*}{ IMC } & 26,1 & $21,8-30,1$ & 27,5 & $24-30$ & $.72 *$ \\
\hline & $\mathrm{n}$ & $\%$ & $\mathrm{n}$ & $\%$ & $p$ \\
\hline \multicolumn{6}{|l|}{ Tabagismo atual } \\
\hline Sim & 2 & $9,5 \%$ & 2 & $22,2 \%$ & $.56 \bullet$ \\
\hline Não & 19 & $90,5 \%$ & 7 & $77,8 \%$ & \\
\hline \multicolumn{6}{|l|}{ Estadio } \\
\hline in situ & 3 & $14,3 \%$ & 4 & $44,4 \%$ & $.13 x$ \\
\hline$\leq 2 \mathrm{~cm}(\mathrm{~T} 1)$ & 8 & $38,1 \%$ & 1 & $11,1 \%$ & \\
\hline$>2 \mathrm{~cm}(\mathrm{~T} 2 / 3 / 4)$ & 10 & $47,6 \%$ & 4 & $44,4 \%$ & \\
\hline \multicolumn{6}{|l|}{ Preservação de aréola } \\
\hline Sim & 4 & $19,1 \%$ & 7 & $77,8 \%$ & $.002 x$ \\
\hline Não & 17 & $80,9 \%$ & 2 & $22,2 \%$ & \\
\hline \multicolumn{6}{|l|}{ Retalho autólogo } \\
\hline Não & 15 & $71,4 \%$ & 9 & $100 \%$ & $.14^{\bullet}$ \\
\hline Sim & 6 & $28,6 \%$ & 0 & $0 \%$ & \\
\hline
\end{tabular}

NOTA: IIQ - Intervalo interquartil; ${ }^{*}$ Teste de Wilcoxon-Mann-Whitney; ' Teste exato de Fisher; $\chi$ Teste de $\chi$-quadrado

\subsection{Análise nível secundário}

Dos 230 pontos de coleta aleatórios avaliados, vinte e um (9.1\%) apresentaram NCET ao longo da ferida cirúrgica no seguimento pós-operatório. A GCA absoluta média medida entre os 230 pontos foi de 123.8 \pm 28.2 (figura 3). Houve uma diferença estatisticamente significativa entre os pontos que evoluíram com NCET e os que evoluíram sem necrose (126.3 \pm 27.1 vs 99.8 $\pm 28.3 ; \mathrm{t}(228)=4.3 ; \mathrm{p}<0001)$ (Figura 4). Do mesmo modo, a média da GCR dos pontos que evoluíram com NCET foi significativamente mais baixa que a 
média daqueles que evoluíram de maneira satisfatória $(.86 \pm .2$ vs $1.04 \pm .2 ; \mathrm{t}(228)=$ $3.8 ; p=.0002)$ (Figuras 5 e 6$)$.

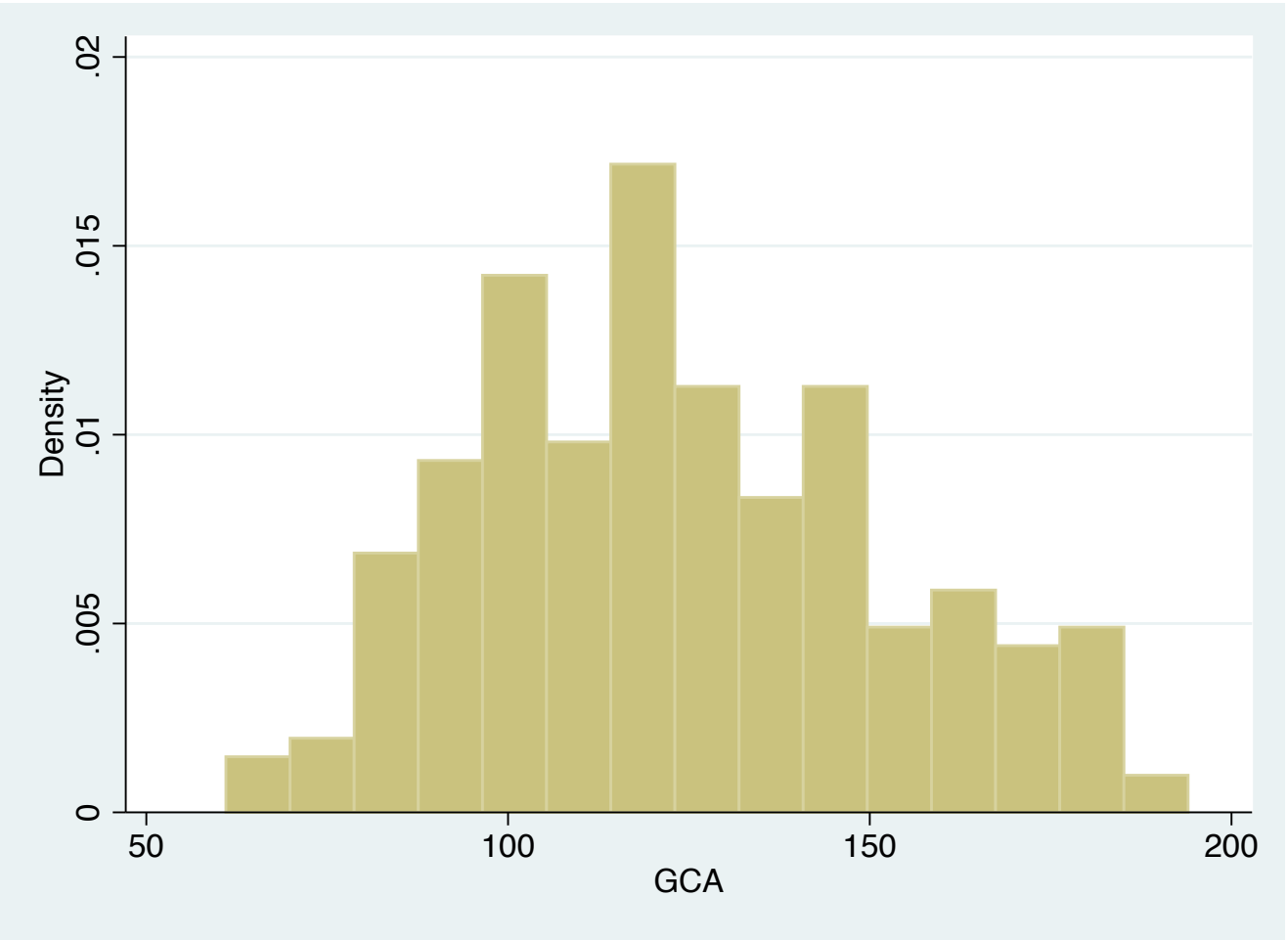

Figura 3 - Distribuição das GCAs medidas (histograma)

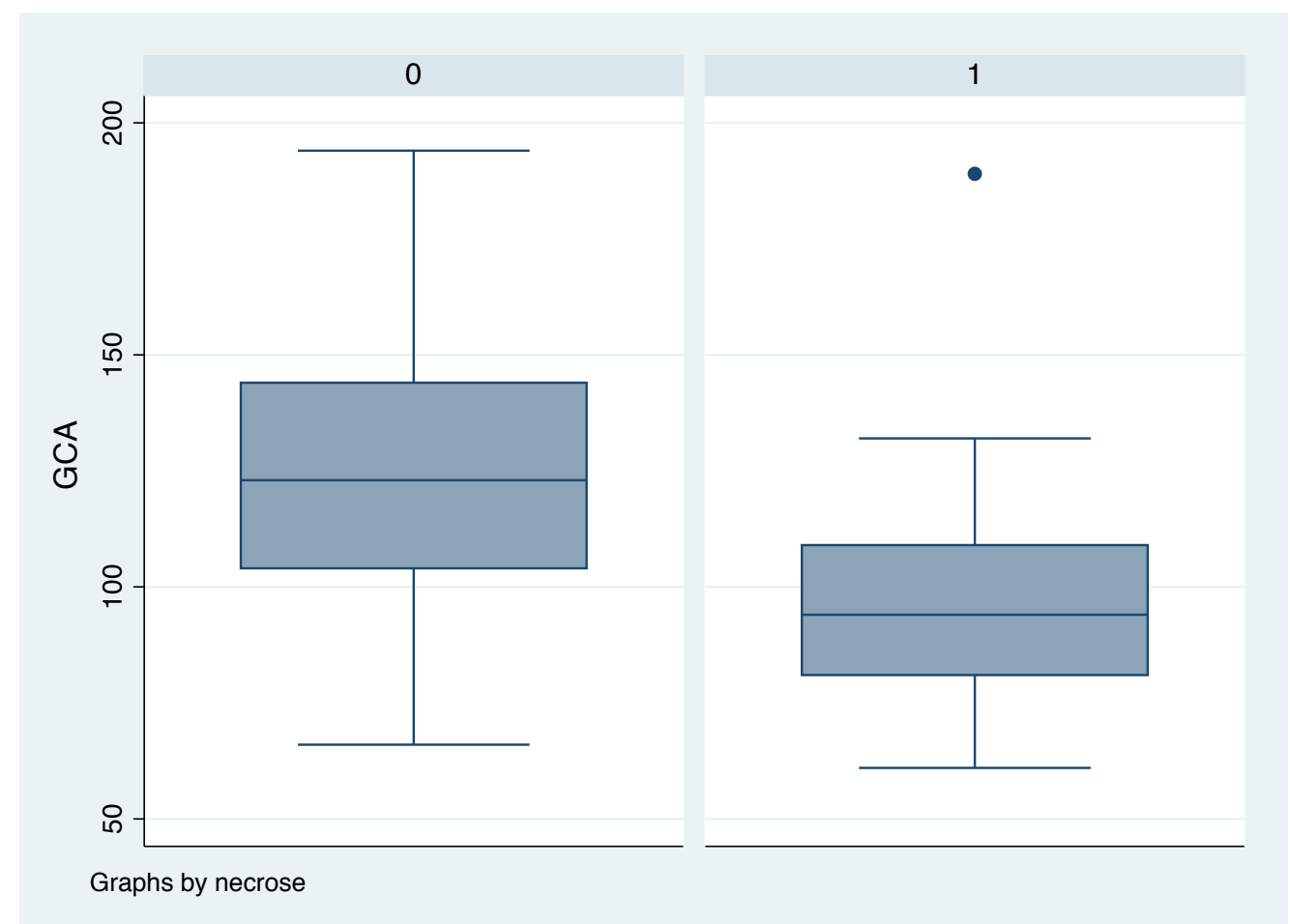

Figura 4 - Gráfico de caixas demonstrando a distribuição das GCA entre os pontos de observação que não apresentaram NCET (0) e os que apresentaram NCET (1) 


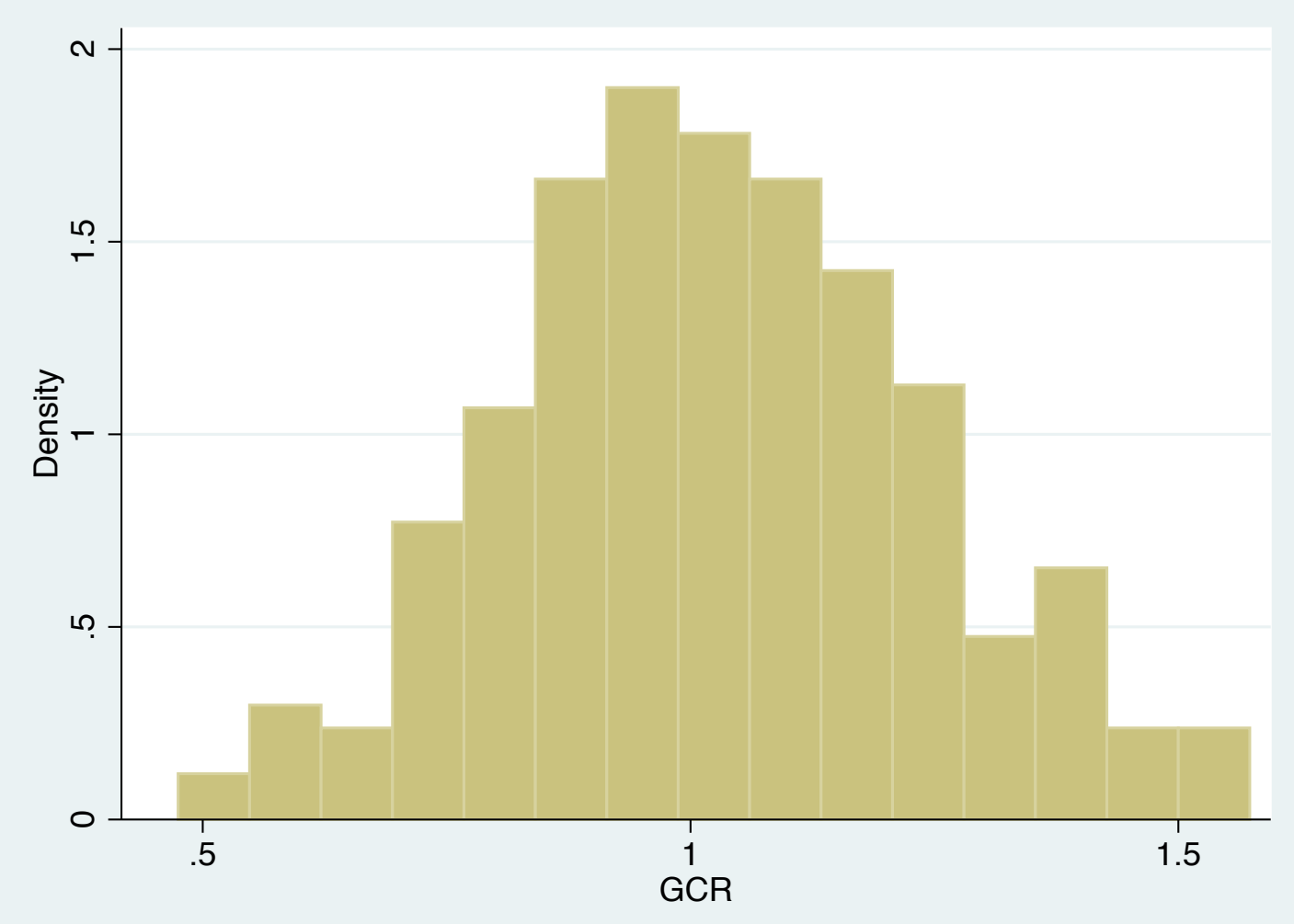

Figura 5 - Distribuição das GCAs medidas (histograma)

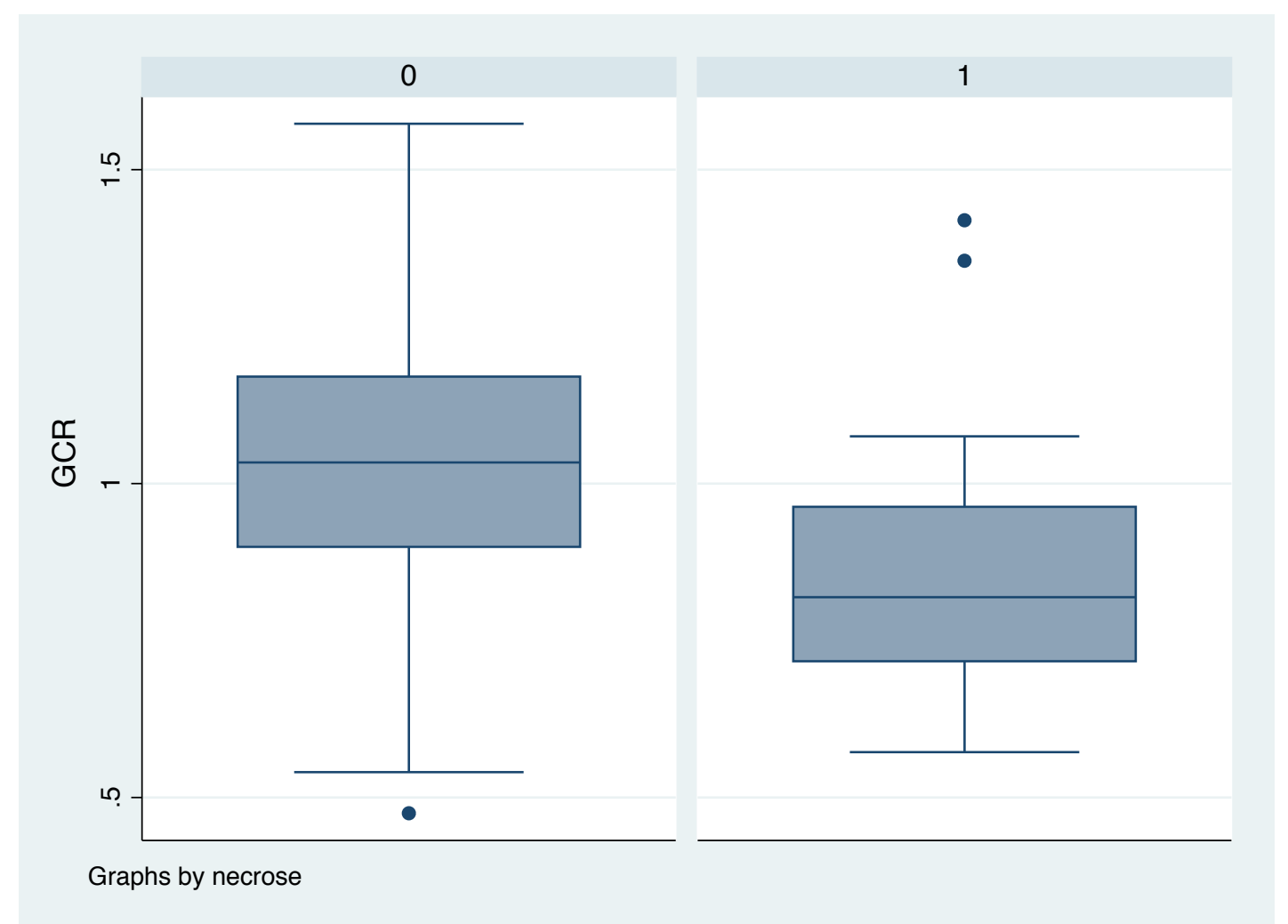

Figura 6 - Gráfico de caixas demonstrando a distribuição das GCR entre os pontos de observação que não apresentaram NCET (0) e os que apresentaram NCET (1). 
$\mathrm{Na}$ análise univariada, compensada para a estrutura hierarquizada de dados, utilizando como desfecho a ocorrência de NCET nos pontos de observação, uma queda de $10 \mathrm{mg} / \mathrm{dL}$ na GCA esteve associada a um aumento de $71 \%$ na chance de NCET (OR=1.71; IC95\%= 1.21 a $2.41 ; p=.002$ ). Uma redução de $10 \%$ na GCR também esteve associada a um aumento de $77 \%$ na chance de NCET (OR=1.77; IC95\%= 1.23 a 2.55; $p=.002)$.

EEGs multivariadas foram modeladas para ajustar a relação entre a redução da GCA ou da GCP e a chance de NCET pelas potenciais variáveis de confusão observadas (tabela 2). Nestes diferentes modelos, a OR de NCET para uma redução de $10 \mathrm{mg} / \mathrm{dL}$ na GCA variou entre 1.68 e 1.81 mantendo as estas variáveis fixas. Apenas para as pacientes em que se preservou a aréola foi observada uma associação na análise multivariada. Mantendo GCA fixo, a preservação da aréola esteve associado a um OR= 8.7 (IC95\%= 1.7 - 44.6; $\mathrm{p}=.01$ ) para NCET. Neste modelo, a redução de $10 \mathrm{mg} / \mathrm{dL}$ da GCA foi associado a um OR= $1.69($ IC95\%= $1.12-2.54 ; p=.012)$, ajustado para a preservação ou não da aréola.

Do mesmo modo, a OR da redução de $10 \%$ na GCR variou entre 1.78 e 1.84 para os diferentes modelos multivariados. A preservação da aréola também demonstrou uma associação estatisticamente significativa $(O R=10.5$; IC95\%= 1.8 - 60.1; $p=.008$ ) com NCET quando ajustada para GCR.

Tabela 2 - Razão de chance (OR) entre as potenciais variáveis de confusão para NCET ajustadas para GCA ou GCR

\begin{tabular}{l|c|c|c|c|c|c}
\hline PREDITOR & \multicolumn{3}{|c|}{ GCA } & \multicolumn{3}{c}{ GCR } \\
\cline { 2 - 7 } & OR & IC95\% & $p$ & OR & IC95\% & $p$ \\
\hline Idade &, 95 & $, 87-1,02$ &, 16 &, 95 & $, 88-1,02$ & .16 \\
IMC & 1,05 & $, 92-1,2$ & .49 &, 97 & $, 84-1,1$ & .67 \\
Tabagismo & 2,2 & $, 8-5,9$ & .12 & 3,7 & $, 52-26,8$ & .19 \\
Preservação & 8,7 & $1,7-44,6$ & .01 & 10,5 & $1,8-60,1$ & .008 \\
da aréola & & & & & & \\
\hline
\end{tabular}


As curvas ROC para GCA e GCR são apresentadas nas figuras 7 e 8, respectivamente.

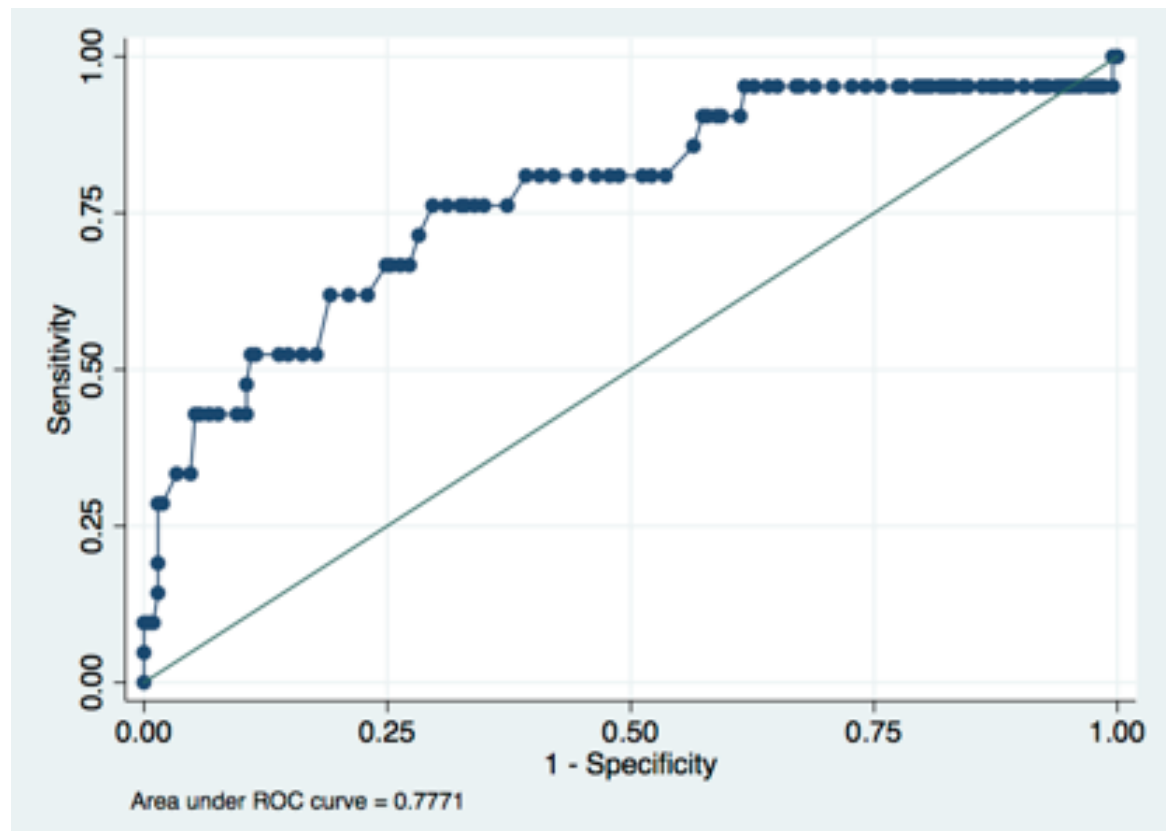

Figura 7 - Curva ROC. Poder discriminatório da GCA para NCET do retalho da mastectomia

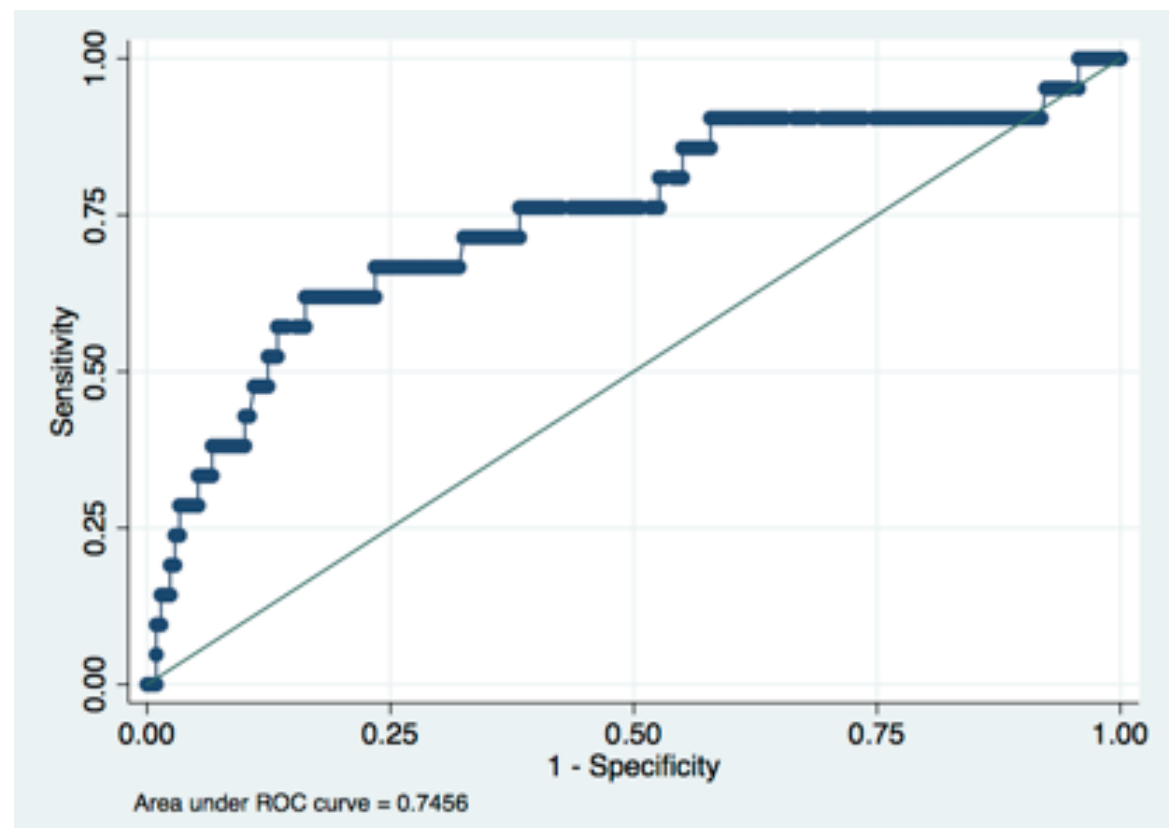

Figura 8 - Curva ROC. Poder discriminatório da GCR para NCET do retalho da mastectomia 
A estatística $C$ (AUC) é uma medida de adequação para modelos com desfechos binários. Ela dá a probabilidade de que, na amostra estudada, um ponto aleatório que evoluiu com NCET apresentasse um resultado do preditor (GCA ou GCR) inferior a um outro ponto aleatório que não tenha evoluído com o desfecho de interesse. Para GCA, C=.78 (IC95\%=.65 a .92) enquanto GCR mostrou $C=.75$ (IC95\%=.47 a .89). Os IC95\% foram calculados por amostragem em bootstrap, ajustados para a estrutura hierarquizada dos dados estudados. Estes resultados mostram que os dois preditores tem um poder discriminatório intermediário para NCET (58).

Usando como valor de referência para positividade do teste diagnóstico um valor de GCA menor que 90 mg/dL, observamos uma Sp de 92\% (193/209) e Sn de 43\% (9/21) para predição do desfecho de interesse. Usando como referência uma relação com a GC periférica menor do que 80\% (GCR< .8), a Sp e Sn do teste foram 89\% (187/209) e 43\% (9/21), respectivamente. Quando os dois valores de corte foram utilizados na amostra (GCA $<90 \mathrm{mg} / \mathrm{dL}$ OU GCR< .8), a Sn do teste foi de $67 \%$ (14/21) enquanto a Sp foi de $86 \%$ (179/209). A tabela 3 apresenta estes e outros indicadores de performance do teste para as três situações descritas. 
Tabela 3 - Acurácia diagnóstica da GC para predição de NCET

\begin{tabular}{|c|c|c|c|c|}
\hline $\begin{array}{c}\text { VALOR DE } \\
\text { REFERÊNCIA }\end{array}$ & TESTE & $\begin{array}{c}\text { NCET } \\
\mathrm{N}=21(9.1 \%)\end{array}$ & $\begin{array}{l}\text { SEM NECROSE } \\
\mathrm{N}=209(90.9 \%)\end{array}$ & $\begin{array}{l}\text { PERFORMANCE } \\
\text { (IC95\%) }\end{array}$ \\
\hline \multirow{6}{*}{$\begin{array}{c}\mathrm{GCA}<90 \\
\mathrm{mg} / \mathrm{dL}\end{array}$} & \multirow{4}{*}{+} & \multirow{4}{*}{9} & \multirow{3}{*}{16} & $\mathrm{Sn}=43 \%(22-66 \%)$ \\
\hline & & & & $S p=92 \%(88-96 \%)$ \\
\hline & & & & $P P V=26 \%(12-43 \%)$ \\
\hline & & & \multirow{3}{*}{193} & NPV $=94 \%(90-97 \%)$ \\
\hline & \multirow[t]{2}{*}{ - } & \multirow[t]{2}{*}{12} & & $\mathrm{LR}+=5.6(1.8-14.86)$ \\
\hline & & & & LR-= .62 (.36-.89) \\
\hline \multirow{6}{*}{ GCR $<80 \%$} & \multirow{4}{*}{+} & \multirow{4}{*}{9} & \multirow{3}{*}{22} & $S n=43 \%(22-66 \%)$ \\
\hline & & & & $\mathrm{Sp}=89 \%(84-93 \%)$ \\
\hline & & & & $P P V=22 \%(11-38 \%)$ \\
\hline & & & \multirow{3}{*}{187} & $N P V=94 \%(90-97 \%)$ \\
\hline & \multirow[t]{2}{*}{-} & \multirow[t]{2}{*}{12} & & $\mathrm{LR}+=4.07(1.41-9.83)$ \\
\hline & & & & LR-= .64 (.36-.93) \\
\hline \multirow{3}{*}{$\begin{array}{c}\mathrm{GCA}<90 \\
\mathrm{mg} / \mathrm{dL} \\
\mathrm{OU}\end{array}$} & \multirow{3}{*}{+} & \multirow{3}{*}{14} & \multirow{3}{*}{30} & $S n=67 \%(43-85 \%)$ \\
\hline & & & & $S p=86 \%(80-90 \%)$ \\
\hline & & & & $P P V=26 \%(15-40 \%)$ \\
\hline \multirow{3}{*}{ GCR $<80 \%$} & \multirow{3}{*}{ - } & \multirow{3}{*}{7} & \multirow{3}{*}{179} & NPV $=96 \%(92-98 \%)$ \\
\hline & & & & $\mathrm{LR}+=4.64(2.17-8.63)$ \\
\hline & & & & LR- $=.39(.16-.71)$ \\
\hline
\end{tabular}


5. DISCUSSÃO 


\subsection{Caracterização da casuística utilizada}

Apesar de adequada para a pergunta proposta, a amostra utilizada é a principal limitação do estudo. Constituída com uma estratégia de recrutamento por conveniência, a população acessível se limitou a sujeitos de uma única instituição. Dificuldades operacionais relacionados a problemas de colaboração de cirurgiões não envolvidos diretamente com o projeto restringiram a inclusão de pacientes àquelas operadas por um único cirurgião plástico. Apesar de aumentar a validade interna da amostra, estas limitações reduzem a variabilidade da mesma e, por conseguinte, a generalização dos resultados encontrados (59). Nossa prevalência de NCET (30\%) (tabela 1) foi compatível com dados da literatura (18-20) e um pouco acima do que estimamos no cálculo da amostra.

Por outro lado, a estrutura de dados adotada permitiu uma otimização de recursos com uma redução importante do número de pacientes necessários para se atingir a significância estatística pretendida no desenho do estudo. Com apenas 30 pacientes, foi possível coletar 230 amostras de sangue para análise (quadro 1). A estratégia de determinação dos pontos de coleta não incluiu características do retalho observadas no intraoperatório pelo cirurgião (figura 1). Assim, é possível considerar que dentro de cada unidade primária de amostragem, ou cluster, as unidades de observação foram determinadas aleatoriamente. Apesar da estrutura hierarquizada dos dados não permitir que estas sejam tratadas como independentes entre elas, a redução da variabilidade pôde ser compensada pela utilização de ferramentas estatísticas adequadas. As EEGs funcionam como modelos de regressão logística para desfechos binomiais, mas levam em consideração a estrutura dos dados para determinar o intervalo de confiança dos efeitos calculados (55).

Tanto na análise reversa (figuras 4 e 6 ) quanto nos modelos de EEG uni e multivariados, as variáveis independentes do estudo (GCA e GCR) mostraram uma razão de chance (odds ratio) estatisticamente significativa com a ocorrência de NCET. De um modo geral, uma redução de $10 \mathrm{mg} / \mathrm{dL}$ na GCA ou uma queda 
de 0.1 na GCR estiveram associadas a um aumento de aproximadamente $75 \%$ na chance de NCET em um ponto aleatório da borda da ferida operatória de um retalho de mastectomia, com intervalos de confiança variando entre $20 \%$ e 150\%. Apesar de não ser o escopo desta tese, vale lembrar que existem diferenças essenciais entre a razão de chance e a razão de risco. Estas diferenças devem ser levadas em conta na interpretação dos resultados apresentados. Estes achados confirmam nossa hipótese principal de que o tecido dos retalhos das mastectomias sob stress perfusional exibe alterações metabólicas precoces que podem ser medidas.

\subsection{Mensuração das variáveis}

Uma importante fonte potencial de erro nas associações observadas é o viés de mensuração das variáveis estudadas. A variável independente principal foi aferida em amostras de sangue colhidas no campo operatório e transferidas para um glicosímetro fora do campo cirúrgico. Embora a precisão deste e de outros aparelhos de glicemia tenha sido estudada para a aferição da glicemia periférica em pacientes diabéticos e não diabéticos, estes instrumentos não foram testados para a mensuração da glicemia nas condições propostas pelo estudo. Em algumas medidas extremas, em que o protocolo previu a confirmação das medidas, pudemos observar algumas diferenças importantes nos valores aferidos para a glicemia no mesmo ponto de coleta. A comparação de múltiplas amostras em cada ponto permitiria esta análise, mas, do ponto de vista operacional, aumentaria de maneira significativa o tempo de anestesia e, em função de um risco maior, inviabilizariam o estudo. Este tipo de viés tende a ser conservador, na medida em que a presença de erro de mensuração normalmente leva a maior variabilidade dentro da amostra, acarretando perda de poder no efeito medido (60).

Por outro lado, podemos considerar que a mensuração do desfecho tem sensibilidade e especificidade praticamente perfeitas, visto que o diagnóstico da NCET é eminentemente clínico e ocorre nos primeiros dias de pós-operatório 
(figura 2). Como neste período as pacientes ainda se encontram em acompanhamento ambulatorial regular, não houveram perdas de seguimento e todos os desfechos positivos e negativos puderam ser capturados. Além disso, a classificação dos desfechos por um investigador cego às medidas realizadas foi uma etapa importante para evitar a inclusão inadvertida de algum viés de mensuração. Como discutido acima, a repetição da classificação dos desfechos por outro investigador, também cego, poderia evidenciar algum ponto de discórdia onde o desempate caberia a um terceiro. Esta estratégia poderia aumentar marginalmente a acurácia do teste de referência. Mesmo assim, acreditamos que a avaliação clínica realizada para o diagnóstico de NCET pode ser considerada como um teste padrão ouro para avaliação do desfecho de interesse.

\subsection{Variáveis de confusão}

Apesar das vantagens apresentadas pela estrutura de dados empregada, a amostra se mostrou bastante limitada para observar significância para as variáveis observadas ao nível das pacientes (tabela 1), mesmo se tratando de fatores de risco estabelecidos para NCET em retalhos de mastectomia como o tabagismo e a obesidade (28). Um grafo acíclico dirigido (DAG - Direct Acyclic Graph) foi utilizado para modelar as relações de influência entre as variáveis observadas no estudo (61) (figura 9) e determinar as associações passíveis de ajuste na análise multivariada.

A limitação referida acima se mostrou relevante tanto na análise ao nível das unidades primárias quanto nos modelos multivariados testados ao nível das observações (tabela 2). Apenas a preservação da aréola, fator de risco conhecido para NCET (25), se mostrou estatisticamente significativa na análise multivariada, sem um impacto relevante nos ORs de GCA e GCR. 


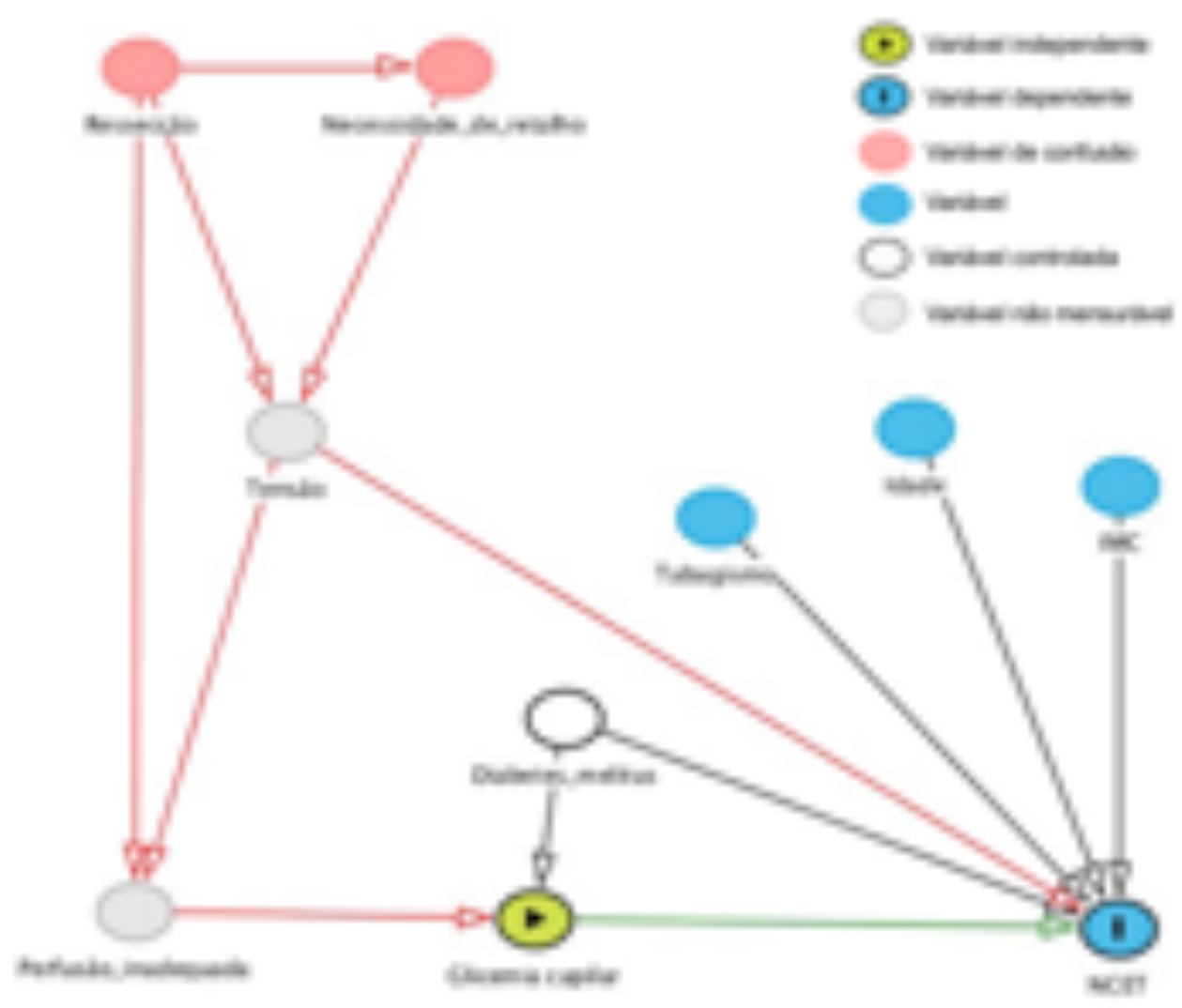

Figura 9 - DAG. Relação de influência entre variáveis observadas FONTE: www.daggity.net

O tabagismo é um fator de risco pré-operatório importante para NCET mas o consumo no pós-operatório recente pode acentuar uma eventual insuficiência da perfusão por vasoconstrição periférica. Modelos de interação entre tabagismo e as variáveis independentes foram construídos, mas, apesar de significantes, mostraram resultados desproporcionais, com intervalos de confiança muito amplos, e foram omitidos. Esta observação pode ser explicada pela baixa frequência de tabagistas em uma amostra relativamente restrita.

Da mesma forma, é possível imaginar que, no intraoperatório, a viabilidade de um segmento de pele do retalho da mastectomia ainda não esteja totalmente definida e dependa de variáveis ainda não determinadas. Em um experimento clínico randomizado controlado, Gdalevitch et al demonstraram que é possível reduzir a taxa de NCET em retalhos de mastectomia de $33.8 \%$ no grupo controle (curativo convencional) para 15.3\% com o uso de um curativo com $45 \mathrm{mg}$ de nitroglicerina tópica (diferença de risco de 18.5\%; IC95\% = 5.3 a 
$31 \% ; p=0.006)(62)$. Esse achado sugere que, assim como nos pacientes queimados, existe uma zona cinzenta cuja evolução depende dos cuidados no pós-operatório, impossíveis de serem avaliados no momento em que o teste é aplicado.

Ademais, o desenho proposto não permite avaliar uma variável importante para a perfusão destes retalhos. As GCs foram medidas após as ressecções cutâneas mas antes da sutura final que aplica tensão nas bordas da ferida operatória. Uma tensão excessiva pode comprometer a perfusão destes retalhos. No DAG, o ajuste da associação entre a GC e NCET depende de variáveis que não puderam ser medidas no estudo. Todos estes fatores são exemplos que podem contribuir para a redução da precisão do teste diagnóstico avaliado.

\subsection{Acurácia para a predição de NCET}

Além de permitir uma análise visual das relações de causa e efeito imaginadas, o DAG permite observar graficamente que a intenção do trabalho foi estudar o papel da GC como uma variável substituta da avaliação da perfusão tecidual e como uma ferramenta diagnóstica para a predição transoperatória de posterior NCET do retalho da mastectomia. A medição de GC na borda da ferida operatória é uma ferramenta barata e reprodutível, características importantes na escolha de um teste diagnóstico. Glicosímetros automatizados estão disponíveis em todas as instituições de saúde, independente do seu tamanho e grau de complexidade. Além destas características, um bom teste diagnóstico deve ser capaz de diferenciar de maneira efetiva os grupos de desfecho, baseados nos resultados observados (63).

Os preditores GCA e GCR demonstraram uma precisão discriminatória moderada para a predição de NCET na borda da ferida operatória dos retalhos da mastectomia ( $C=.78$ (IC95\%=.65 a .92) e $C=.75$ (IC95\%=.47 a .89) respectivamente) (figuras 7 e 8). A amplitude dos intervalos de confiança dos efeitos estimados se deve, em parte, a estrutura dos dados. $O$ ajuste estatístico 
para a não independência dos dados compensa a menor variabilidade dos dados pelo aumento dos ICs. Esse fenómeno parece mais importante para a GCR, para quem apenas uma tendência de precisão discriminatória foi observada (IC inclui .5). Um aumento exponencial do viés de mensuração pela derivação matemática de variáveis medidas originalmente com algum erro (GCR= GCA/GCP) pode explicar esta observação (64).

$\mathrm{Na}$ amostra estudada, quando foram assumidos como valores de corte para a positividade do teste diagnóstico $90 \mathrm{mg} / \mathrm{dL}$ para a GCA ou .8 para a GCR, o teste apresentou uma Sn de 67\% (43-85\%) e uma Sp de 86\% (80-90\%) (tabela 3). Estas observações diferem marginalmente da precisão diagnóstica relatada para outros testes desenvolvidos com objetivo similar, como a angiografia laserassistida com injeção intravenosa de verde de indocianina $(A L A-V I)(39,40)$, que será discutida mais a diante. Por serem parâmetros fixos dos testes diagnósticos, a Sn e a Sp são normalmente apresentadas como os resultados mais relevantes em estudos de testes diagnósticos. No estudo em questão, a Sn representa o risco de um teste positivo em segmentos que evoluirão com NCET. Paralelamente, a Sp corresponde ao risco de um teste negativo (GCA > 90 $\mathrm{mg} / \mathrm{dL}$ ou $\mathrm{GCR}>$.8) em segmentos do retalho que evoluirão de maneira favorável. Os VPPs e VPNs são medidas mais significativas da precisão diagnóstica em termos de tomada de decisões clínicas com base no resultado de um teste. O VPP expressa o risco de um desfecho ser positivo quando o teste em análise dá positivo. Em contrapartida, o VPN representa o risco de um desfecho ser negativo quando o teste é negativo. No entanto, estes parâmetros de acurácia diagnóstica dependem da prevalência do desfecho na população que está sendo testada, também conhecida como risco pré-teste (65). A medida que a prevalência do desfecho aumenta, o VPP aumenta e o VPN diminui. Neste estudo, a GC foi usado como ferramenta de rastreamento para NCET em segmentos aleatórios dos retalhos das mastectomias. Com uma prevalência de desfechos positivos inferior a 10\% (21/230), a GC, utilizando os valores de referência discutidos anteriormente, apresentou um VPN de 96\% e um VPP de apenas $26 \%$. Estes resultados sugerem que a GC é eficiente na identificação de segmentos da borda da ferida operatória que evoluirão de maneira satisfatória, mas não identificam claramente aqueles que morrerão. Na prática, o uso da GC 
como ferramenta exclusiva de rastreamento para NCET pode levar a ressecções desnecessárias de tecidos viáveis dos retalhos da mastectomia.

Em segmentos com maior risco de NCET, o resultado do teste pode ser mais informativo. A figura 10 mostra uma estimativa das VPN e VPP para os valores de corte definidos, baseado na $\mathrm{Sn}$ e Sp aferidas, com a variação do risco pré-teste para NCET (66). A seleção de pontos de maior risco para NCET pode ser alcançada, por exemplo, pela avaliação subjetiva da viabilidade dos retalhos da mastectomia e/ou pela associação de outras ferramentas diagnósticas já testadas com esta finalidade (18).

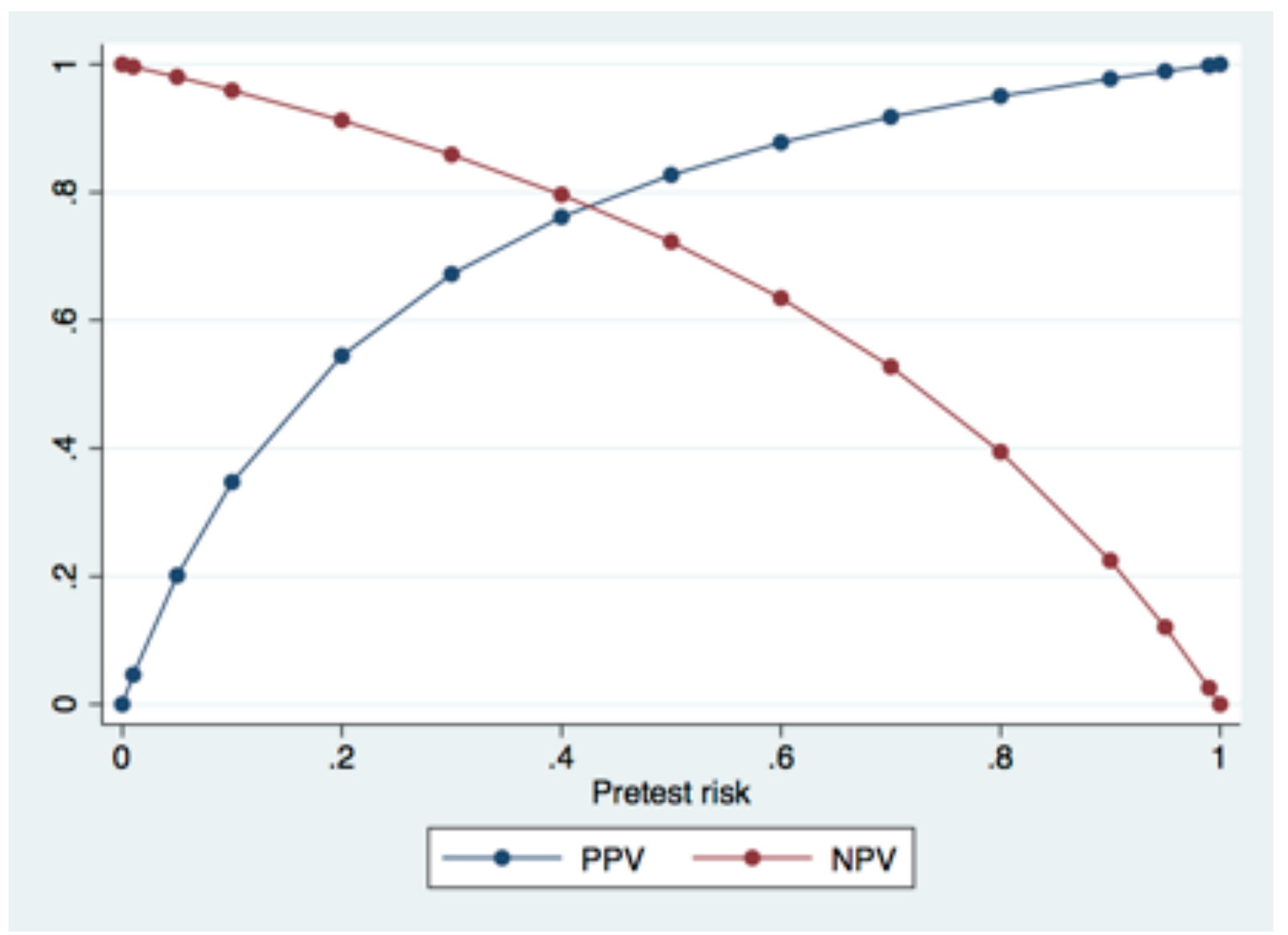

Figura 10 - Valores preditivos negativos (NPV) e positivos (PPV) dos critérios combinados ( $<90 \mathrm{mg} / \mathrm{DL}$ ou $<80 \%$ ), de acordo com o risco pré-teste de NCET 


\subsection{Extensão da área de NCET}

Com o desenho proposto, não foi possível determinar a capacidade da GC em avaliar a extensão da área de necrose no retalho da mastectomia. Esta é uma das principais limitações do estudo para se determinar a utilidade da ferramenta diagnóstica proposta na redução de complicações pós-operatórias nas pacientes com câncer de mama tratadas com mastectomias.

Em teoria, exames dinâmicos utilizando marcadores injetáveis para o mapeamento da perfusão destes tecidos poderiam auxiliar na delimitação das áreas de sofrimento. No entanto, estas técnicas de angiografia intra-operatória podem superestimar as áreas de posterior necrose, podendo também levar a ressecções desnecessárias. Em um estudo prospectivo avaliando 51 mamas reconstruídas com implantes-expansores com 21 necroses de qualquer espessura $(41,2 \%)$, Phillips et al compararam a avaliação clínica com as imagens obtidas com o uso da fluoresceína e da ALA-VI. As ressecções intraoperatórias foram guiadas pela avaliação clínica e as áreas de necrose foram comparadas posteriormente com as imagens registradas. $\mathrm{Na}$ avaliação qualitativa, os dois métodos identificaram 19 das 21 necroses $(S n=90 \%)$ mas, nestas mamas, a ALA-VI e a fluorescência hiperestimaram a área de necrose em $67 \%$ e $82 \%$ respectivamente. Além disso, os dois métodos observaram áreas de não perfusão em mamas que não evoluíram com necrose posterior. Entre as 30 mamas que não apresentaram o desfecho de interesse, a ALA-VI demonstrou uma $\mathrm{Sp}$ de $50 \%$ e a fluoresceína de apenas 30\% (40). Esses dados podem explicar os resultados de um estudo que comparou 3 grupos de 20 pacientes em que se realizaram as ressecções intra-operatórias baseados em cada um destes métodos. Enquanto $27 \%$ dos pacientes avaliados clinicamente evoluíram com alguma necrose do retalho da mastectomia, $14 \%$ do grupo avaliado pela ALA-VI e nenhum paciente avaliado pela fluoresceína apresentaram a complicação (38).

Assim, como discutido anteriormente para a GC, estas ferramentas também não têm acurácia perfeita para a predição de NCET em retalhos de mastectomia. Mesmo incluindo um "intervalo cinzento" para a avaliação intraoperatória dos retalhos com a ALA-VI entre 25 e $45 \%$ de score de perfusão 
utilizando um módulo de análise quantitativa, Moyer e Losken observaram um VPN de $90 \%$ e um VPP de $98 \%$. O escore de perfusão de $33 \%$ teve um VPP de $88 \%$ e um VPN de $16 \%$ (39). Depois de um entusiasmo inicial, comum a introdução de novas técnicas e tecnologias na área da saúde (37), estudos recentes têm questionado a validade (67) e viabilidade económica (68) do uso irrestrito da ALA-VI como ferramenta de rastreamento para NCET em retalhos de mastectomia e sugerem que esta seja reservada para grupos de mais alto risco (69).

\subsection{Perspectivas futuras}

Apesar dos achados positivos deste estudo confirmarem nossa hipótese inicial de que o tecido dos retalhos das mastectomias sob stress perfusional exibe alterações metabólicas precoces que podem ser mensuradas no intraoperatório, a GC se mostrou uma ferramenta diagnóstica sub ótima para o rastreamento de NCET nestas pacientes.

Rojdmark et al estudaram alterações metabólicas de retalhos cutâneos pediculados em um modelo suíno com o uso de fluoresceína e cateteres de microdiálise. Eles observaram que a fluoresceína delimita uma área de perfusão mais próxima da base do retalho do que a posterior área de necrose. Neste retalhos, a concentração de glicose diminuiu próximo a região delimitada pela fluoresceína e distalmente, subestimando a viabilidade do retalho (70). Os achados deste estudo são compatíveis com nossas observações (VPN alto I VPP baixo). Neste mesmo estudo, as concentrações de lactato e glicerol aumentaram mais próximo da borda necrótica nas primeiras horas de pósoperatório.

Assim, é possível imaginar que a mensuração intraoperatória destes metabólitos poderiam ser ainda mais informativos quanto a viabilidade dos tecidos do retalho da mastectomia. Embora dos metabólitos avaliados a glicemia seja o único que disponha de um teste diagnóstico de resultado rápido 
amplamente disponível na rede hospitalar, testes com características similares estão comercialmente disponíveis para medir o lactato em amostras sanguíneas.

\subsection{Considerações finais}

Embora não seja o escopo deste estudo, dados referentes à indicação das mastectomias e ao acesso à reconstrução imediata chamaram a atenção durante a fase preparatória do projeto.

$\mathrm{Na}$ Europa, o peso das cirurgias conservadoras tem aumentado em relação ao número de mastectomias. Utilizando registros de uma base de dados centralizada de 13 unidades de mama na Alemanha, Suiça, Bélgica, Austria e Itália (EusomaDB - European Society of Breast Cancer Specialists Data Base), uma análise da tendência em 15,369 pacientes com câncer de mama unilateral em estadios iniciais (I e II) mostrou que entre 2005 e 2010 houve uma redução de $4.24 \%$ por ano na indicação de mastectomias (71). Inversamente, nos EUA cerca de $36 \%$ das mulheres com câncer de mama em estadio I ou II e $72 \%$ das com doença em estadio III são submetidas a mastectomias (5). Um estudo com 1,216,820 mulheres com câncer de mama precoce e candidatas a cirurgia conservadora utilizando o National Cancer Data Base, um registro de câncer que inclui $70 \%$ dos novos casos de câncer diagnosticados no país, mostrou um aumento de $34.3 \%$ em 1998 para $37.8 \%$ na proporção de mastectomias realizadas.

Recentemente, tem se observado um aumento importante do número de mastectomias contralaterais profiláticas realizadas. Entre 1998 e 2011, a proporção de mulheres candidatas a cirurgia conservadora que se submeteram a mastectomia bilateral subiu de $1,9 \%$ a $11,2 \%$ (72). Esse aumento é especialmente importante entre pacientes mais jovens. Em um estudo usando a mesma base de dados com 553,593 mulheres com estadio entre 0 e II, observouse que a taxa de mastectomia contralateral profilática entre mulheres com menos de 45 anos aumentou de 9,3\% para 26,4\% entre 2003 e 2010, enquanto entre as mulheres com idade superior a 45 anos, essa taxa variou de $4,1 \%$ a $9,7 \%$ (73), apesar da ausência de evidência de benefícios de sobrevida. Em um estudo 
semelhante, utilizando a base de dados do Surveillance, Epidemiology, and End Results (SEER) com 496,488 mulheres com doença unilateral estadio I a III tratadas entre 1998 e 2012, observou-se um aumento de mastectomias contralaterais profiláticas de 3,9\% em 2002 a 12,7\% em 2012 (p<.001). Nesta coorte, não houve melhora significativa na sobrevida específica neste grupo quando comparado ao grupo submetido a cirurgia conservadora (Razão de probabilidade $(\mathrm{RP})=1.08 ; \mathrm{IC} 95 \%=1.01-1.16)$ ou geral $(\mathrm{RP}=1.08 ; \mathrm{IC} 95 \%=$ $1.03-1.14)(74)$.

No mundo todo, um número crescente de mulheres vítimas do câncer de mama tem obtido acesso à reconstrução mamária como parte do seu tratamento. Nos EUA, a taxa de mulheres submetidas a mastectomias que fizeram a reconstrução imediata aumentou de 11,6\% em 1998 para 36,44\% em 2011 (72). O aumento foi mais importante entre mulheres consideradas de alto risco, em função de comorbidades clínicas ou oncológicas (razão de taxa de incidência = 1,09 vs 1,06 entre as mulheres consideradas de baixo risco), demonstrando uma redução das contraindicações para a reconstrução imediata (75). Em nosso meio, um estudo ecológico recente utilizando dados do DATASUS mostrou que a proporção de pacientes submetidas a reconstrução mamária e a mastectomias pelo Sistema Único de Saúde subiu de 15\% em 2008 para 29.1\% em 2014 (76).

Assim, podemos concluir que buscar um aumento da segurança na reconstrução mamária imediata é indispensável para promover uma melhor experiência para nossas pacientes e para permitir o destino de recursos adicionais para garantir maior acesso à reconstrução mamária. 
6. CONCLUSÕES 
1. A avaliação da viabilidade de retalhos cutâneos de mastectomia é um processo complexo que envolve uma avaliação subjetiva e depende da experiência do cirurgião. Não existe uma ferramenta objetiva única capaz de predizer perfeitamente a ocorrência de NCET em retalhos de mastectomias.

2. As associações estatisticamente significativas observadas entre a GC e a ocorrência de NCET pós-operatória sugerem que estes tecidos exibem alterações metabólicas precoces quando se encontram sob stress perfusional. Estas alterações podem ser mensuradas na borda da ferida operatória dos retalhos de mastectomias.

3. Entender a precisão dos diferentes testes disponíveis para a cirurgião reconstrutor de mama é essencial para usá-los adequadamente. Neste estudo, a performance da GC como uma ferramenta de rastreamento para NET foi sub ótima, com um poder discriminatório moderado.

4. O nível de glicose intersticial pode fornecer informações adicionais para auxiliar o cirurgião na avaliação da viabilidade destes segmentos e, quando associado a outros testes diagnósticos e à avaliação subjetiva, pode ajudar nas decisões intraoperatórias. 
7. REFERÊNCIAS 
1. The international study on aesthetic/cosmetic procedures performed in 2016 [press release]. New York: GLOBE NEWSWIRE, June 27, 20172017.

2. Siegel RL, Miller KD, Jemal A. Cancer Statistics, 2017. CA: a cancer journal for clinicians. 2017;67(1):7-30.

3. Instituto Nacional do Cancer. Mama 2017 [Available from: http://www2.inca.gov.br/wps/wcm/connect/tiposdecancer/site/home/mama/canc er mama+.

4. American Cancer Society. Breast Cancer Facts \& Figures 20132014. Atlanta: : American Cancer Society, Inc; 2013.

5. Miller KD, Siegel RL, Lin CC, Mariotto AB, Kramer JL, Rowland JH, et al. Cancer treatment and survivorship statistics, 2016. CA: a cancer journal for clinicians. 2016;66(4):271-89.

6. National Comprehensive Cancer Network. Breast Cancer (Version 2017 [Available from: https://www.nccn.org/professionals/physician gls/pdf/breast.pdf.

7. Litière S, Werutsky G, Fentiman IS, Rutgers E, Christiaens M-R, Van Limbergen $E$, et al. Breast conserving therapy versus mastectomy for stage I-II breast cancer: 20 year follow-up of the EORTC 10801 phase 3 randomised trial. The lancet oncology. 2012;13(4):412-9.

8. van Maaren MC, de Munck L, de Bock GH, Jobsen JJ, van Dalen T, Linn SC, et al. 10 year survival after breast-conserving surgery plus radiotherapy compared with mastectomy in early breast cancer in the Netherlands: a population-based study. The lancet oncology. 2016;17(8):115870.

9. Veronesi U, Saccozzi R, Del Vecchio M, Banfi A, Clemente C, De Lena $M$, et al. Comparing radical mastectomy with quadrantectomy, axillary dissection, and radiotherapy in patients with small cancers of the breast. $\mathrm{N}$ Engl J Med. 1981;305(1):6-11.

10. Women's Health and Cancer Rights Act of 1998 [Available from: https://www.cms.gov/Regulations-and-Guidance/Health-InsuranceReform/HealthInsReformforConsume/downloads/WHCRA Statute.pdf. 
11. Sigurdson L, Lalonde DH. MOC-PSSM CME article: Breast reconstruction. Plast Reconstr Surg. 2008;121(1 Suppl):1-12.

12. Kronowitz SJ. Immediate versus delayed reconstruction. Clin Plast Surg. 2007;34(1):39-50; abstract vi.

13. Fischer JP, Tuggle CT, Au A, Kovach SJ. A 30-day risk assessment of mastectomy alone compared to immediate breast reconstruction (IBR). Journal of plastic surgery and hand surgery. 2014;48(3):209-15.

14. Chavez-MacGregor M, Clarke CA, Lichtensztajn DY, Giordano SH. Delayed Initiation of Adjuvant Chemotherapy Among Patients With Breast Cancer. JAMA Oncol. 2016;2(3):322-9.

15. Gieni M, Avram R, Dickson L, Farrokhyar F, Lovrics P, Faidi S, et al. Local breast cancer recurrence after mastectomy and immediate breast reconstruction for invasive cancer: a meta-analysis. Breast. 2012;21(3):230-6.

16. Zhang P, Li CZ, Wu CT, Jiao GM, Yan F, Zhu HC, et al. Comparison of immediate breast reconstruction after mastectomy and mastectomy alone for breast cancer: A meta-analysis. Eur J Surg Oncol. 2017;43(2):285-93.

17. Kroll SS. The early management of flap necrosis in breast reconstruction. Plast Reconstr Surg. 1991;87(5):893-901.

18. Robertson SA, Jeevaratnam JA, Agrawal A, Cutress RI. Mastectomy skin flap necrosis: challenges and solutions. Breast Cancer (Dove Med Press). 2017;9:141-52.

19. Fischer JP, Nelson JA, Au A, Tuggle CT, 3rd, Serletti JM, Wu LC. Complications and morbidity following breast reconstruction--a review of 16,063 cases from the 2005-2010 NSQIP datasets. Journal of plastic surgery and hand surgery. 2014;48(2):104-14.

20. Matsen CB, Mehrara B, Eaton A, Capko D, Berg A, Stempel M, et al. Skin Flap Necrosis After Mastectomy With Reconstruction: A Prospective Study. Ann Surg Oncol. 2015.

21. Lemaine V, Hoskin TL, Farley DR, Grant CS, Boughey JC, Torstenson TA, et al. Introducing the SKIN score: a validated scoring system to assess severity of mastectomy skin flap necrosis. Ann Surg Oncol. 2015;22(9):2925-32. 
22. Robertson SA, Rusby JE, Cutress RI. Determinants of optimal mastectomy skin flap thickness. The British journal of surgery. 2014;101(8):899911.

23. Larson DL, Basir Z, Bruce T. Is oncologic safety compatible with a predictably viable mastectomy skin flap? Plast Reconstr Surg. 2011;127(1):2733.

24. Gfrerer L, Mattos D, Mastroianni M, Weng QY, Ricci JA, Heath MP, et al. Assessment of patient factors, surgeons, and surgeon teams in immediate implant-based breast reconstruction outcomes. Plast Reconstr Surg. 2015;135(2):245e-52e.

25. Lee KT, Pyon JK, Bang SI, Lee JE, Nam SJ, Mun GH. Does the reconstruction method influence development of mastectomy flap complications in nipple-sparing mastectomy? J Plast Reconstr Aesthet Surg. 2013;66(11):154350.

26. Sullivan SR, Fletcher DR, Isom CD, Isik FF. True incidence of all complications following immediate and delayed breast reconstruction. Plast Reconstr Surg. 2008;122(1):19-28.

27. Alderman AK, Wilkins EG, Kim HM, Lowery JC. Complications in postmastectomy breast reconstruction: two-year results of the Michigan Breast Reconstruction Outcome Study. Plast Reconstr Surg. 2002;109(7):2265-74.

28. McCarthy CM, Mehrara BJ, Riedel E, Davidge K, Hinson A, Disa JJ, et al. Predicting complications following expander/implant breast reconstruction: an outcomes analysis based on preoperative clinical risk. Plast Reconstr Surg. 2008;121(6):1886-92.

29. Losken A, Styblo TM, Schaefer TG, Carlson GW. The use of fluorescein dye as a predictor of mastectomy skin flap viability following autologous tissue reconstruction. Ann Plast Surg. 2008;61(1):24-9.

30. Gurtner GC, Jones GE, Neligan PC, Newman MI, Phillips BT, Sacks JM, et al. Intraoperative laser angiography using the SPY system: review of the literature and recommendations for use. Annals of Surgical Innovation and Research. 2013;7(1). 
31. Chattha A, Bucknor A, Chen AD, Lee BT, Lin SJ. Indocyanine Green Angiography Use in Breast Reconstruction: A National Analysis of Outcomes and Cost in 110,320 Patients. Plast Reconstr Surg. 2017.

32. Wapnir I, Dua M, Kieryn A, Paro J, Morrison D, Kahn D, et al. Intraoperative imaging of nipple perfusion patterns and ischemic complications in nipple-sparing mastectomies. Ann Surg Oncol. 2014;21(1):100-6.

33. Sood M, Glat P. Potential of the SPY intraoperative perfusion assessment system to reduce ischemic complications in immediate postmastectomy breast reconstruction. Annals of Surgical Innovation and Research. 2013;7(1).

34. Popiel B, Gupta D, Misra S. Value of an intraoperative real time tissue perfusion assessment system following a nipple-sparing radical mastectomy for advanced breast cancer. International journal of surgery case reports. 2014;5(1):30-3.

35. Munabi NC, Olorunnipa OB, Goltsman D, Rohde $\mathrm{CH}$, Ascherman JA. The ability of intra-operative perfusion mapping with laser-assisted indocyanine green angiography to predict mastectomy flap necrosis in breast reconstruction: a prospective trial. J Plast Reconstr Aesthet Surg. 2014;67(4):449-55.

36. Griffiths M, Chae MP, Rozen WM. Indocyanine green-based fluorescent angiography in breast reconstruction. Gland surgery. 2016;5(2):13349.

37. Komorowska-Timek E, Gurtner GC. Intraoperative perfusion mapping with laser-assisted indocyanine green imaging can predict and prevent complications in immediate breast reconstruction. Plast Reconstr Surg. 2010;125(4):1065-73.

38. Rinker B. A Comparison of Methods to Assess Mastectomy Flap Viability in Skin-Sparing Mastectomy and Immediate Reconstruction: A Prospective Cohort Study. Plast Reconstr Surg. 2016;137(2):395-401.

39. Moyer HR, Losken A. Predicting mastectomy skin flap necrosis with indocyanine green angiography: the gray area defined. Plast Reconstr Surg. 2012;129(5):1043-8. 
40. Phillips BT, Lanier ST, Conkling N, Wang ED, Dagum AB, Ganz JC, et al. Intraoperative perfusion techniques can accurately predict mastectomy skin flap necrosis in breast reconstruction: results of a prospective trial. Plast Reconstr Surg. 2012;129(5):778e-88e.

41. Duggal CS, Madni T, Losken A. An outcome analysis of intraoperative angiography for postmastectomy breast reconstruction. Aesthetic surgery journal / the American Society for Aesthetic Plastic surgery. 2014;34(1):61-5.

42. Harless CA, Jacobson SR. Tailoring through Technology: A Retrospective Review of a Single Surgeon's Experience with Implant-Based Breast Reconstruction before and after Implementation of Laser-Assisted Indocyanine Green Angiography. Breast J. 2016;22(3):274-81.

43. Rao R, Saint-Cyr M, Ma AM, Bowling M, Hatef DA, Andrews V, et al. Prediction of post-operative necrosis after mastectomy: a pilot study utilizing optical diffusion imaging spectroscopy. World J Surg Oncol. 2009;7:91.

44. Krebs HA. The tricarboxylic acid cycle. Harvey lectures. 1948; Series 44:165-99.

45. Su CT, Im MJ, Hoopes JE. Tissue glucose and lactate following vascular occlusion in island skin flaps. Plast Reconstr Surg. 1982;70(2):202-5.

46. Cohen BE, Harmon CS, Phizackerley PJ. Glucose metabolism in experimental skin flaps. Plast Reconstr Surg. 1983;71(1):79-86.

47. Birke-Sorensen H, Andersen NT. Metabolic markers obtained by microdialysis can detect secondary intestinal ischemia: an experimental study of ischemia in porcine intestinal segments. World J Surg. 2010;34(5):923-32.

48. de Lima Oliveira M, Kairalla AC, Fonoff ET, Martinez RC, Teixeira MJ, Bor-Seng-Shu E. Cerebral microdialysis in traumatic brain injury and subarachnoid hemorrhage: state of the art. Neurocrit Care. 2014;21(1):152-62.

49. Maruniak-Chudek I, Swietlinski J. [Microdialysis: its application in experimental and clinical studies of disturbances in tissue metabolism]. Postepy higieny i medycyny doswiadczalnej (Online). 2007;61:384-402.

50. Sitzman TJ, Hanson SE, King TW, Gutowski KA. Detection of flap venous and arterial occlusion using interstitial glucose monitoring in a rodent model. Plast Reconstr Surg. 2010;126(1):71-9. 
51. Hara H, Mihara M, Narushima M, Yamamoto T, Todokoro T, Araki $\mathrm{J}$, et al. Flap salvage following postoperative venous thrombosis diagnosed by blood glucose measurement in the flaps. Eplasty. 2011;11:e28.

52. Hara H, Mihara M, lida T, Narushima M, Todokoro T, Yamamoto T, et al. Blood glucose measurement for flap monitoring to salvage flaps from venous thrombosis. J Plast Reconstr Aesthet Surg. 2012;65(5):616-9.

53. Bashir MM, Tayyab Z, Afzal S, Khan FA. Diagnostic Accuracy of Blood Glucose Measurements in Detecting Venous Compromise in Flaps. J Craniofac Surg. 2015;26(5):1492-4.

54. Im MJ, Angel MF, Vander Kolk CA, Manson PN. Microanalyses of enzymes and metabolites in ischemia/reperfusion-induced partial-thickness skin wounds. Wound repair and regeneration : official publication of the Wound Healing Society [and] the European Tissue Repair Society. 1993;1(4):253-8.

55. Vittinghoff E, Glidden DV, Shiboski SC, McCulloch CE. Regression Methods in Biostatistics2012.

56. Hortobagyi GN, Connolly JL, D'Orsi CJ, Edge SB, Mittendorf EA, Rugo HS, et al. Breast. 2017:589-636.

57. Hara H, Mihara M, lida T, Narushima M, Koshima I. Blood glucose measurement in flap monitoring for salvage of flaps from venous thrombosis. Plast Reconstr Surg. 2012;129(3):587e-9e.

58. Merkow RP, Hall BL, Cohen ME, Dimick JB, Wang E, Chow WB, et al. Relevance of the c-statistic when evaluating risk-adjustment models in surgery. J Am Coll Surg. 2012;214(5):822-30.

59. Portney LG, Watkins MP. Foundations of Clinical Research: Applications to Practice. 3rd Edition ed. Old Tappan, NJ,: Pearson Prentice Hall; 2015.

60. Part II: Concepts of Measurement. In: Portney LG, Watkins MP, editors. Foundations of Clinical Research: Applications to Practice. 3rd Edition ed. Old Tappan, NJ,: Pearson Prentice Hall; 2015.

61. Altomare D, Consonni G, La Rocca L. Objective Bayesian search of Gaussian directed acyclic graphical models for ordered variables with nonlocal priors. Biometrics. 2013;69(2):478-87. 
62. Gdalevitch P, Van Laeken N, Bahng S, Ho A, Bovill E, Lennox P, et al. Effects of nitroglycerin ointment on mastectomy flap necrosis in immediate breast reconstruction: a randomized controlled trial. Plast Reconstr Surg. 2015;135(6):1530-9.

63. Lehe JD, Sitoe NE, Tobaiwa O, Loquiha O, Quevedo JI, Peter TF, et al. Evaluating operational specifications of point-of-care diagnostic tests: a standardized scorecard. PloS one. 2012;7(10):e47459.

64. Batista BN, Baiocchi JMT, Campanholi LL, Bergmann A, Duprat JP. Agreement between Perometry and Sequential Arm Circumference Measurements in Objective Determination of Arm Volume. J Reconstr Microsurg. 2017.

65. Banoo S, Bell D, Bossuyt P, Herring A, Mabey D, Poole F, et al. Evaluation of diagnostic tests for infectious diseases: general principles. Nature reviews Microbiology. 2006;4(9 Suppl):S21-31.

66. Erb HN. Prior probability (the pretest best guess) affects predictive values of diagnostic tests. Vet Clin Pathol. 2011;40(2):154-8.

67. Mattison GL, Lewis PG, Gupta SC, Kim HY. SPY Imaging Use in Postmastectomy Breast Reconstruction Patients: Preventative or Overly Conservative? Plast Reconstr Surg. 2016;138(1):15e-21e.

68. Kanuri A, Liu AS, Guo L. Whom should we SPY? A cost analysis of laser-assisted indocyanine green angiography in prevention of mastectomy skin flap necrosis during prosthesis-based breast reconstruction. Plast Reconstr Surg. 2014;133(4):448e-54e.

69. Reintgen C, Leavitt A, Pace E, Molas-Pierson J, Mast BA. Risk Factor Analysis for Mastectomy Skin Flap Necrosis: Implications for Intraoperative Vascular Analysis. Ann Plast Surg. 2016.

70. Rojdmark J, Heden P, Ungerstedt U. Prediction of border necrosis in skin flaps of pigs with microdialysis. J Reconstr Microsurg. 2000;16(2):129-34.

71. Garcia-Etienne CA, Tomatis M, Heil J, Friedrichs K, Kreienberg R, Denk $A$, et al. Mastectomy trends for early-stage breast cancer: a report from the EUSOMA multi-institutional European database. European journal of cancer. 2012;48(13):1947-56. 
72. Kummerow KL, Du L, Penson DF, Shyr Y, Hooks MA. Nationwide trends in mastectomy for early-stage breast cancer. JAMA Surg. 2015;150(1):916.

73. Pesce CE, Liederbach E, Czechura T, Winchester DJ, Yao K. Changing surgical trends in young patients with early stage breast cancer, 2003 to 2010: a report from the National Cancer Data Base. J Am Coll Surg. 2014;219(1):19-28.

74. Wong SM, Freedman RA, Sagara Y, Aydogan F, Barry WT, Golshan M. Growing Use of Contralateral Prophylactic Mastectomy Despite no Improvement in Long-term Survival for Invasive Breast Cancer. Annals of Surgery. 2017;265(3):581-9.

75. Albornoz CR, Cordeiro PG, Pusic AL, McCarthy CM, Mehrara BJ, Disa JJ, et al. Diminishing relative contraindications for immediate breast reconstruction: a multicenter study. J Am Coll Surg. 2014;219(4):788-95.

76. Freitas-Junior R, Gagliato DM, Moura Filho JWC, Gouveia PA, Rahal RMS, Paulinelli RR, et al. Trends in breast cancer surgery at Brazil's public health system. Journal of surgical oncology. 2017;115(5):544-9. 
APÊNDICES 
Apêndice A - Ficha de coletas de dados

\section{Estudo de acurácia diagnóstica da glicemia capilar intraoperatória para a predição de necrose do retalho cutâneo pós-mastectomias}

Pesquisador responsável: Dr. Bernardo Nogueira Batista - (11)98175-7220

\section{ETIQUETA}

Data cirurgia:

Idade:

$P$ :

A:

Estadio clínico:

Mastologista:

Procedimento/Tipo de Reconstrução:

Fatores de risco:

DM

Tabagismo

Outros:

Medidas

\section{Glicemia periférica}

\begin{tabular}{|c|c|c|}
\hline \hline Ponto & Medida 1 & Medida 2 \\
\hline 12h & & \\
\hline & & \\
\hline & & \\
\hline $3 \mathrm{~h}$ & & \\
\hline & & \\
\hline $6 \mathrm{~h}$ & & \\
\hline & & \\
\hline & & \\
\hline $\mathbf{9 h}$ & & \\
\hline & & \\
\hline & & \\
\hline
\end{tabular}

- $\quad$ Após a ressecção final de pele, realizar as medidas nos 4 pontos cardinais (3/6/9/12h);

- $\quad$ Realizar medidas adicionais entre estes pontos caso a distancia entre eles seja superior a $5 \mathrm{~cm}$;

- $\quad$ Se uma medida apresentar valor $<80$ $\mathrm{mg} / \mathrm{dL}$, realizar medida confirmatória (medidas 2);

- Solicitar ao anestesista medida de glicemia periférica (dedo ou lóbulo de orelha) do paciente;

- Fotografar o defeito de pele com a marcação dos pontos onde a glicemia foi mensurada.

Em caso de dúvida, entrar em contato com Bernardo (98175-7220) ou Stephanie (95448-1377). Projeto aprovado no comitê de Ética em Pesquisa do Hospital Sírio Libanês - processo nº HSL 2013-15. 
Apêndice $B$ - Pacientes que não tiveram NCET

Paciente 1

Idade: $\underline{73}$ anos

Peso: $81 \mathrm{~kg}$

Altura: $\underline{1,58} \mathbf{~ m}$

IMC: $\underline{32,4} \mathbf{~ k g} \cdot \mathbf{m}^{-2}$

Tabagismo: Não

Data da cirurgia: $18 / 12 / 12$

Lateralidade: Direita

Procedimento oncológico: Mastectomia

Reconstrução: Retalho de músculo grande dorsal

pT $\underline{2}$ pN $\underline{0}$

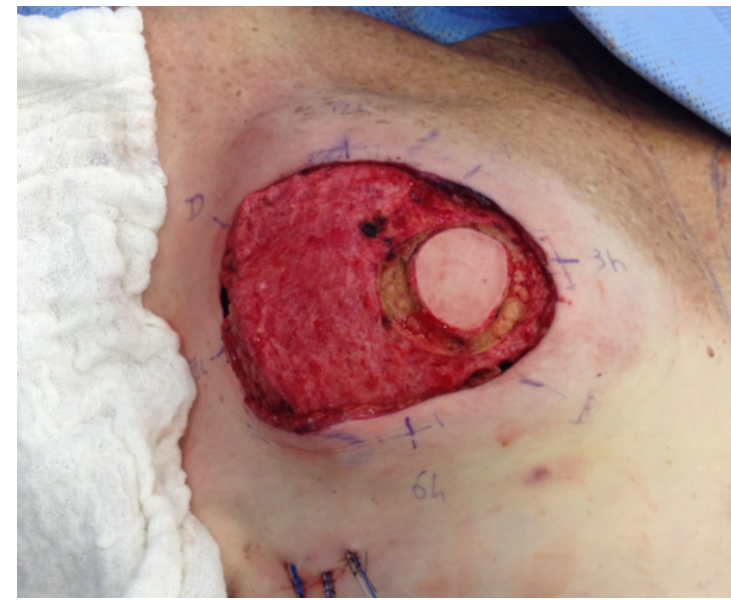

Foto fechamento

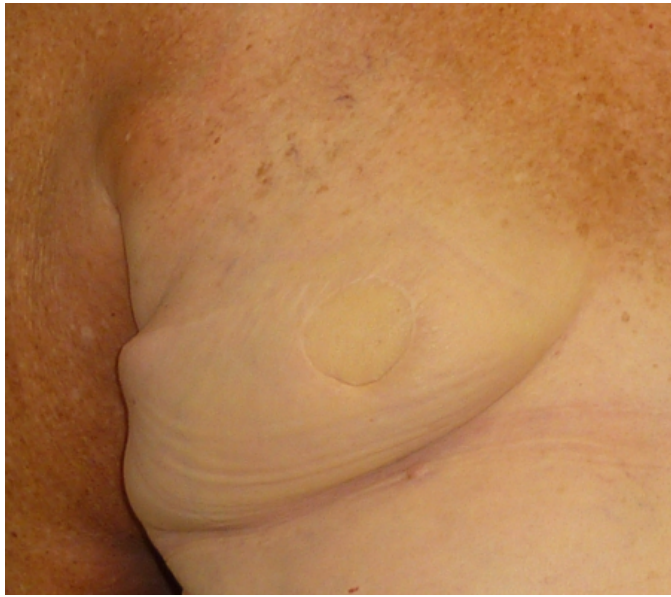

Foto seguimento

\begin{tabular}{|l|l|l|l|l|l|l|l|l|}
\hline Periférica & $\mathbf{1 2 h}$ & $\mathbf{1 h}$ & $\mathbf{3 h}$ & $\mathbf{4 h}$ & $\mathbf{6 h}$ & $\mathbf{7 h}$ & $\mathbf{9 h}$ & $\mathbf{1 0 h}$ \\
\hline \hline 145 & 134 & 143 & 141 & 183 & 126 & 114 & 167 & 94 \\
\hline & \\
\hline \multicolumn{1}{|c|}{ DESFECHO } & 0 & 0 & 0 & 0 & 0 & 0 & 0 & 0 \\
\hline
\end{tabular}


Paciente 3

Idade: $\underline{52}$ anos

Peso: 62,5 kg

Altura: $\underline{1,62} \mathbf{~ m}$

IMC: $\underline{23,8} \mathbf{~ k g} \cdot \mathrm{m}^{-2}$

Tabagismo: Não

Data da cirurgia: 16/4/13

Lateralidade: Direita

Procedimento oncológico: Mastectomia

Reconstrução: Implante expansor

pT $\underline{2}$ pN $\underline{0}$
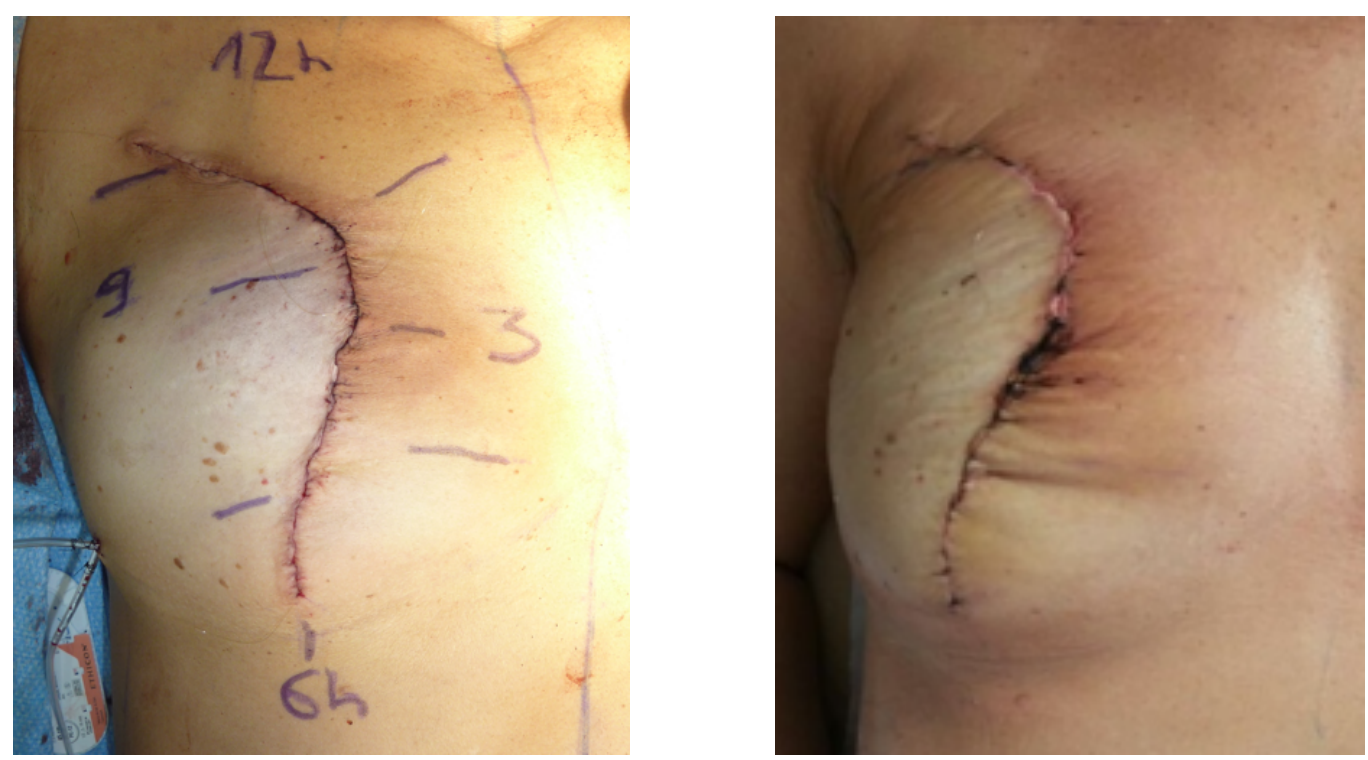

Foto fechamento

Foto seguimento

\begin{tabular}{|l|l|l|l|l|l|l|l|l|}
\hline Periférica & $\mathbf{1 2 h}$ & $\mathbf{1 h}$ & $\mathbf{3 h}$ & $\mathbf{4 h}$ & $\mathbf{6 h}$ & $\mathbf{7 h}$ & $\mathbf{9 h}$ & $\mathbf{1 0 h}$ \\
\hline \hline 95 & 101 & 100 & 76 & 89 & 123 & 135 & 116 & 141 \\
\hline \multicolumn{1}{|c|}{ DESFECHO } & 0 & 0 & 0 & 0 & 0 & 0 & 0 & 0 \\
\hline
\end{tabular}


Paciente 4

Idade: $\underline{61}$ anos

Peso: 60 kg

Altura: $\underline{1,53} \mathbf{~ m}$

IMC: 25,6 kg.m-2

Tabagismo: Não

Data da cirurgia: $7 / 5 / 13$

Lateralidade: Esquerda

Procedimento oncológico: Mastectomia

Reconstrução: Implante expansor

pT 1 pN 1

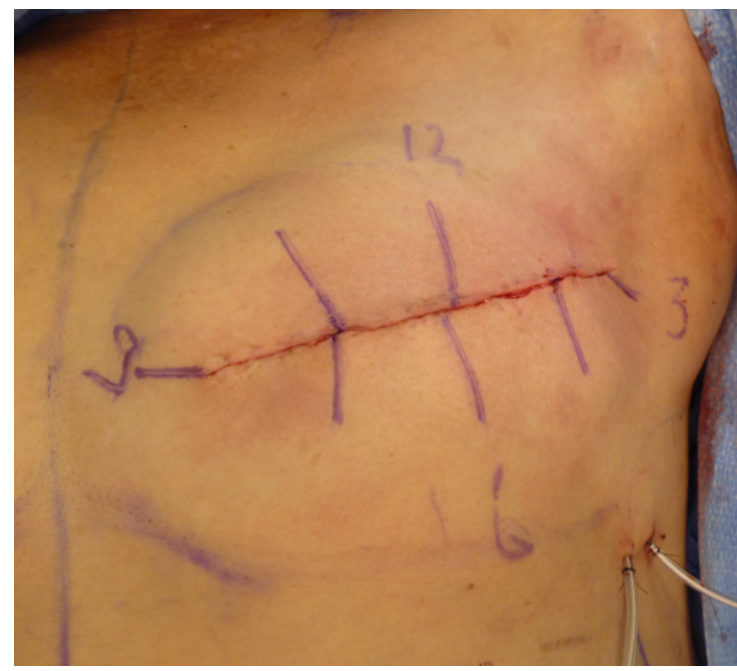

Foto fechamento

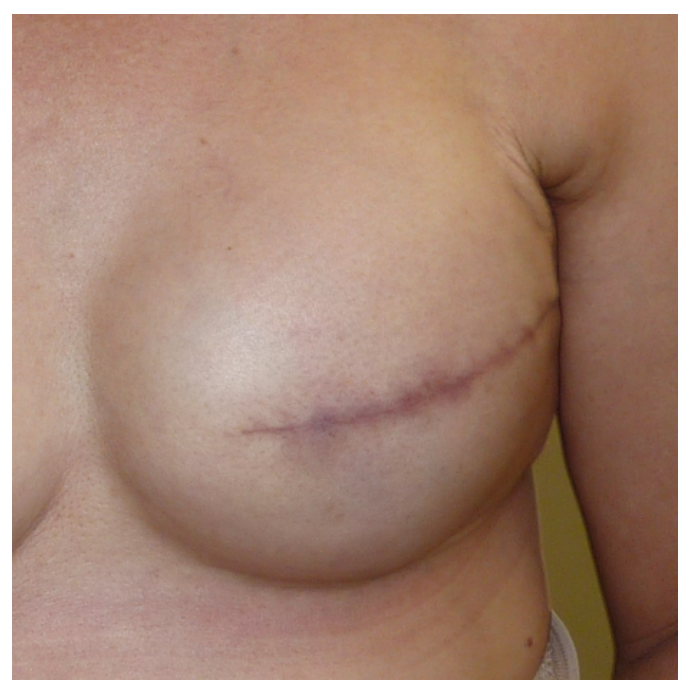

Foto seguimento

\begin{tabular}{|l|l|l|l|l|l|l|l|l|}
\hline Periférica & $\mathbf{1 2 h}$ & $\mathbf{1 h}$ & $\mathbf{3 h}$ & $\mathbf{4 h}$ & $\mathbf{6 h}$ & $\mathbf{7 h}$ & $\mathbf{9 h}$ & $\mathbf{1 0 h}$ \\
\hline \hline 82 & 115 & 100 & 98 & 129 & 121 & 96 & 91 & 126 \\
\hline \multicolumn{8}{|c|}{} \\
\multicolumn{10}{|l|}{ DESFECHO } & 0 & 0 & 0 & 0 & 0 & 0 & 0 & 0 \\
\hline
\end{tabular}




\section{Paciente 5}

Idade: $\underline{54}$ anos

Peso: 53 kg

Altura: $\underline{1,56} \mathbf{~ m}$

IMC: $\underline{21,8} \mathbf{~ k g} \cdot \mathbf{m}^{-2}$

Tabagismo: Não

Data da cirurgia: $28 / 5 / 13$

Lateralidade: Esquerda

Procedimento oncológico: Mastectomia

Reconstrução: Retalho de músculo grande dorsal com implante expansor

pT $\underline{2}$ pN $\underline{2}$

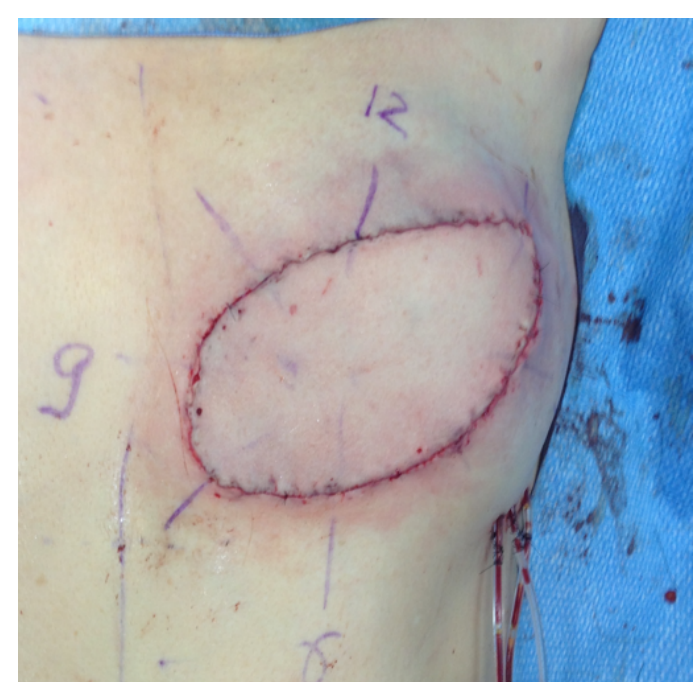

Foto fechamento

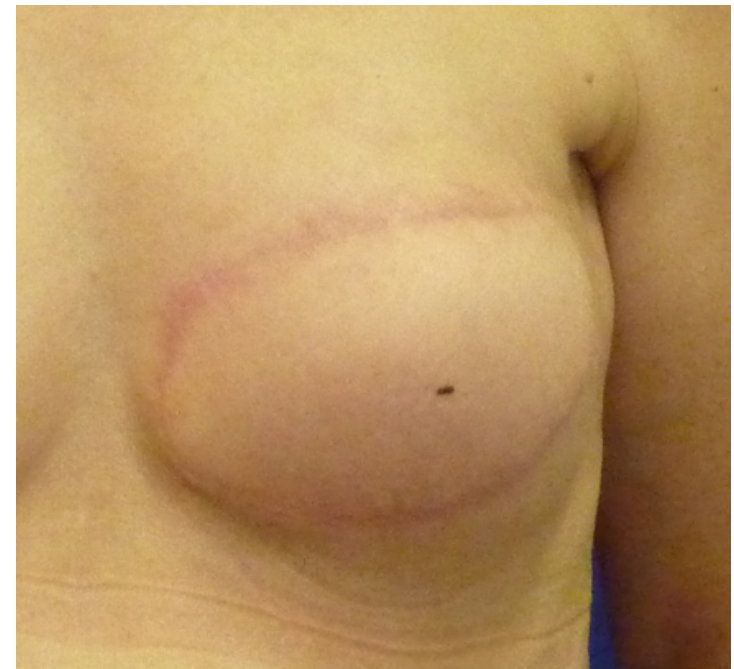

Foto seguimento

\begin{tabular}{|l|l|l|l|l|l|l|l|l|}
\hline Periférica & $\mathbf{1 2 h}$ & $\mathbf{1 h}$ & $\mathbf{3 h}$ & $\mathbf{4 h}$ & $\mathbf{6 h}$ & $\mathbf{7 h}$ & $\mathbf{9 h}$ & $\mathbf{1 0 h}$ \\
\hline \hline 125 & 102 & 39 & 103 & 107 & 99 & 106 & 138 & 145 \\
\hline & 73 & & & & & & \\
\hline DESFECHO & 0 & 0 & 0 & 0 & 0 & 0 & 0 & 0 \\
\hline
\end{tabular}


Paciente 6

Idade: $\underline{36}$ anos

Peso: _kg

Altura: m

IMC: $\mathrm{kg} \cdot \mathrm{m}^{-2}$

Tabagismo:

Data da cirurgia: $5 / 6 / 13$

Lateralidade: Direita

Procedimento oncológico: Mastectomia

Reconstrução: Implante expansor

pT_pN

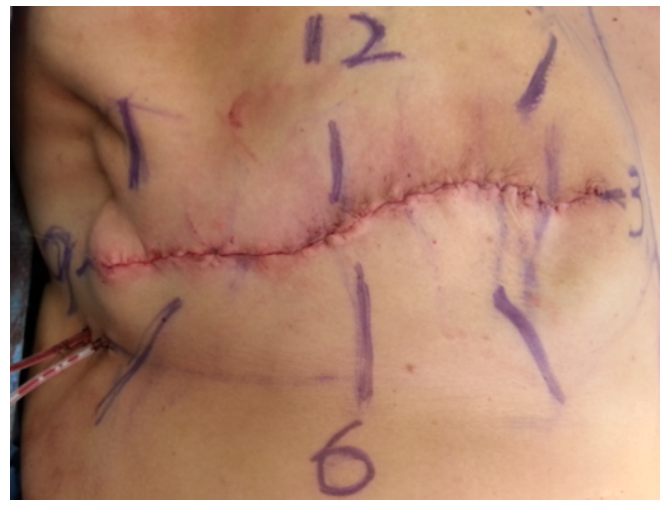

Foto fechamento

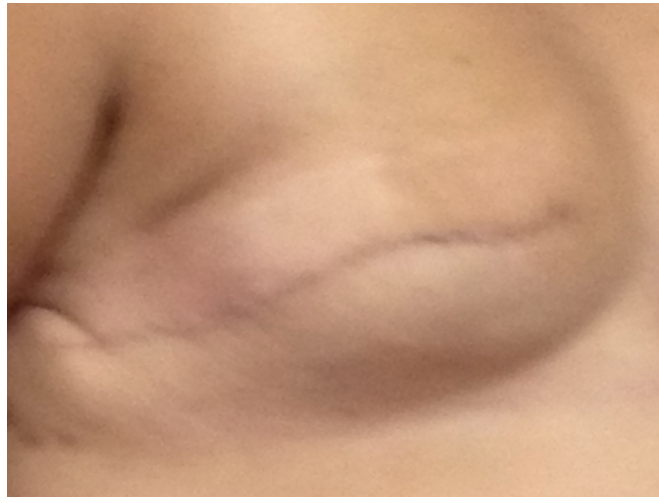

Foto seguimento

\begin{tabular}{|l|l|l|l|l|l|l|l|l|}
\hline Periférica & $\mathbf{1 2 h}$ & $\mathbf{1 h}$ & $\mathbf{3 h}$ & $\mathbf{4 h}$ & $\mathbf{6 h}$ & $\mathbf{7 h}$ & $\mathbf{9 h}$ & $\mathbf{1 0 h}$ \\
\hline \hline 103 & 111 & 120 & 120 & 147 & 122 & 138 & 96 & 126 \\
\hline & \\
\hline DESFECHO & 0 & 0 & 0 & 0 & 0 & 0 & 0 & 0 \\
\hline
\end{tabular}


Paciente 8

Idade: $\underline{52}$ anos

Peso: $61 \mathrm{~kg}$

Altura: $\underline{1,53} \mathbf{m}$

IMC: $\underline{26,1} \mathbf{k g} \cdot \mathrm{m}^{-2}$

Tabagismo: Não

Data da cirurgia: $22 / 7 / 13$

Lateralidade: Esquerda

Procedimento oncológico: Mastectomia

Reconstrução: Implante expansor

pT $\underline{2}$ pN 1

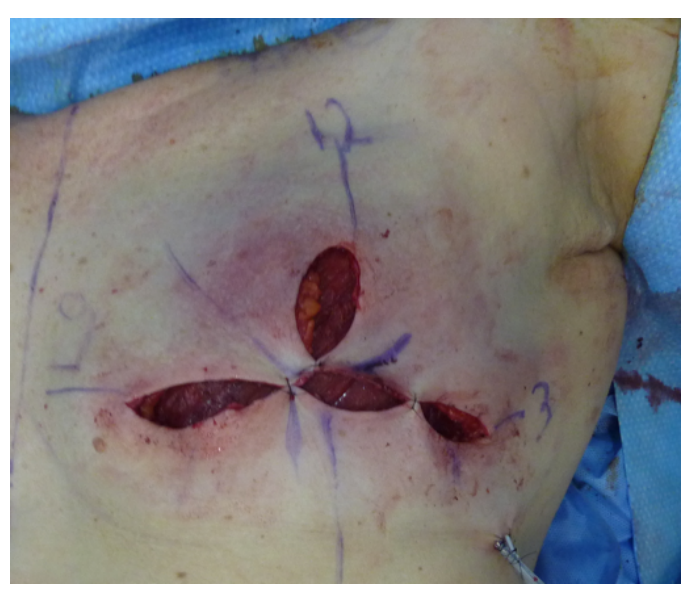

Foto fechamento

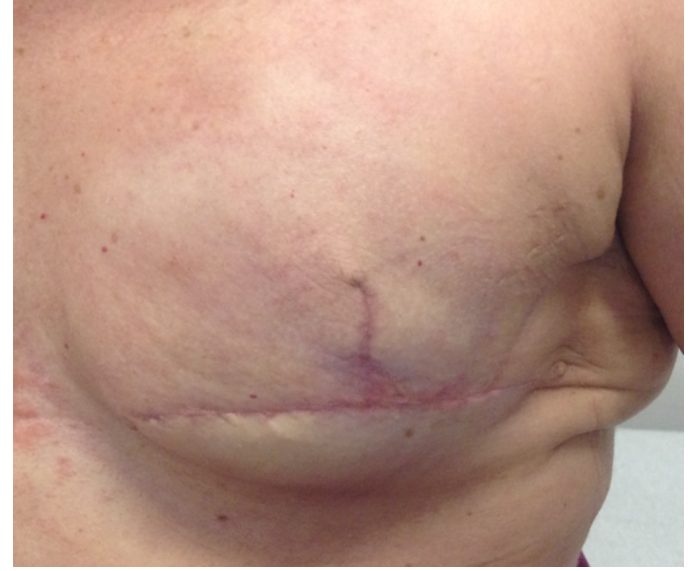

Foto seguimento

\begin{tabular}{|l|l|l|l|l|l|l|l|l|}
\hline Periférica & $\mathbf{1 2 h}$ & $\mathbf{1 h}$ & $\mathbf{3 h}$ & $\mathbf{4 h}$ & $\mathbf{6 h}$ & $\mathbf{7 h}$ & $\mathbf{9 h}$ & $\mathbf{1 0 h}$ \\
\hline \hline 119 & 134 & 71 & 107 & 76 & 132 & 123 & 138 & 111 \\
\hline & & 109 & & 120 & & & & \\
\hline DESFECHO & 0 & 0 & 0 & 0 & 0 & 0 & 0 & 0 \\
\hline
\end{tabular}


Paciente 9

Idade: $\underline{38}$ anos

Peso: $\underline{73}$ kg

Altura: $\underline{1,64} \mathbf{~ m}$

IMC: $\underline{27,1} \mathbf{k g} \cdot \mathbf{m}^{-2}$

Tabagismo: Não

Data da cirurgia: $24 / 7 / 13$

Lateralidade: Direita

Procedimento oncológico: Mastectomia

Reconstrução: Retalho tranverso do músculo reto abdominal pediculado, supercarregado

pT is $\underline{\text { pN } \underline{0}}$

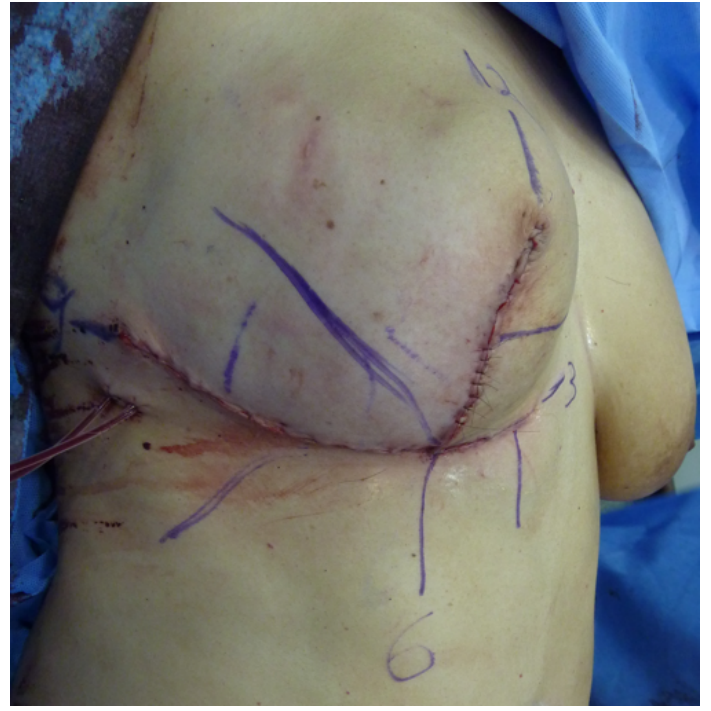

Foto fechamento

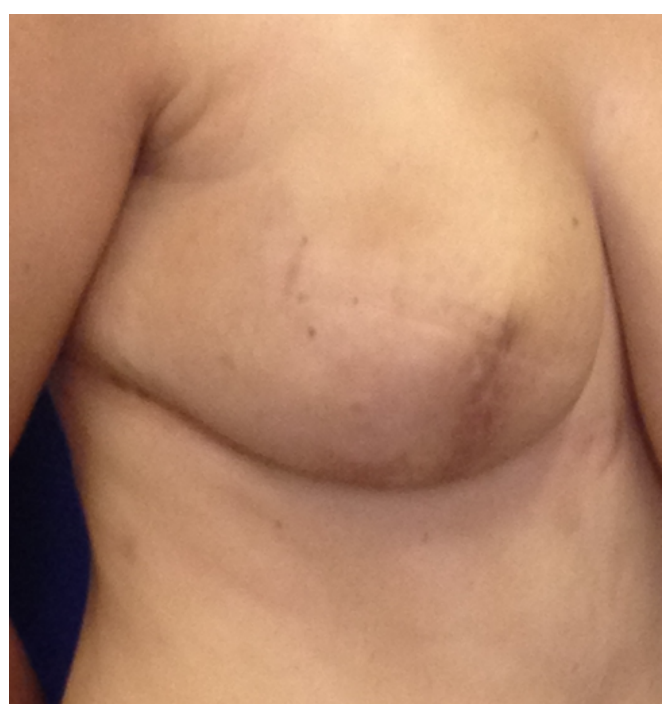

Foto seguimento

\begin{tabular}{|l|l|l|l|l|l|l|l|l|}
\hline Periférica & $\mathbf{1 2 h}$ & $\mathbf{1 h}$ & $\mathbf{3 h}$ & $\mathbf{4 h}$ & $\mathbf{6 h}$ & $\mathbf{7 h}$ & $\mathbf{9 h}$ & $\mathbf{1 0 h}$ \\
\hline \hline 164 & 155 & 154 & 144 & 48 & 145 & 179 & 120 & 167 \\
\hline & & & 162 & & & \\
\hline DESFECHO & 0 & 0 & 0 & 0 & 0 & 0 & 0 & 0 \\
\hline
\end{tabular}


Paciente 10

Idade: $\underline{60}$ anos

Peso: 77 kg

Altura: $\underline{1,6} \mathbf{m}$

IMC: $\underline{30,1} \mathbf{~ k g} \cdot \mathrm{m}^{-2}$

Tabagismo: $\underline{\mathrm{SIM}}$

Data da cirurgia: 9/9/13

Lateralidade: Esquerda

Procedimento oncológico: Mastectomia

Reconstrução: Retalho de músculo grande dorsal com implante

pT 1 pN $\underline{0}$

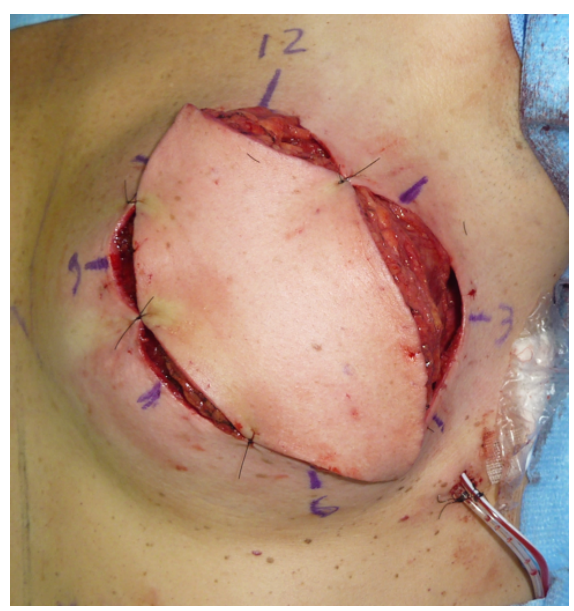

Foto fechamento

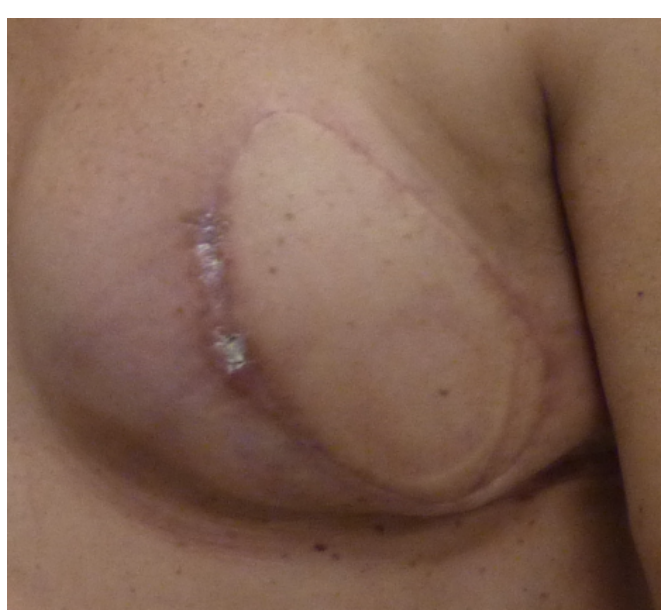

Foto seguimento

\begin{tabular}{|l|l|l|l|l|l|l|l|l|}
\hline Periférica & $\mathbf{1 2 h}$ & $\mathbf{1 h}$ & $\mathbf{3 h}$ & $\mathbf{4 h}$ & $\mathbf{6 h}$ & $\mathbf{7 h}$ & $\mathbf{9 h}$ & $\mathbf{1 0 h}$ \\
\hline \hline 156 & 147 & 143 & 159 & 180 & 169 & 118 & 123 & 129 \\
\hline & \\
\hline DESFECHO & 0 & 0 & 0 & 0 & 0 & 0 & 0 & 0 \\
\hline
\end{tabular}




\section{Paciente 14}

Idade: $\underline{52}$ anos

Peso: 62,5 kg

Altura: $\underline{1,70} \mathbf{m}$

IMC: $\underline{21,6} \mathbf{~ k g} \cdot \mathbf{m}^{-2}$

Tabagismo: SIM

Data da cirurgia: $17 / 12 / 13$

Lateralidade: Esquerda

Procedimento oncológico: Mastectomia

Reconstrução: Retalho de músculo grande dorsal com implante

pT 1 pN 1

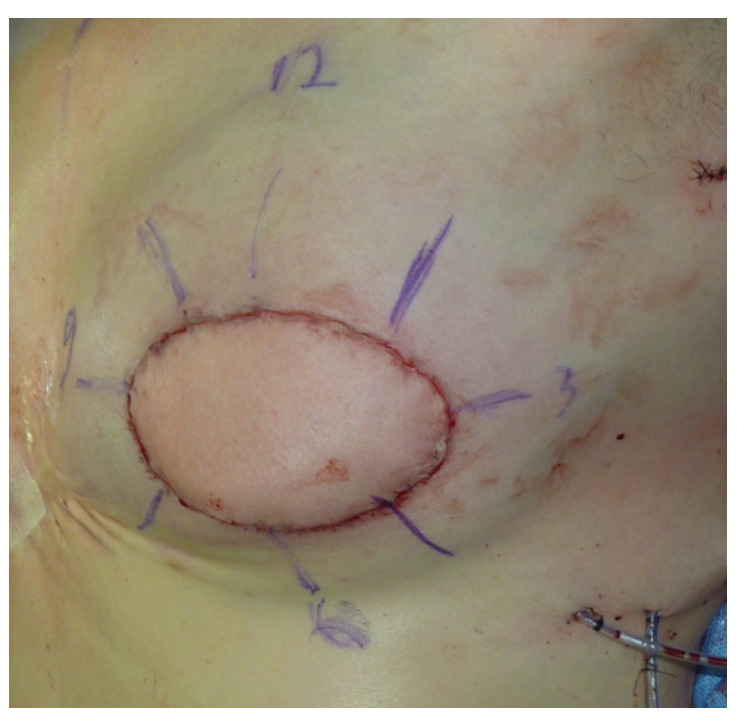

Foto fechamento

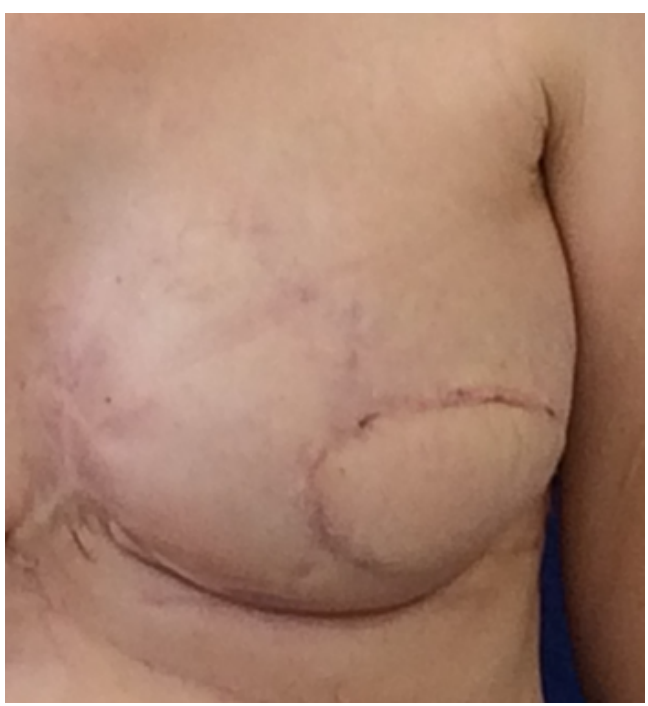

Foto seguimento

\begin{tabular}{|c|c|c|c|c|c|c|c|c|}
\hline Periférica & $12 \mathrm{~h}$ & $1 \mathrm{~h}$ & $3 h$ & $4 h$ & $6 h$ & $7 \mathrm{~h}$ & $9 \mathrm{~h}$ & $10 \mathrm{~h}$ \\
\hline$\overline{139}$ & 184 & 167 & 144 & 140 & 160 & 125 & 138 & 152 \\
\hline DESFECHO & 0 & 0 & 0 & 0 & 0 & 0 & 0 & 0 \\
\hline
\end{tabular}


Paciente 15

Idade: $\underline{58}$ anos

Peso: $51 \mathrm{~kg}$

Altura: $\underline{1,61} \mathbf{~ m}$

IMC: $\underline{19,7} \mathbf{~ k g} \cdot \mathbf{m}^{-2}$

Tabagismo: Não

Data da cirurgia: 8/1/14

Lateralidade: Esquerda

Procedimento oncológico: Mastectomia

Reconstrução: Implante expansor

pT 1 pN $\underline{0}$

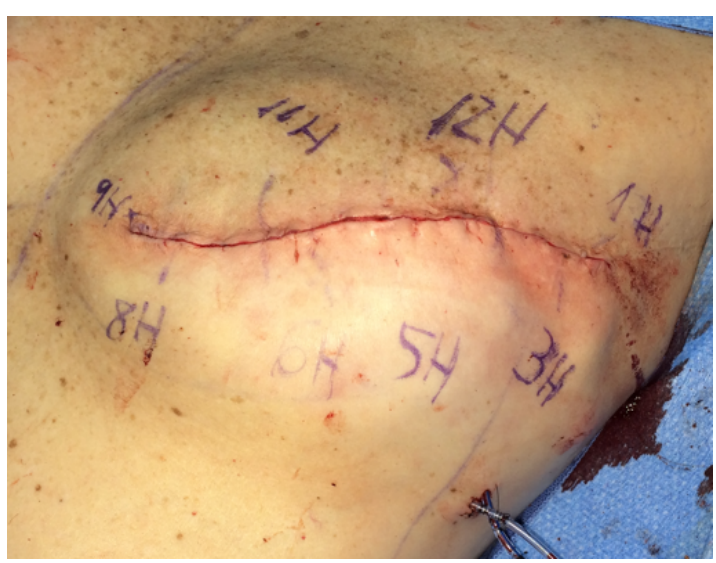

Foto fechamento

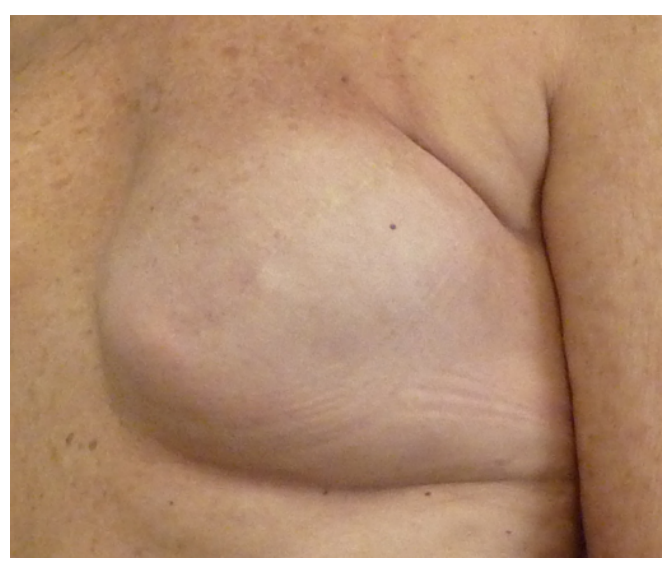

Foto seguimento

\begin{tabular}{|c|c|c|c|c|c|c|c|c|}
\hline Periférica & $12 \mathrm{~h}$ & $1 \mathrm{~h}$ & $3 h$ & $4 \mathrm{~h}$ & $6 h$ & $7 \mathrm{~h}$ & $9 \mathrm{~h}$ & $10 \mathrm{~h}$ \\
\hline 86 & 1119 & 91 & 95 & $\overline{103}$ & 105 & 104 & 78 & 1115 \\
\hline DESFECHO & 0 & 0 & 0 & 0 & 0 & 0 & 0 & 0 \\
\hline
\end{tabular}


Paciente 16

Idade: $\underline{59}$ anos

Peso: 68 kg

Altura: $\underline{1,58} \mathbf{m}$

IMC: $\underline{27,3} \mathbf{~ k g} \cdot \mathbf{m}^{-2}$

Tabagismo: Não

Data da cirurgia: $14 / 1 / 14$

Lateralidade: Esquerda

Procedimento oncológico: Mastectomia

Reconstrução: Retalho perfurante da epigástrica inferior

pT 1 pN 2

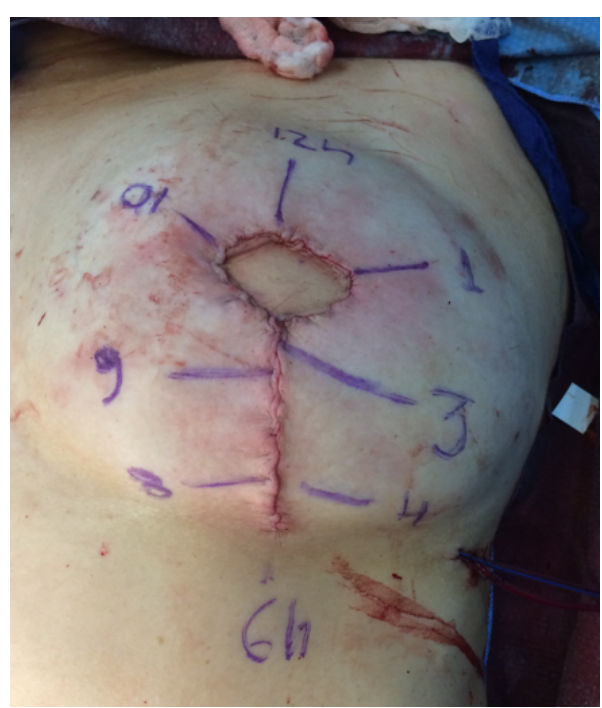

Foto fechamento

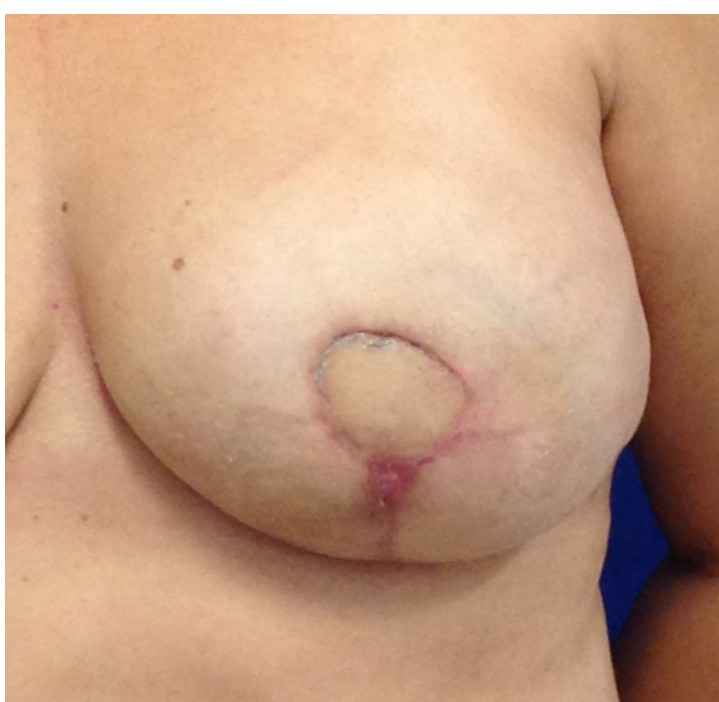

Foto seguimento

\begin{tabular}{|c|c|c|c|c|c|c|c|c|}
\hline Periférica & $12 \mathrm{~h}$ & $1 \mathrm{~h}$ & $3 \mathrm{~h}$ & $4 h$ & $6 h$ & $7 \mathrm{~h}$ & $9 \mathrm{~h}$ & $10 \mathrm{~h}$ \\
\hline 185 & 99 & $\overline{c 161}$ & 151 & 159 & 1168 & 165 & 140 & 176 \\
\hline DESFECHC & 0 & 0 & 0 & 0 & c & 0 & 0 & 0 \\
\hline
\end{tabular}


Paciente 17

Idade: $\underline{37}$ anos

Peso: 57 kg

Altura: $\underline{1,55} \mathrm{~m}$

IMC: $\underline{20,2} \mathbf{~ k g} \cdot \mathbf{m}^{-2}$

Tabagismo: Não

Data da cirurgia: 22/1/14

Lateralidade: Esquerda

Procedimento oncológico: Mastectomia

Reconstrução: Prótese

pT $2 \underline{2}$ pN 1

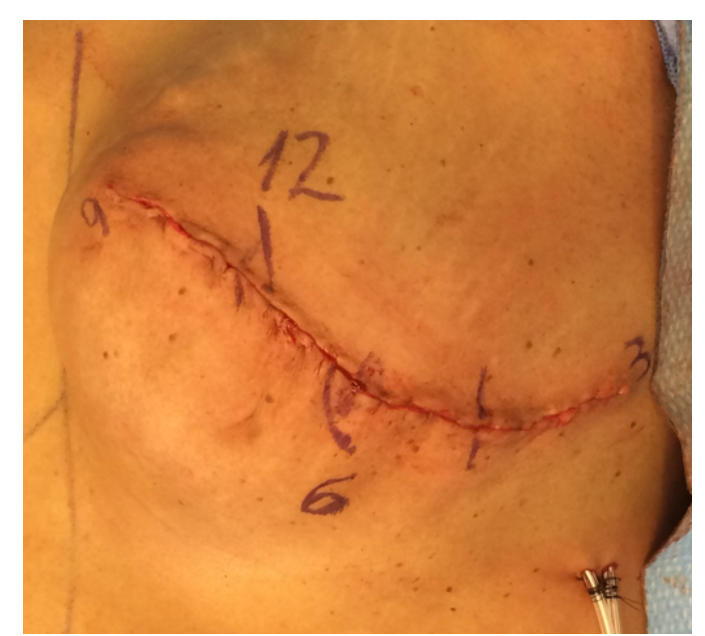

Foto fechamento

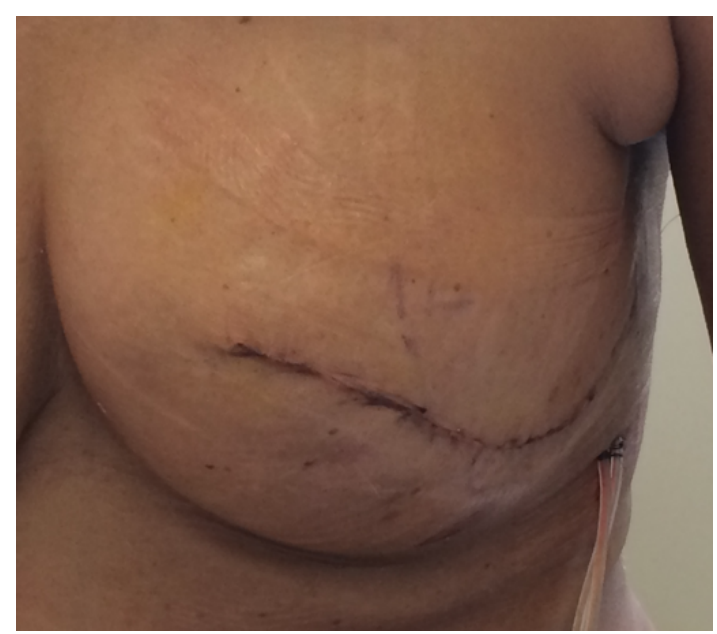

Foto seguimento

\begin{tabular}{|l|l|l|l|l|l|l|l|l|}
\hline Periférica & $\mathbf{1 2 h}$ & $\mathbf{1 h}$ & $\mathbf{3 h}$ & $\mathbf{4 h}$ & $\mathbf{6 h}$ & $\mathbf{7 h}$ & $\mathbf{9 h}$ & $\mathbf{1 0 h}$ \\
\hline \hline 108 & 116 & 143 & 125 & 112 & 145 & 119 & 92 & 114 \\
\hline \multicolumn{10}{|l|}{} \\
\hline \multicolumn{10}{|l|}{ DESFECHO } & 0 & 0 & 0 & 0 & 0 & 0 & 0 & 0 \\
\hline
\end{tabular}


Paciente 20

Idade: $\underline{52}$ anos

Peso: 87 kg

Altura: $\underline{1,6} \mathbf{m}$

IMC: $\underline{34,0} \mathbf{~ k g} \cdot \mathbf{m}^{-2}$

Tabagismo: Não

Data da cirurgia: $20 / 5 / 14$

Lateralidade: Direita

Procedimento oncológico: Mastectomia

Reconstrução: Implante expansor

pT $\underline{3}$ pN $\underline{2}$

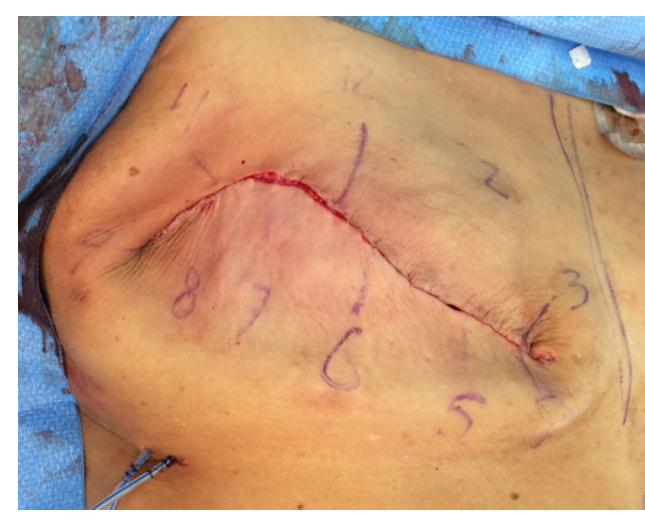

Foto fechamento

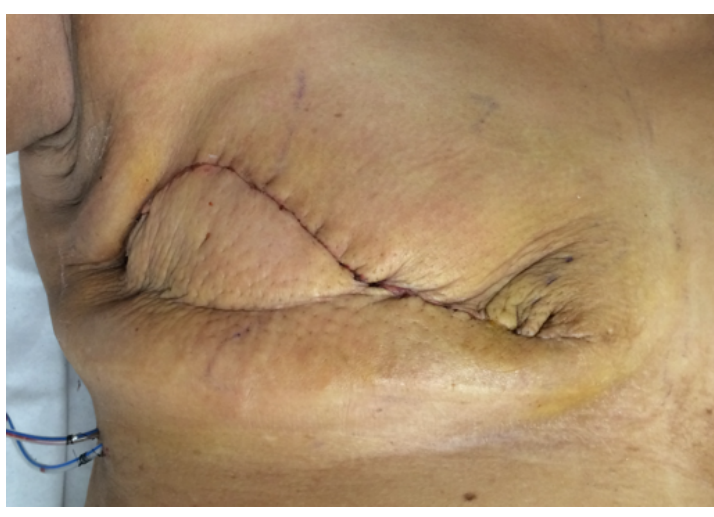

Foto seguimento

\begin{tabular}{|c|c|c|c|c|c|c|c|c|}
\hline Periférica & $12 \mathrm{~h}$ & $1 \mathrm{~h}$ & $3 h$ & $4 h$ & $6 \mathrm{~h}$ & $7 \mathrm{~h}$ & $9 \mathrm{~h}$ & $10 \mathrm{~h}$ \\
\hline 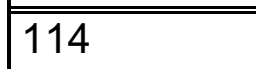 & $\overline{115}$ & 99 & 96 & $\overline{106}$ & $\overline{101}$ & $\overline{84}$ & 85 & 98 \\
\hline DESFECHO & 0 & 0 & 0 & 0 & 0 & 0 & 0 & 0 \\
\hline
\end{tabular}


Paciente 21

Idade: $\underline{28}$ anos

Peso: $\underline{88}$ kg

Altura: $\underline{1,69} \mathbf{m}$

IMC: $\underline{30,8} \mathbf{~ k g} \cdot \mathbf{m}^{-2}$

Tabagismo: Não

Data da cirurgia: $2 / 7 / 14$

Lateralidade: Direita

Procedimento oncológico: Mastectomia

Reconstrução: Implante expansor

pT $\underline{2}$ pN $\underline{0}$

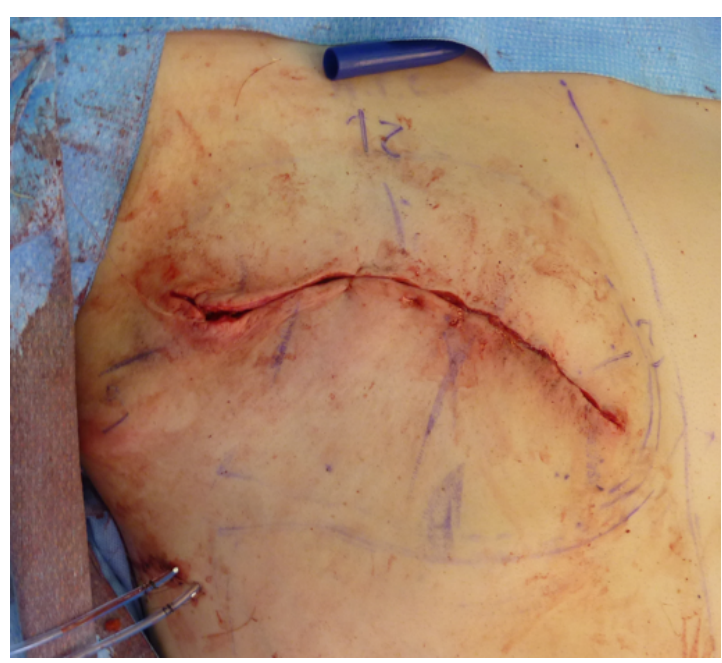

Foto fechamento

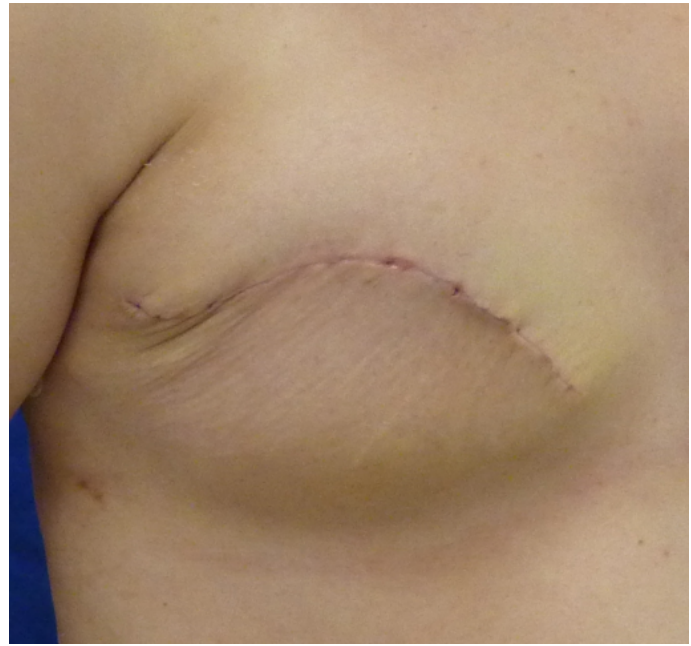

Foto seguimento

\begin{tabular}{|c|c|c|c|c|c|c|c|c|}
\hline Periférica & $12 \mathrm{~h}$ & $1 \mathrm{~h}$ & $3 h$ & $4 \mathrm{~h}$ & $6 h$ & $7 \mathrm{~h}$ & $9 \mathrm{~h}$ & $10 \mathrm{~h}$ \\
\hline 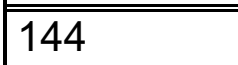 & 152 & 62 & 159 & $\overline{145}$ & 150 & $\overline{125}$ & 185 & 172 \\
\hline & & & & & & & & \\
\hline DESFECHO & 0 & 0 & 0 & 0 & 0 & 0 & 0 & 0 \\
\hline
\end{tabular}


Paciente 23

Idade: $\underline{47}$ anos

Peso: 60 kg

Altura: $\underline{1,62} \mathrm{~m}$

IMC: $\underline{22,9} \mathbf{~ k g} \cdot \mathrm{m}^{-2}$

Tabagismo: Não

Data da cirurgia: $5 / 1 / 15$

Lateralidade: Esquerda

Procedimento oncológico: Mastectomia

Reconstrução: Implante expansor

pT 1 pN $\underline{0}$

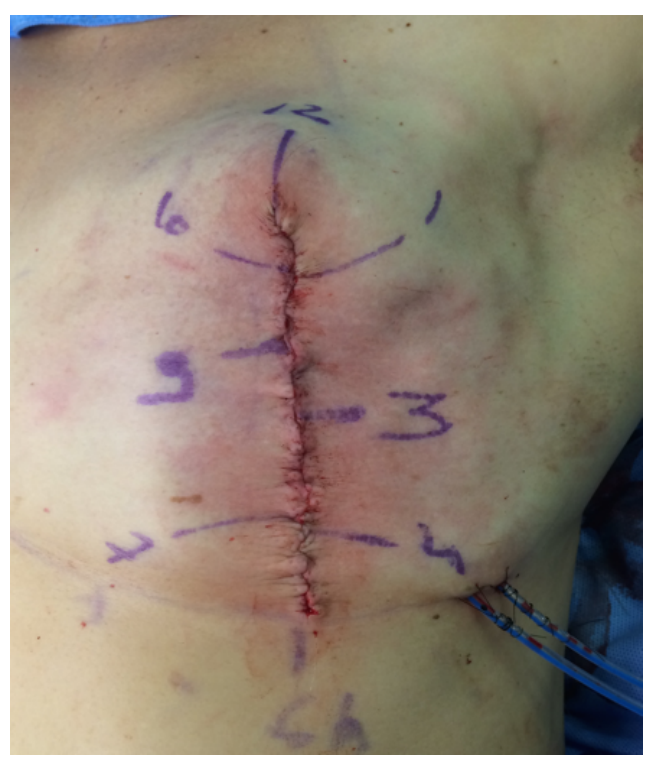

Foto fechamento

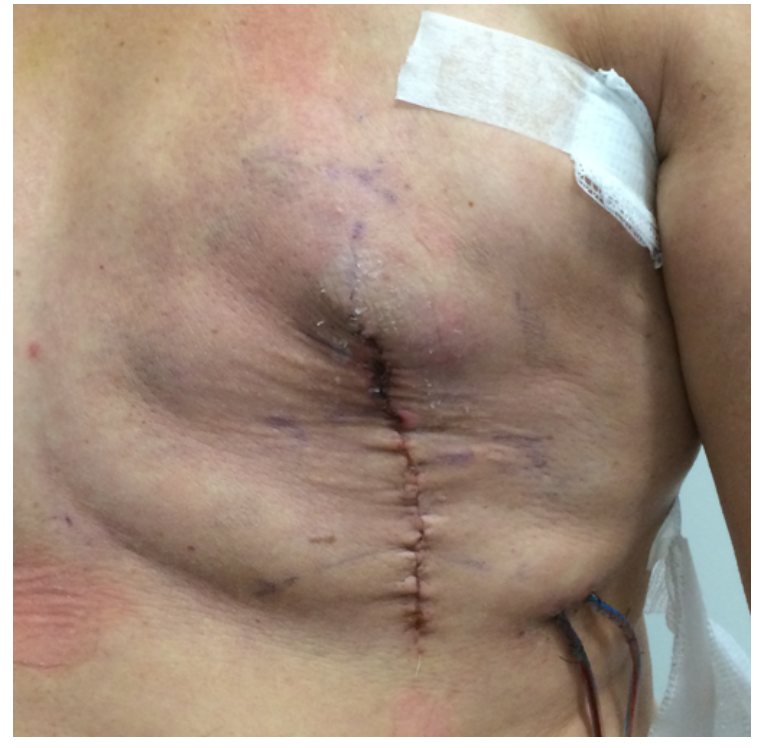

Foto seguimento

\begin{tabular}{|l|l|l|l|l|l|l|l|l|}
\hline Periférica & $\mathbf{1 2 h}$ & $\mathbf{1 h}$ & $\mathbf{3 h}$ & $\mathbf{4 h}$ & $\mathbf{6 h}$ & $\mathbf{7 h}$ & $\mathbf{9 h}$ & $\mathbf{1 0 h}$ \\
\hline \hline 122 & 71 & 115 & 58 & 118 & 139 & 126 & 91 & 85 \\
\hline & 102 & & 97 & \multicolumn{1}{|l|}{} \\
\hline DESFECHO & 0 & 0 & 0 & 0 & 0 & 0 & 0 & 0 \\
\hline
\end{tabular}


Paciente 24

Idade: $\underline{47}$ anos

Peso: 48,7 kg

Altura: $\underline{1,59} \mathbf{m}$

IMC: $\underline{19,3} \mathbf{~ k g} \cdot \mathbf{m}^{-2}$

Tabagismo: Não

Data da cirurgia: $27 / 1 / 15$

Lateralidade: Esquerda

Procedimento oncológico: Adenectomia

Reconstrução: Implante expansor

pT $\underline{3}$ pN $\underline{0}$

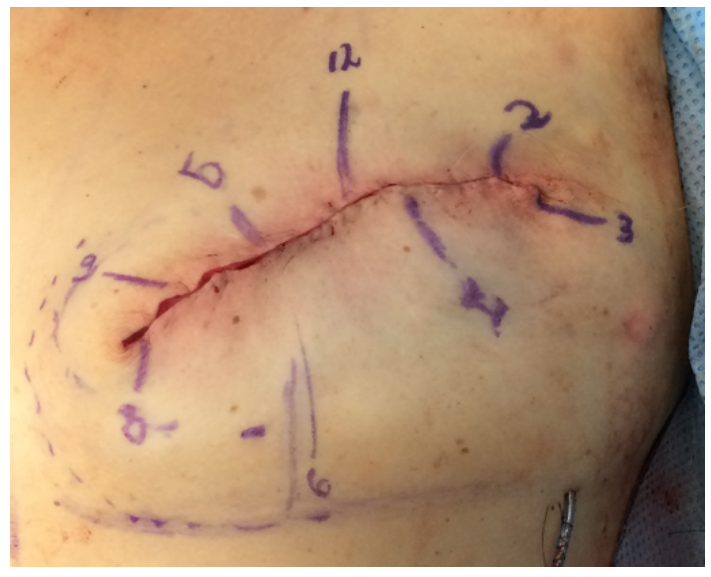

Foto fechamento

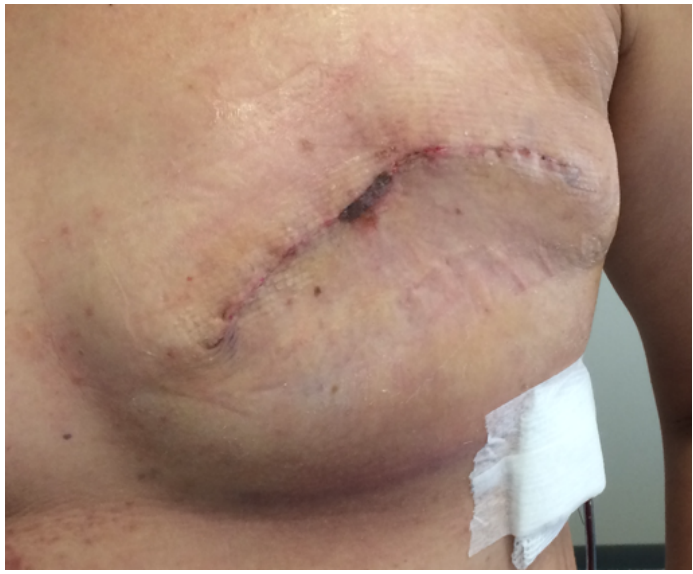

Foto seguimento

\begin{tabular}{|c|c|c|c|c|c|c|c|c|}
\hline Periférica & $12 h$ & $1 \mathrm{~h}$ & $3 h$ & $4 h$ & $6 h$ & $7 \mathrm{~h}$ & $9 \mathrm{~h}$ & $10 \mathrm{~h}$ \\
\hline 139 & 194 & 130 & 168 & 77 & 131 & 117 & 149 & 160 \\
\hline DESFECHO & 0 & 0 & 0 & 0 & 0 & 0 & 0 & 0 \\
\hline
\end{tabular}


Paciente 25

Idade: $\underline{33}$ anos

Peso: 64 kg

Altura: $\underline{1,75} \mathbf{m}$

IMC: $\underline{20,9} \mathbf{~ k g} \cdot \mathbf{m}^{-2}$

Tabagismo: Não

Data da cirurgia: $24 / 2 / 15$

Lateralidade: Esquerda

Procedimento oncológico: Adenectomia

Reconstrução: Implante

pT $\underline{0}$ pN $\underline{0}$

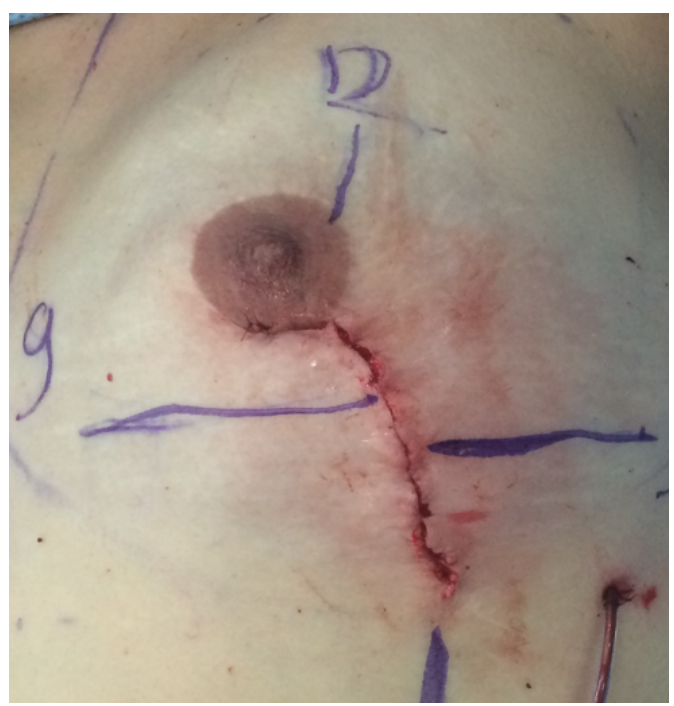

Foto fechamento

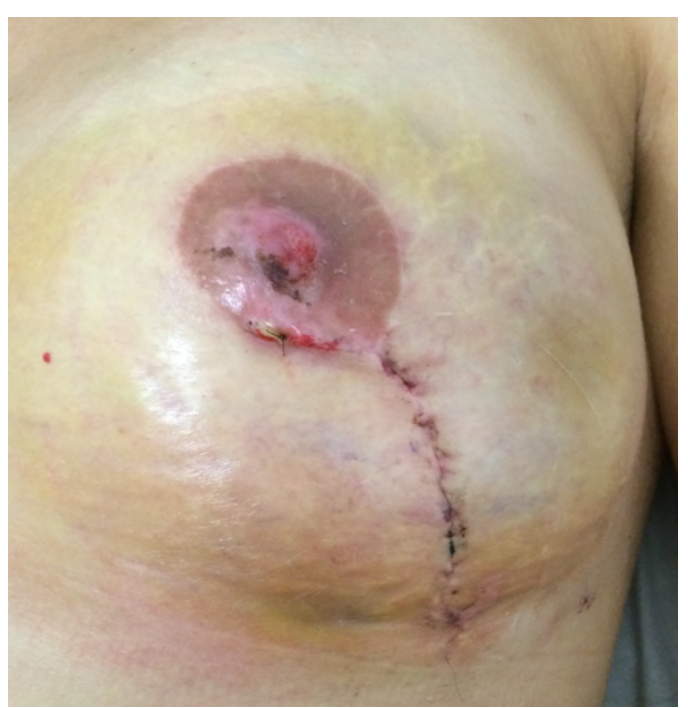

Foto seguimento

\begin{tabular}{|l|l|l|l|l|}
\hline Periférica & $\mathbf{1 2 h}$ & $\mathbf{3 h}$ & $\mathbf{6 h}$ & $\mathbf{9 h}$ \\
\hline \hline 97 & 113 & 121 & 119 & 98 \\
\hline \multicolumn{5}{|c|}{$\mathbf{n}^{-}$} \\
\hline DESFECHO & 0 & 0 & 0 & 0 \\
\hline
\end{tabular}


Paciente 26

Idade: $\underline{69}$ anos

Peso: $81 \mathrm{~kg}$

Altura: $\underline{1,67} \mathbf{m}$

IMC: $\underline{29,0} \mathbf{~ k g} \cdot \mathrm{m}^{-2}$

Tabagismo: Não

Data da cirurgia: $10 / 3 / 15$

Lateralidade: Direita

Procedimento oncológico: Adenectomia

Reconstrução: Implante expansor

pT 1 pN $\underline{0}$

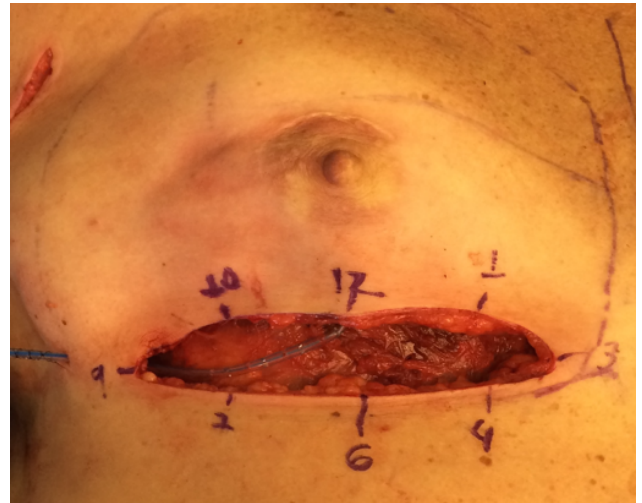

Foto fechamento

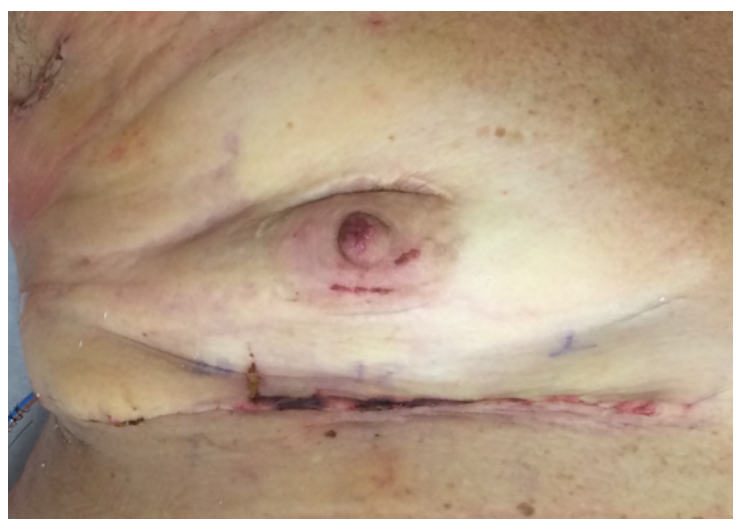

Foto seguimento

\begin{tabular}{|c|c|c|c|c|c|c|c|c|}
\hline Periférica & $12 \mathrm{~h}$ & $1 \mathrm{~h}$ & $3 h$ & $4 h$ & $6 h$ & $7 \mathrm{~h}$ & $9 h$ & $10 \mathrm{~h}$ \\
\hline 139 & 66 & 86 & 72 & 117 & 142 & 123 & 133 & 110 \\
\hline DESFECHO & 0 & 0 & 0 & 0 & 0 & 0 & 0 & 0 \\
\hline
\end{tabular}


Paciente 27

Idade: $\underline{27}$ anos

Peso: 83,5 kg

Altura: $\underline{1,71} \mathbf{m}$

IMC: $\underline{28,6} \mathbf{k g} \cdot \mathrm{m}^{-2}$

Tabagismo: Não

Data da cirurgia: $31 / 3 / 15$

Lateralidade: Esquerda

Procedimento oncológico: Mastectomia

Reconstrução: Implante expansor

pT 4 pN 1

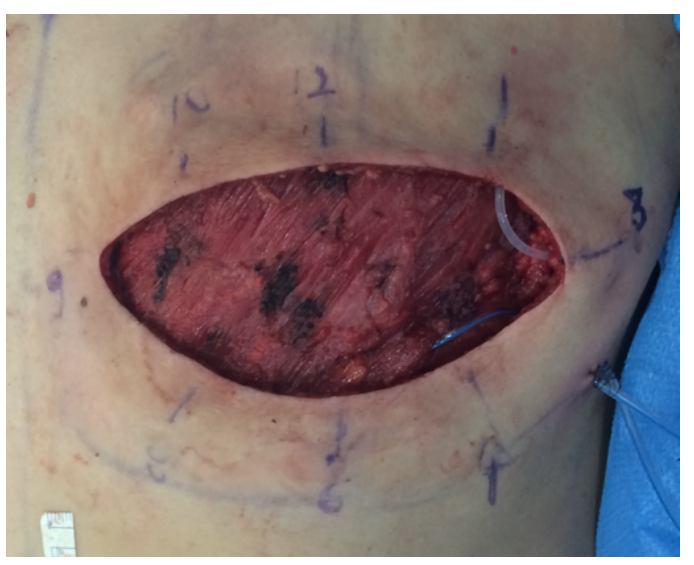

Foto fechamento

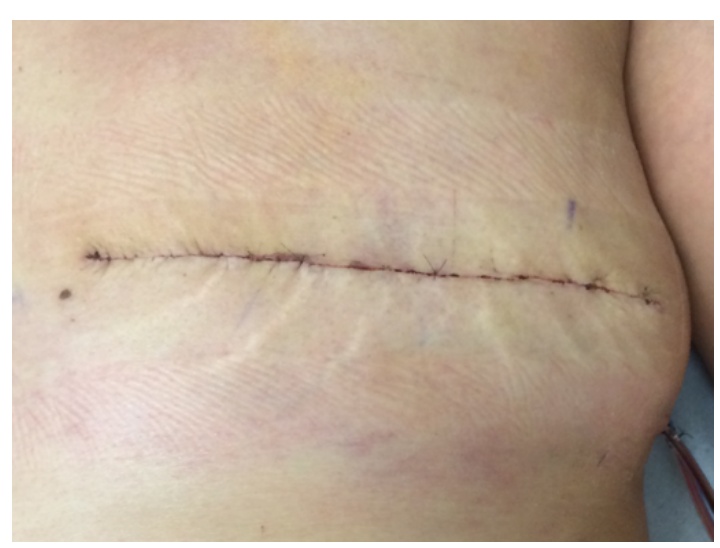

Foto seguimento

\begin{tabular}{|l|l|l|l|l|l|l|l|l|}
\hline Periférica & $\mathbf{1 2 h}$ & $\mathbf{1 h}$ & $\mathbf{3 h}$ & $\mathbf{4 h}$ & $\mathbf{6 h}$ & $\mathbf{7 h}$ & $\mathbf{9 h}$ & $\mathbf{1 0 h}$ \\
\hline \hline 93 & 127 & 126 & 128 & 105 & 131 & 141 & 116 & 92 \\
\hline \multicolumn{8}{|l|}{} \\
\hline DESFECHO & 0 & 0 & 0 & 0 & 0 & 0 & 0 & 0 \\
\hline
\end{tabular}


Paciente 28

Idade: $\underline{49}$ anos

Peso: 47 kg

Altura: $\underline{1,59} \mathrm{~m}$

IMC: $\underline{18,6} \mathbf{~ k g} \cdot \mathrm{m}^{-2}$

Tabagismo: Não

Data da cirurgia: $8 / 4 / 15$

Lateralidade: Direita

Procedimento oncológico: Adenectomia

Reconstrução: Implante expansor

pT $\underline{2}$ pN $\underline{0}$

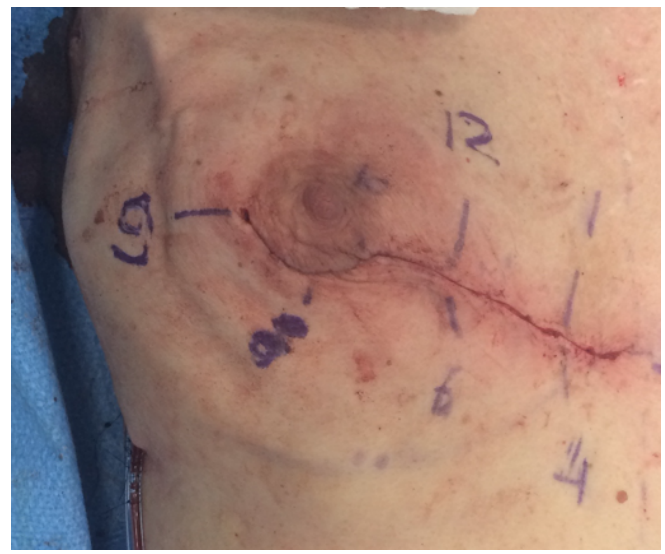

Foto fechamento

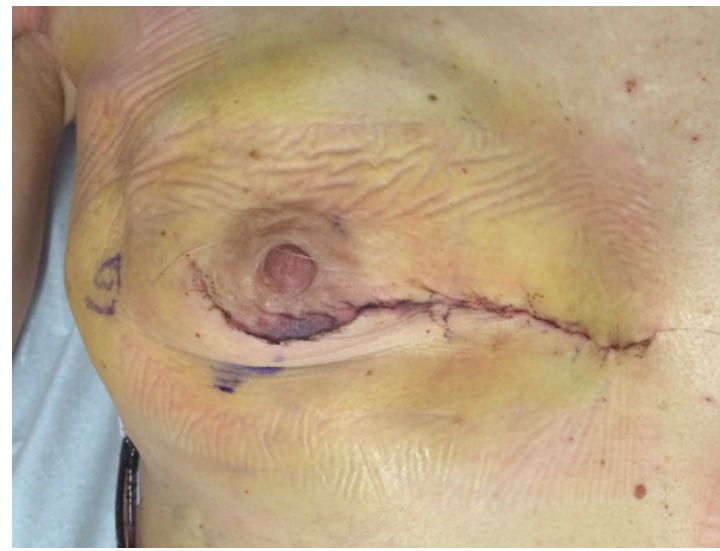

Foto seguimento

\begin{tabular}{|l|l|l|l|l|l|l|l|l|}
\hline Periférica & $\mathbf{1 2 h}$ & $\mathbf{1 h}$ & $\mathbf{3 h}$ & $\mathbf{4 h}$ & $\mathbf{6 h}$ & $\mathbf{7 h}$ & $\mathbf{9 h}$ & $\mathbf{1 0 h}$ \\
\hline \hline 107 & 102 & 110 & 122 & 101 & 131 & 116 & 135 & 115 \\
\hline \multicolumn{8}{|c|}{} \\
\hline DESFECHO & 0 & 0 & 0 & 0 & 0 & 0 & 0 & 0 \\
\hline
\end{tabular}


Paciente 29

Idade: $\underline{41}$ anos

Peso: _kg

Altura: m

IMC: $\mathrm{kg} \cdot \mathrm{m}^{-2}$

Tabagismo: Não

Data da cirurgia: $7 / 7 / 15$

Lateralidade: Direita

Procedimento oncológico: Mastectomia

Reconstrução: Implante expansor

pT_pN

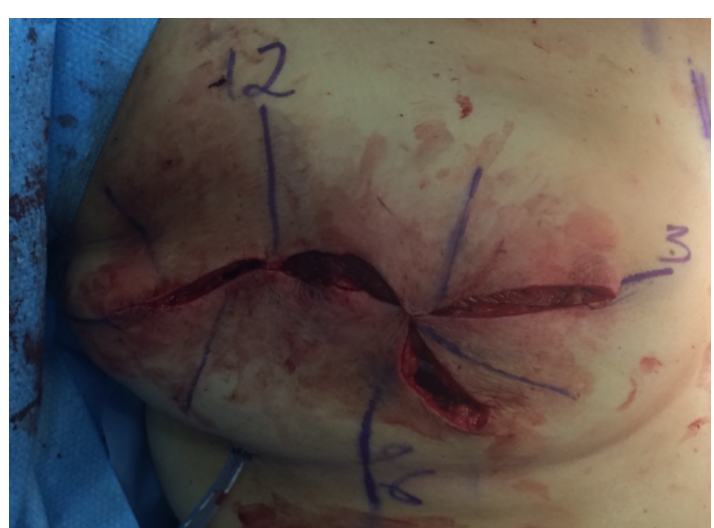

Foto fechamento

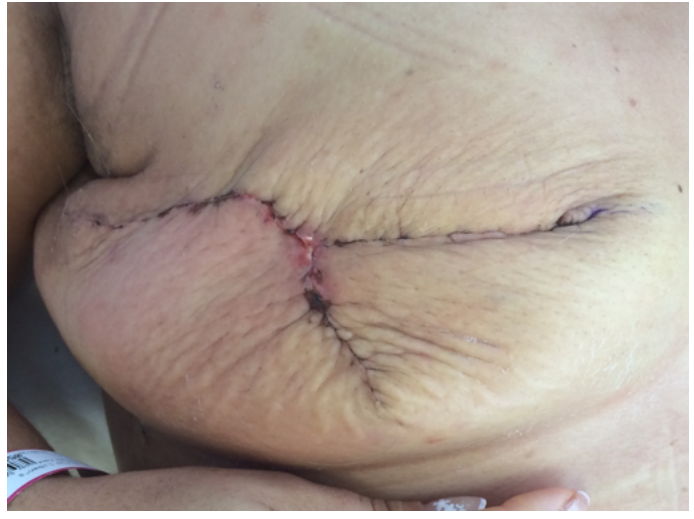

Foto seguimento

\begin{tabular}{|l|l|l|l|l|l|l|l|l|}
\hline Periférica & $\mathbf{1 2 h}$ & $\mathbf{1 h}$ & $\mathbf{3 h}$ & $\mathbf{4 h}$ & $\mathbf{6 h}$ & $\mathbf{7 h}$ & $\mathbf{9 h}$ & $\mathbf{1 0 h}$ \\
\hline \hline 147 & 181 & 147 & 140 & 124 & 110 & 171 & 133 & 170 \\
\hline & \\
\hline
\end{tabular}


Apêndice $\mathrm{C}$ - Pacientes que apresentaram NCET em algum segmento do retalho da mastectomia

\section{Paciente 2}

Idade: $\underline{48}$ anos

Peso: $\underline{71,9} \mathbf{~ k g}$

Altura: $\underline{1,73} \mathbf{~ m}$

IMC: $\underline{24,0} \mathbf{~ k g} \cdot \mathrm{m}^{-2}$

Tabagismo: Não

Data da cirurgia: 22/1/13

Lateralidade: Direita

Procedimento oncológico: Mastectomia

Reconstrução: Implante expansor

pT $\underline{2}$ pN $\underline{0}$

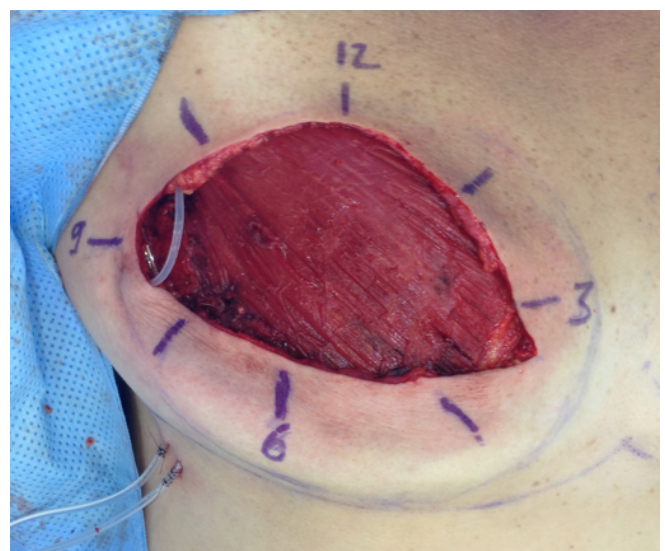

Foto fechamento

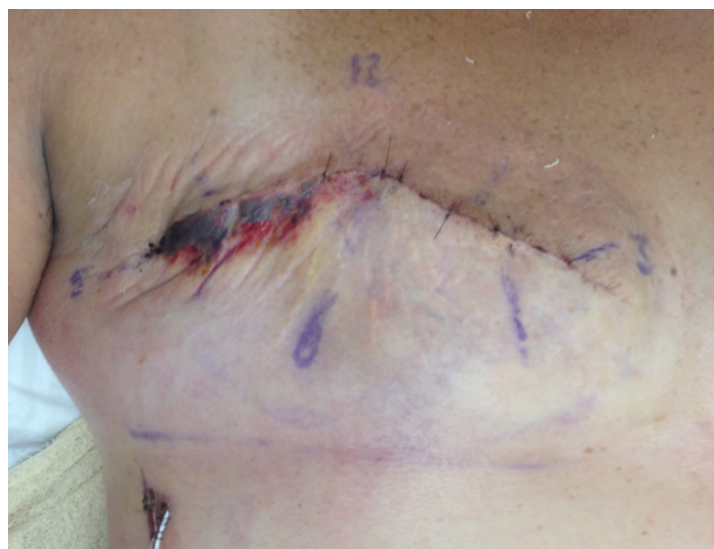

Foto seguimento

\begin{tabular}{|c|c|c|c|c|c|c|c|c|}
\hline Periférica & $12 \mathrm{~h}$ & $1 \mathrm{~h}$ & $3 h$ & $4 h$ & $6 h$ & $7 \mathrm{~h}$ & $9 \mathrm{~h}$ & $10 \mathrm{~h}$ \\
\hline 96 & 84 & 123 & $\overline{c 102}$ & 85 & 83 & 260 & 65 & 91 \\
\hline & & & & & & 81 & 22 & \\
\hline DESFECHO & 0 & 0 & 0 & & & 1 & 1 & 0 \\
\hline
\end{tabular}


Paciente 7

Idade: $\underline{63}$ anos

Peso: 62 kg

Altura: $\underline{1,56} \mathrm{~m}$

IMC: $\underline{25,5} \mathbf{k g} \cdot \mathrm{m}^{-2}$

Tabagismo: Não

Data da cirurgia: 2/7/13

Lateralidade: Esquerda

Procedimento oncológico: Adenectomia

Reconstrução: Implante expansor

pT is $\underline{\text { pN } \underline{0}}$

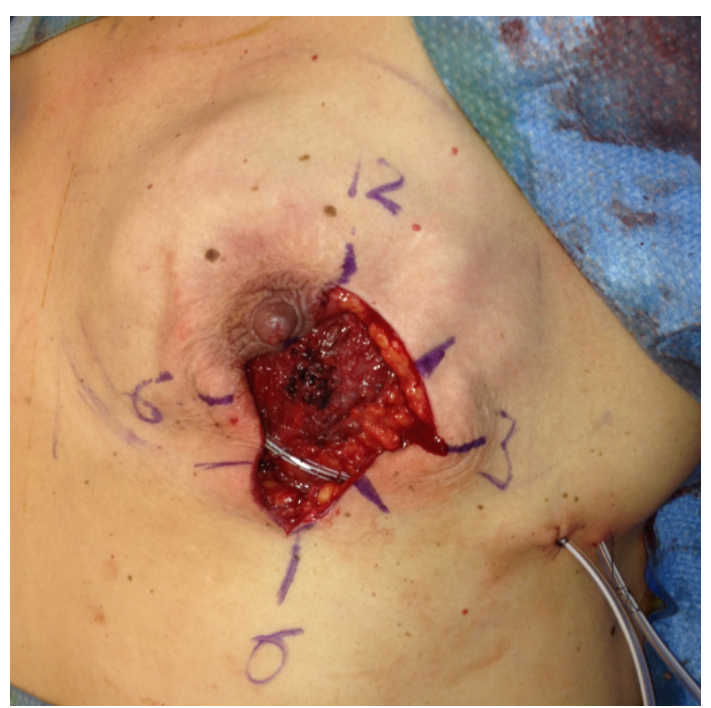

Foto fechamento

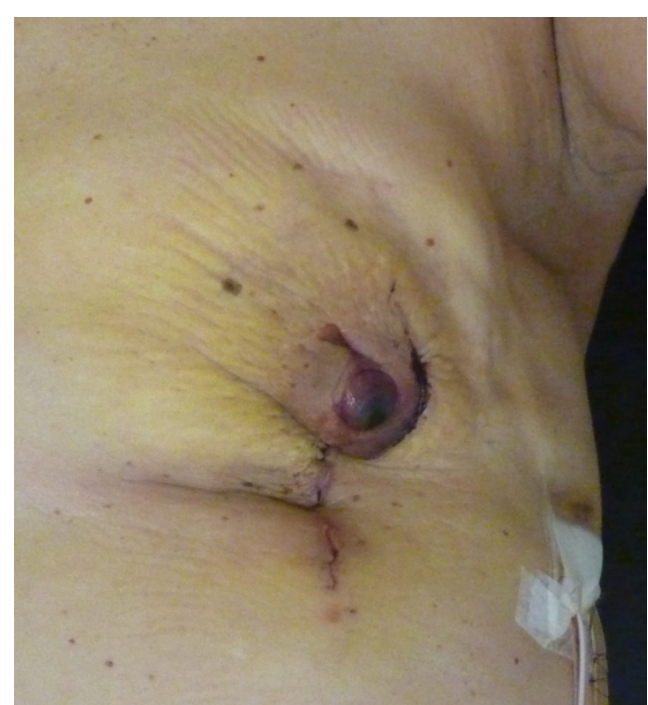

Foto seguimento

\begin{tabular}{|l|l|l|l|l|l|l|l|l|}
\hline Periférica & $\mathbf{1 2 h}$ & $\mathbf{l h}$ & $\mathbf{3 h}$ & $\mathbf{4 h}$ & $\mathbf{6 h}$ & $\mathbf{7 h}$ & $\mathbf{9 h}$ & $\mathbf{1 0 h}$ \\
\hline \hline 106 & 119 & 113 & 126 & 119 & 103 & 109 & 117 & 76 \\
\hline & \\
\hline DESFECHO & 0 & 0 & 0 & 0 & 0 & 0 & 0 & $\mathbf{1}$ \\
\hline
\end{tabular}


Paciente 11

Idade: $\underline{45}$ anos

Peso: $\underline{75}$ kg

Altura: $\underline{1,54} \mathbf{m}$

IMC: $\underline{31,6} \mathbf{~ k g} \cdot \mathrm{m}^{-2}$

Tabagismo: SIM

Data da cirurgia: $11 / 9 / 13$

Lateralidade: Esquerda

Procedimento oncológico: Mastectomia

Reconstrução: Implante

pT $\underline{2}$ pN $\underline{3}$

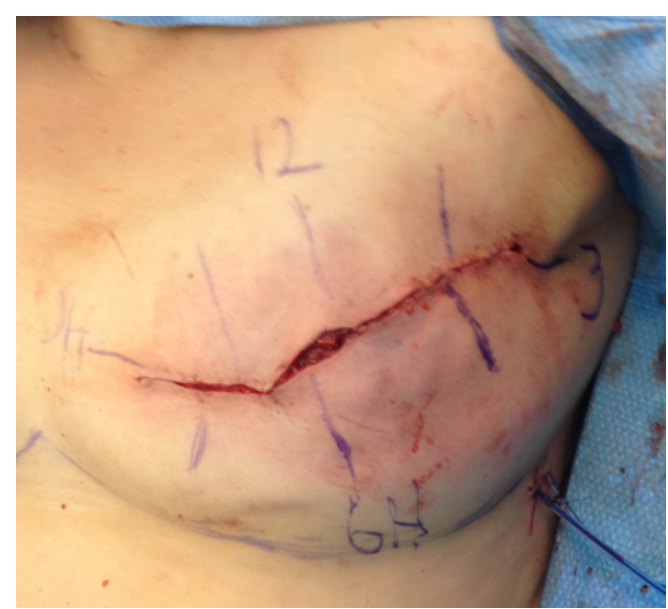

Foto fechamento

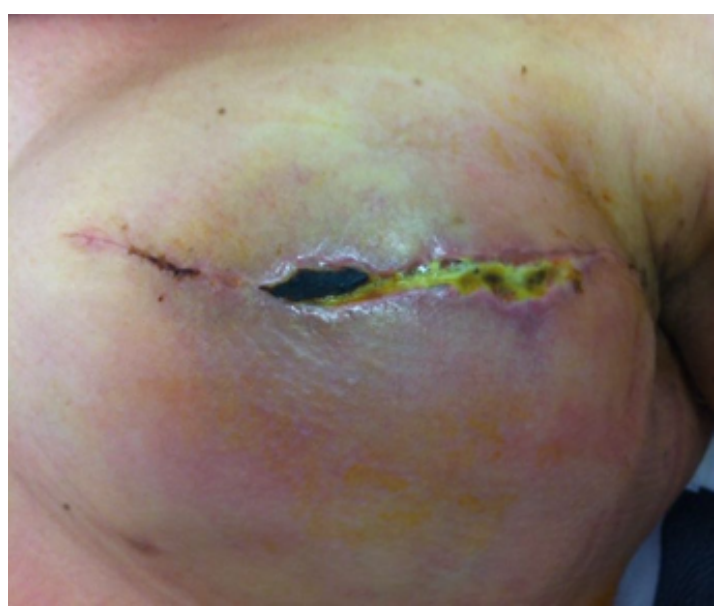

Foto seguimento

\begin{tabular}{|l|l|l|l|l|l|l|l|l|}
\hline Periférica & $\mathbf{1 2 h}$ & $\mathbf{1 h}$ & $\mathbf{3 h}$ & $\mathbf{4 h}$ & $\mathbf{6 h}$ & $\mathbf{7 h}$ & $\mathbf{9 h}$ & $\mathbf{1 0 h}$ \\
\hline \hline 180 & 116 & 177 & 181 & 189 & 146 & 141 & 67 & 103 \\
\hline & & & & & & 182 & \\
\hline DESFECHO & $\mathbf{1}$ & 0 & 0 & $\mathbf{1}$ & 0 & 0 & 0 & $\mathbf{1}$ \\
\hline
\end{tabular}


Paciente 12

Idade: $\underline{34}$ anos

Peso: 42 kg

Altura: $\underline{1,39} \mathbf{m}$

IMC: $\underline{21,7} \mathbf{~ k g} \cdot \mathbf{m}^{-2}$

Tabagismo: Não

Data da cirurgia: $22 / 10 / 13$

Lateralidade: Esquerda

Procedimento oncológico: Adenectomia

Reconstrução: Implante

pT $2 \underline{\text { pN } \underline{1}}$

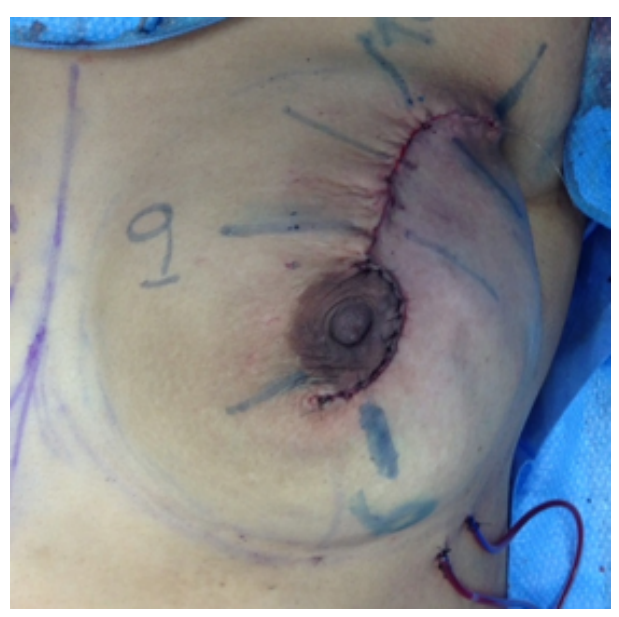

Foto fechamento

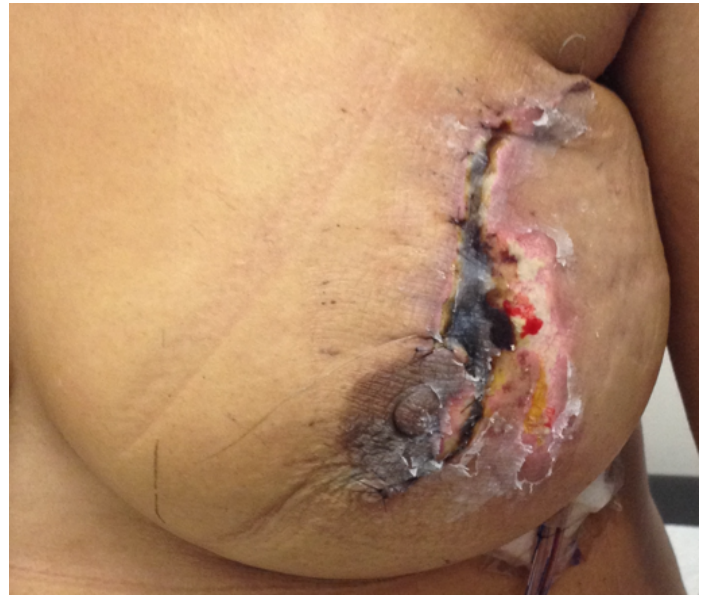

Foto seguimento

\begin{tabular}{|l|l|l|l|l|l|l|l|l|}
\hline Periférica & $\mathbf{1 2 h}$ & $\mathbf{1 h}$ & $\mathbf{3 h}$ & $\mathbf{4 h}$ & $\mathbf{6 h}$ & $\mathbf{7 h}$ & $\mathbf{9 h}$ & $\mathbf{1 0 h}$ \\
\hline \hline 131 & 96 & 121 & 109 & 81 & 144 & 142 & 156 & 162 \\
\hline & & & & & & & \\
\hline DESFECHO & $\mathbf{1}$ & 0 & $\mathbf{1}$ & $\mathbf{1}$ & 0 & $\mathbf{1}$ & 0 & 0 \\
\hline
\end{tabular}


Paciente 13

Idade: $\underline{55}$ anos

Peso: $\underline{74}$ kg

Altura: $\underline{1,57} \mathbf{~ m}$

IMC: $\underline{30,0} \mathbf{~ k g} \cdot \mathbf{m}^{-2}$

Tabagismo: Não

Data da cirurgia: 5/11/13

Lateralidade: Esquerda

Procedimento oncológico: Adenectomia

Reconstrução: Implante

pT is $\underline{\text { pN } \underline{0}}$

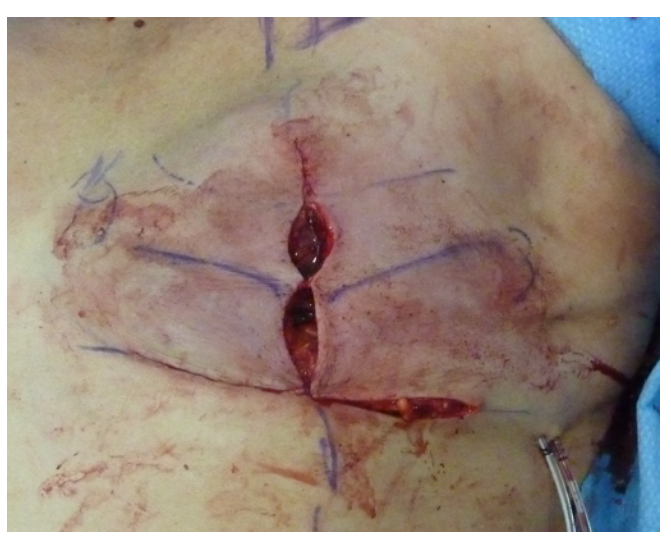

Foto fechamento

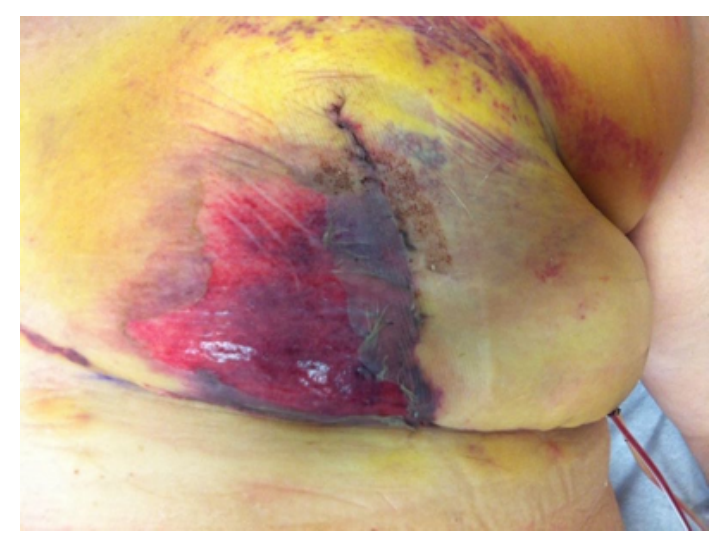

Foto seguimento

\begin{tabular}{|l|l|l|l|l|l|l|l|l|}
\hline Periférica & $\mathbf{1 2 h}$ & $\mathbf{1 h}$ & $\mathbf{3 h}$ & $\mathbf{4 h}$ & $\mathbf{6 h}$ & $\mathbf{7 h}$ & $\mathbf{9 h}$ & $\mathbf{1 0 h}$ \\
\hline \hline 135 & 158 & 171 & 127 & 168 & 156 & 100 & 127 & 107 \\
\hline \multicolumn{10}{|c|}{} & & & & & & & \\
\hline DESFECHO & 0 & 0 & 0 & 0 & 0 & $\mathbf{1}$ & $\mathbf{1}$ & $\mathbf{1}$ \\
\hline
\end{tabular}


Paciente 18

Idade: $\underline{48}$ anos

Peso: 75 kg

Altura: $\underline{1,65} \mathbf{m}$

IMC: $\underline{27,5} \mathbf{k g} \cdot \mathbf{m}^{-2}$

Tabagismo: SIM

Data da cirurgia: $25 / 3 / 14$

Lateralidade: Direita

Procedimento oncológico: Adenectomia

Reconstrução: Implante expansor

pT 1 pN 1

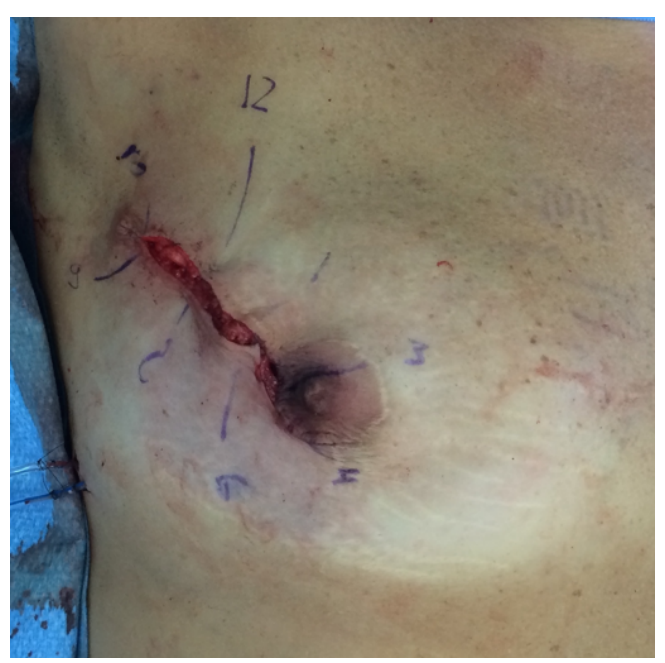

Foto fechamento

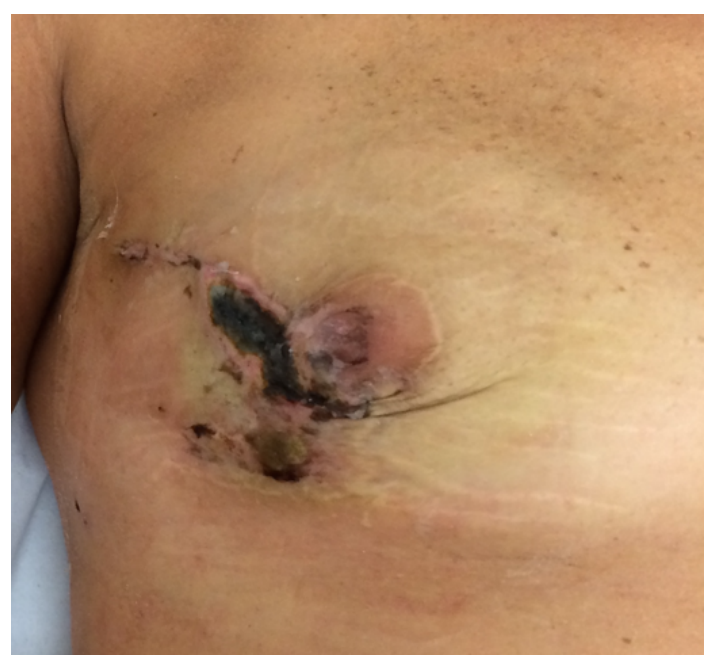

Foto seguimento

\begin{tabular}{|l|l|l|l|l|l|l|l|l|}
\hline Periférica & $\mathbf{1 2 h}$ & $\mathbf{1 h}$ & $\mathbf{3 h}$ & $\mathbf{4 h}$ & $\mathbf{6 h}$ & $\mathbf{7 h}$ & $\mathbf{9 h}$ & $\mathbf{1 0 h}$ \\
\hline \hline 81 & 44 & 103 & 61 & 78 & 73 & 84 & 100 & 72 \\
\hline & 101 & & 55 & 64 & 86 & & & 88 \\
\hline DESFECHO & 0 & 0 & $\mathbf{1}$ & $\mathbf{1}$ & $\mathbf{1}$ & 0 & 0 & 0 \\
\hline
\end{tabular}


Paciente 19

Idade: $\underline{55}$ anos

Peso: 53 kg

Altura: $\underline{1,62} \mathbf{m}$

IMC: $\underline{20,2} \mathbf{~ k g} \cdot \mathbf{m}^{-2}$

Tabagismo: SIM

Data da cirurgia: $6 / 5 / 14$

Lateralidade: Esquerda

Procedimento oncológico: Adenectomia

Reconstrução: Implante expansor

pT is $\underline{\text { pN } \underline{0}}$

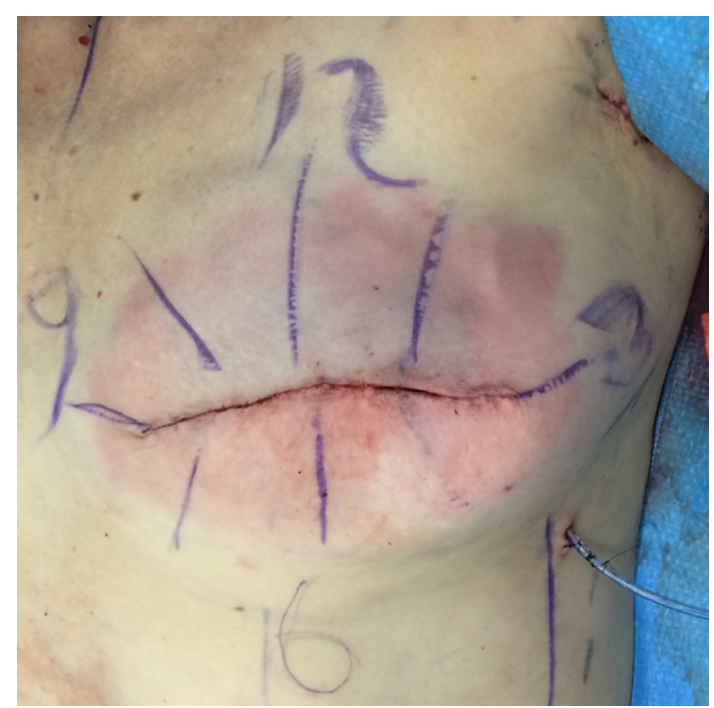

Foto fechamento

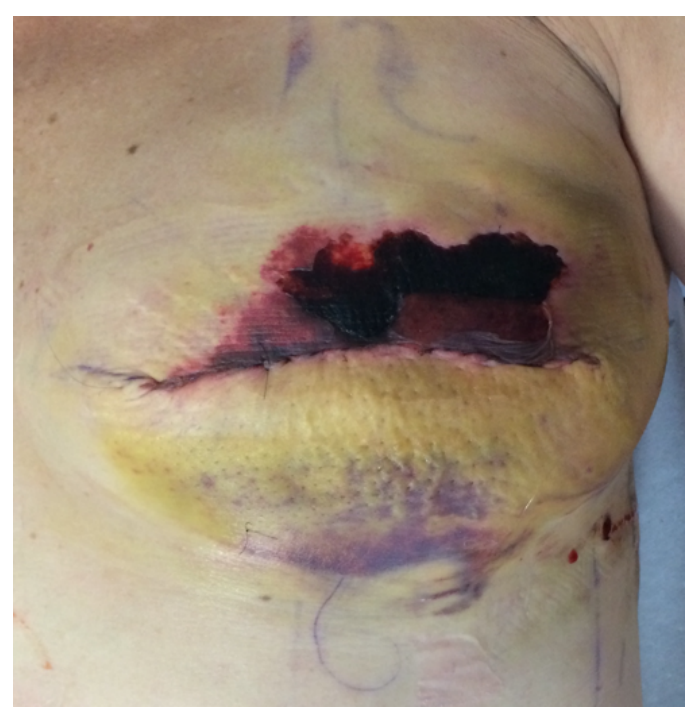

Foto seguimento

\begin{tabular}{|c|c|c|c|c|c|c|c|c|}
\hline Periférica & $12 \mathrm{~h}$ & $1 \mathrm{~h}$ & $3 h$ & $4 \mathrm{~h}$ & $6 h$ & $7 \mathrm{~h}$ & $9 \mathrm{~h}$ & $10 \mathrm{~h}$ \\
\hline 105 & 84 & $\overline{57}$ & 69 & 109 & 99 & 97 & 111 & 78 \\
\hline & & 93 & 88 & & & & & 86 \\
\hline DESFECHO & 1 & 1 & 0 & 0 & & ( & 0 & 1 \\
\hline
\end{tabular}


Paciente 22

Idade: $\underline{39}$ anos

Peso: $81 \mathrm{~kg}$

Altura: $\underline{1,56} \mathbf{m}$

IMC: $\underline{33,3} \mathbf{~ k g} \cdot \mathbf{m}^{-2}$

Tabagismo: Não

Data da cirurgia: $30 / 7 / 14$

Lateralidade: Esquerda

Procedimento oncológico: Adenectomia

Reconstrução: Implante expansor

pT $2 \underline{\text { pN } \underline{1}}$

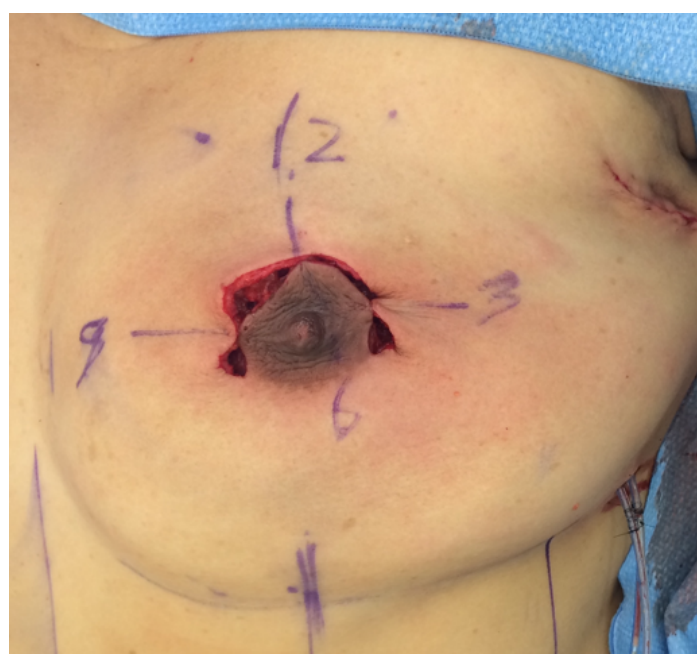

Foto fechamento

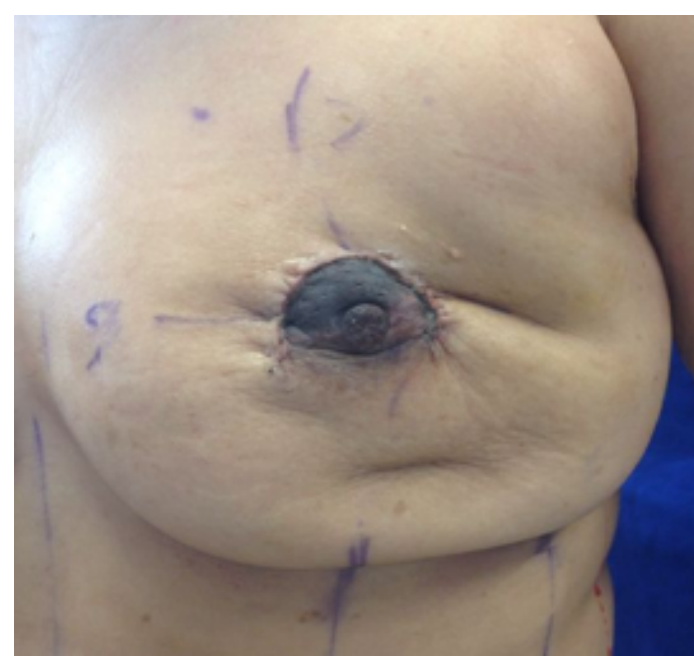

Foto seguimento

\begin{tabular}{|l|l|l|l|l|}
\hline Periférica & $\mathbf{1 2 h}$ & $\mathbf{3 h}$ & $\mathbf{6 h}$ & $\mathbf{9 h}$ \\
\hline \hline 161 & 118 & 87 & 94 & 153 \\
\hline \multicolumn{5}{|c|}{0} \\
\hline DESFECHO & 0 & 0 & $\mathbf{1}$ & 0 \\
\hline
\end{tabular}


Paciente 27

Idade: $\underline{27}$ anos

Peso: 83,5 kg

Altura: $\underline{1,71} \mathbf{m}$

IMC: $\underline{28,6} \mathbf{~ k g} \cdot \mathbf{m}^{-2}$

Tabagismo: Não

Data da cirurgia: $31 / 3 / 15$

Lateralidade: Direita

Procedimento oncológico: Adenectomia

Reconstrução: Implante expansor

pT $\underline{0}$ pN $\underline{0}$

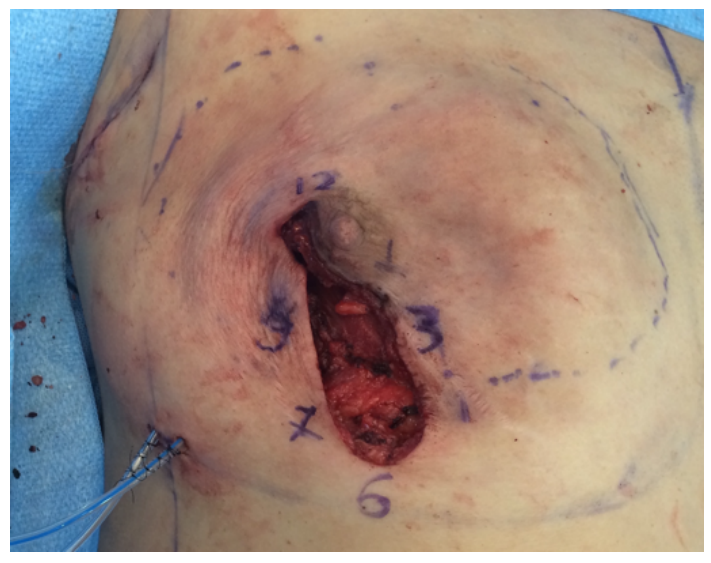

Foto fechamento

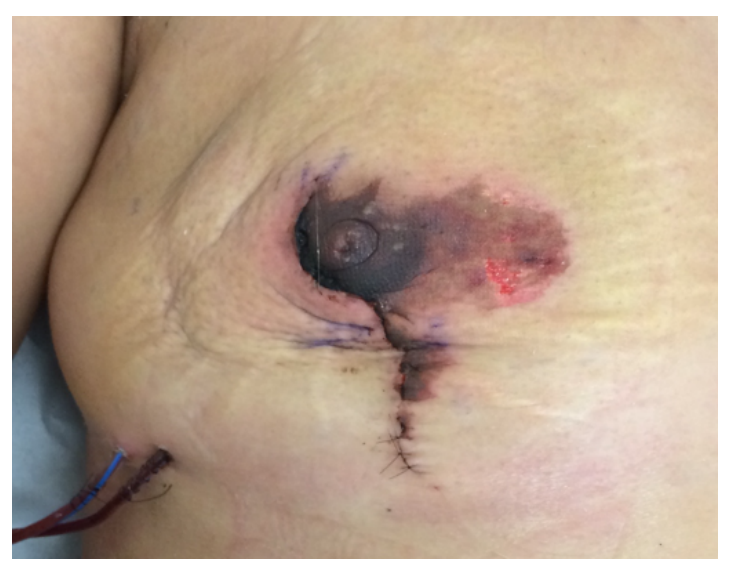

Foto seguimento

\begin{tabular}{|l|l|l|l|l|l|l|}
\hline Periférica & $\mathbf{1 2 h}$ & $\mathbf{1 h}$ & $\mathbf{3 h}$ & $\mathbf{6 h}$ & $\mathbf{7 h}$ & $\mathbf{9 h}$ \\
\hline \hline 93 & 100 & 126 & 132 & 142 & 131 & 134 \\
\hline \multicolumn{7}{|c|}{} \\
\hline DESFECHO & $\mathbf{1}$ & $\mathbf{1}$ & $\mathbf{1}$ & 0 & 0 & 0 \\
\hline
\end{tabular}

